1343.05

N 394

3318 (')

₹

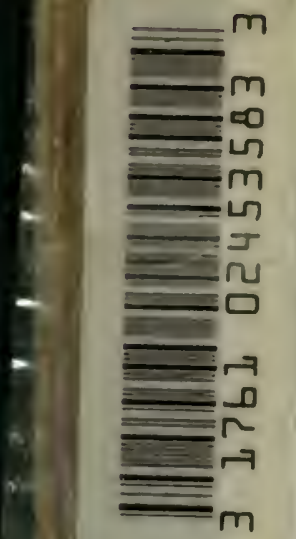

Wilckens, Otto

Revision der Fauna der Quiriquina-Schichten 


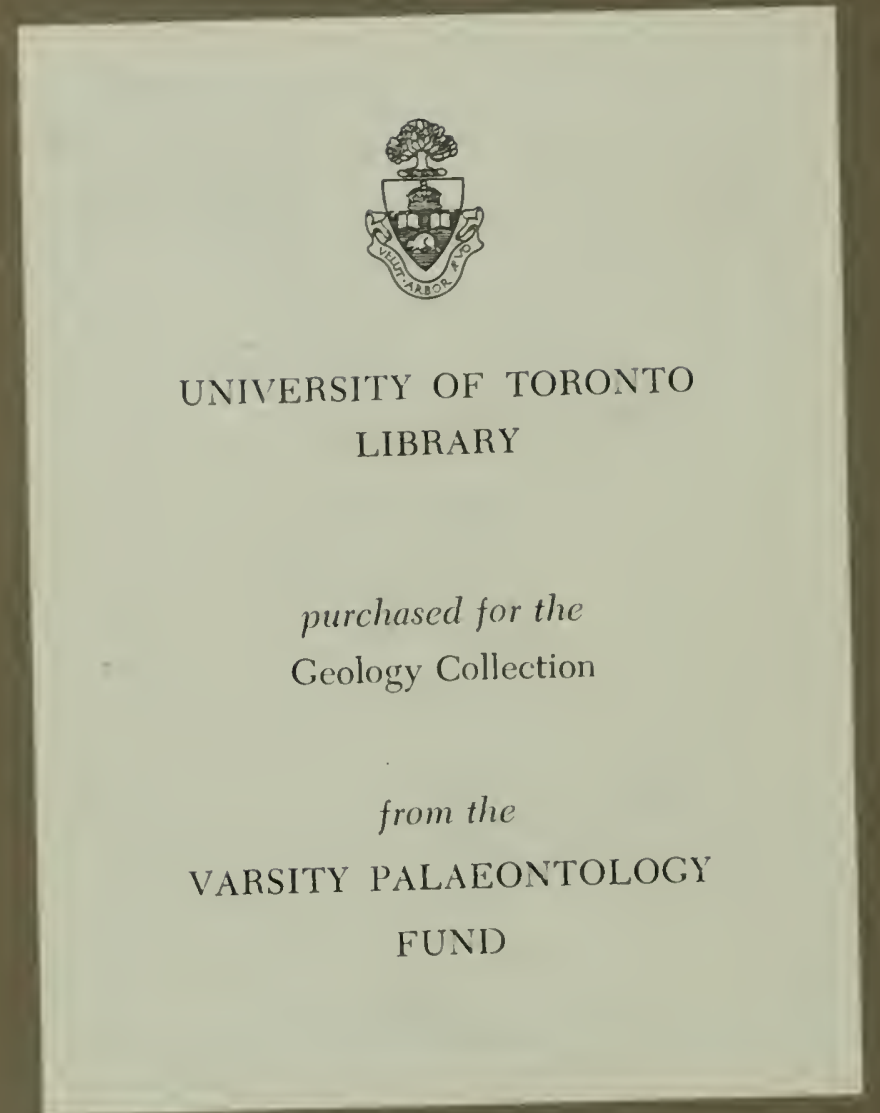




\section{Beiträge}

$\%$ \%

\section{Geologie und Palaeontologie von}

\section{Südamerika.}

Unter Mitwirkung von Fachgenossen

herausgegeben von

Dr. Gustav Steinmann,

Professor für Geologie und Mineralogie a. d. Universität Freiburg i. B.

XI.

Revision der Fauna der Quiriquina-Schichten.

Von Otto Wilckens in Freiburg i. B.

Mit 4 Tafeln und 1 Textfigur.

Separat-Abdruck aus dem Nenen Jahrbuch für Mineralogie etc. Beilageband XVIII.

\section{Stuttgart.}

E. Schweizerbart'sche Verlagshandlung (E. Nägele).

1904 . 

Beiträge zur Geologie und Palaeontologie von Südamerika.

Unter Mitwirkmg von Fachgenossen heransgegeben

vol G. Steinmann.

XI.

Revision der Fauna der Quiriquina-Schichten.

Von

Otto Wilckens in Freiburg i. B.

Nit Taf. XVII-XX und 1 T'extfigur.

In geringer Flächenausdehnung lagern an der chilenischen Küste in der Umgebung der Stadt Concepcion über dem krystallinen Gebirge obersenonische Kalksandsteine und Grünsande, die nach ihrem am genausten untersuchten Vorkommen auf der kleinen Insel Quiriquina in der Bai von Talcahuano, von Steinmans den Namen Quiriquina-Schichten erhalten haben. Ihr Auftreten und ihr Alter ist von Steinmanx (dies. Jahrb. Beil.-Bd. X. p. 1 ff.) im dritten seiner „Beiträge zur Geologie and Palaeontologie von Südamerika" eingehend erörtert worden; auch ist ihre Fauna von Steinmanx, Deecke und Möricke auf Grund des von Steisuans gesammelten Materials einer ernenten Untersuchung unterzogen. Dies Miaterial ist in Bezug auf Cephalopoden ungemein reichhaltig, an Bivalven und Gastropoden aber arm. Eine Revision dieser Molluskenclassen diirfte daher nicht ganz zwecklos erscheinen, damit die ganze Quiriquina-Fauna in einer Weise bekannt ist, die ihre Vergleichung mit den Faumen anderer Gebiete der pacifischen Kreide ermöglicht. Das für diese Bearbeitung nothwendige 
Material besitzt das geologische Institut der Universität Freiburg i. B. in Gestalt der umfangreichen Aufsammlungen, die der schwedische Botaniker P. Dusen im September 1896 auf Quiriquina, bei Tomé und bei San Vicente ${ }^{1}$, gemacht hat. Diese Sammlung überwies mir Herr Prof. Steinuans zur Bearbeitung. und es drängt mich, ihm auch an dieser Stelle meinen tiefstgefühlten Dank auszusprechen, nicht nur für die Überlassung des schönen Materials, sondern auch für das freundliche Interesse, mit dem er den Fortgang meiner Arbeit verfolgt, und die vielfache Anregung und Unterstützung, die er mir hat angedeihen lassen.

Bis jetzt war PhilippI's Werk „Die tertiären und quartären Versteinerungen Chiles" 2 (Leipzig 1887) die Hauptquelle für die Kenntniss der Quiriquina-Fauna. (Wir sehen dabei von den Cephalopoden ab, deren Bearbeitung PhILIPPI von

1 Die Beschreibung dieser Fundpunkte findet man bei Steinmans (a. a. O. p. 1 ff.) und bei Philippi (Die tert. und quart. Verst. Chiles p. 14 ff.). Die folgende Kartenskizze zeigt ihre Lage. Auf derselben ist die Ver-
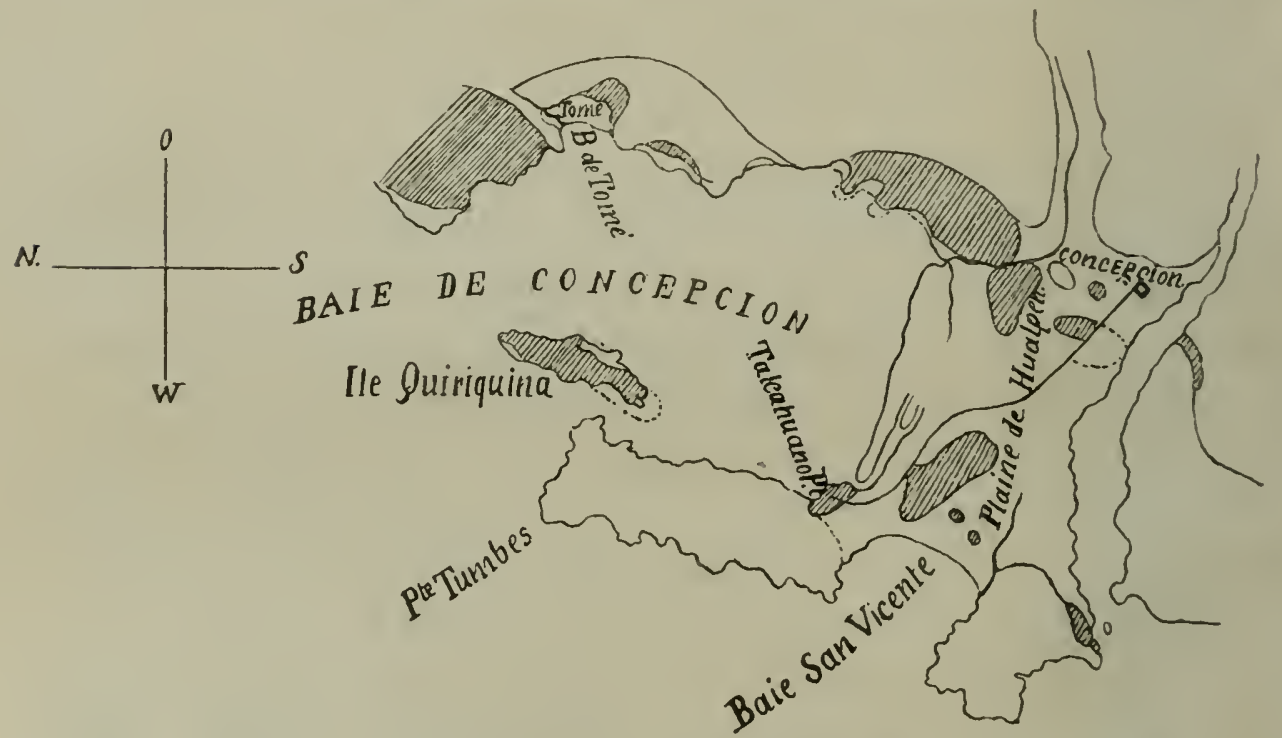

Fig. 1. Karte der Gegend von Concepcion mit der Lage der Fundpunkte Tomé San Vicente, Quiriquina.

breitung der Kreide- und Tertiärschichten durch schräge Schraffur angedeutet. Das Kärtchen ist den Annales des Jrines (4. sér. 19. Taf. IV Fig. 1) entnommen. Es zeigt zugleich die Lage ron Tumbez. Hnalpen und Talcahuano.

${ }^{2}$ Dem Titel zum 'Trotz sind in diesen Buch anch die chilenischen Kreidefossilien beschrieben. 
vornherein S'Traxmaxi ibterliess.) In ihm sind nicht nur die schon von D'Orbasy, Gabe und Hope beschriobenen Areen aufs Nene beschrieben und abgebildet, sondern es hommt \% diesen schon bekannten noch eine betrachlliche duzah neuer Arten hinzu. Leider Weist Pundro's Buch netren seinen grossen Vorziigen auch eine Reihe ron fehlorn auf, die einige Vorsicht bei seinem Gebratuche nö̈thig machen. Puluprer selbst hat mit Bedanern hervorgehoben, das ihm keine Literatur zur Verfügmng gestanden hat, ım die Quiriquina-Fanna mit anderen Famen zu vergleichen. Das wàre ja olme zu grosse Schwierigkeit nachzuholen. Aber leider hat Phulppr gänzlich davon Abstand genommen, irgendwelche Kritik zu üben. Wenn er es auch nicht versïunt, hite unl da seine Bedenken gegen diese oder jene Auffassung seint.r Vorgänger zu äussern - Klarheit bringt er in die vielfache Verwirrung, die in Bezug auf diese Fama. namentlich durch Ungenauigkeiten D'OrBigny's, entstanden ist, in keiner Weise. Im Gegentheil liat Phicipr durch seine Methode, fast jeciem Stiick, das ihm vorlag; einen besonderen Namen zu g'eben !. die Unklarheit nur noch erhöht. Auch lassen manche seiner Abbildungen zu wünschen übrig.

Im Folgenden sollen die Arten, die sich in dem 1):sexschen Material gefunden haben, aufgefüht werden. Inre genaue Beschreibung ist oft erforderlich, da meist nur ganz kurze Diagnosen von ihnen existiren. Wir haben dabei (ielegenheit, die Arten D'Orbigny's, Gabis's und Philippis's zu prüfen, und können schliesslich eine revidirte Liste der (Zniriquina-Fauna geben, welche einen Vergleich mit der Fauma anderer pacifischer Senonablagerungen gestattet.

\section{Verzeichniss der Quiriquina-Literatur.}

Crossier, I.: Description du terrain tertiaire à liguites les envirous de Concepcion, sư la côte du Chili etc. Ann. des Mines. 4 ième Sér. 19. p. 185 ff. und Taf. III. IV. 1851.

(Dieser Abhandlung ist die nebensteliende specialkarte der Gegend ron Concepcion entnommen.)

1 Wenn das auch nicht ganz buchstiblich zu nehmen ist. so kanu man dies doch, wie weiter unten bei Besprechung der Gattungen C'urlium, Mactra. Cytherea, Pecten n. a. grezeigt wird, mit einem gewissen Recht sagen. 
Darwin, Ch.: Geologische Beobachtungen über Siidamerika. Deutsch von Carus. Stuttgart 1878.

GABB. WT. MI. : Descriptions of some new species of cretaceous fossils from South America, in the Collection of the Acarlemy. Proc. of the Acad. of Nat. Sc. of Philadelphia. 1860. p. 197, 198. Taf. III.

(Im Folgenden abgekiirzt: GABB, Proc. Nat. Sc. Phil. 1860.)

Hupé in GAY's Historia fisica e politica de Chile: 8. Zoologia.

(Im Folgenden abgekürzt: Hupé, GaY's Hist. Chile. 8.)

Iallard et Fuchs: Notes géologiques sur le Chile. Ann. des Mines.

7 ième Sér. 3. p. 94. 1873.

1) Orbigny, Alcide:

1. Voyage dans l'Amérique méridionale. 3. 1842. Partie III: Géologie. Partie IV: Paléontologie.

(Partie IV irn Folgenden abgekürzt: Voy. Amér. 3Iér. Pal.)

2. Voyage (de l'Astrolabe et de la Zélée) au Pol Sud et dans l'Océanie. Géologie. Atlas. Paris 1846. (Nach D'Orbigry, Prodrome. Das Buch von Grange über den geologischen Theil der Expedition ist von 1848.)

(Im Folgenden abgekürzt: Voy. Pol Sud.)

Dies Werk besteht nur in einem Atlas ohne zugehörenden Text.

Die in ihm abgebildeten Arten finden sich aber aufgezählt im

3. Prodrome de Paléontologie etc. 2. Paris $18 j 0$.

(Im Folgenden abgekürzt: Prodr. 2.)

4. Cours élémentaire de Paléontologie et de Géologie stratigraphique.

2. Fasc. I. p. 672. 1852.

Philippi, R. A.: Die tertiären und quartären Versteinerungen Chiles. Jit 58 Tafeln. Leipzig 1887.

(Im Folgenden algekürzt: Tert. quart. Verst. Chiles.)

Steinmann, G., Defcke, W., MIöricke, W.: Das Alter und die Fauna der Quiriquina-Schichten. - Beiträge zur Geologie und Palaeontologie von Siidamerika, unter Mitwirkung von Fachgenossen herausgegeben voll G. Steinnann. III. Dies. Jahrb. Beil.-Bd. X. p. 1 ff.

A. Das Auftreten und Alter der Quiriquina-Schichten von G. STEIsMANN.

B. Über Saurierreste aus den Quiriquina-Schichten von WV. Defeche.

C. Die Cephalopoden der Quiriquina-Schichten von G. Sterviasx.

D. Die Gastropoden und Bivalven der Quiriquina-Schichten ron IV. MIÖRICKE.

\section{Der Erhaltungszustand der Fossilien aus den Quiriquina-Schichten}

ist bei dem Dusex'schen Material im Allgemeinen ein sehr guter. Das Gestein, in das die Schalen eingebettet sind, ist ein kalkiger, glankonitischer Sandstein, dessen Korngrösse mannigfachen Schwankungen unterworfen ist. Z. Th. sind 


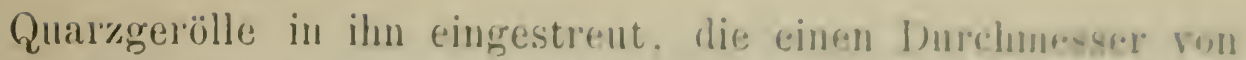
$5-10$, ja bis $25 \mathrm{~mm}$ haben. In diester Gesteinsart finden sich die Muscheln meist nu in \%ertrimmertem \%ustande. Vorherrschend sind aber feine, grünliche sandsteine mit Glimmer und viel Glaukonit. Das kalkige Bindemittel ist in wechselnder Menge vorhanden, fehlt aber niemals ganz. Oft ist das Gestein von Brocken und Fetzen frosilen Holzes durchspickt, das einzeln auch in grösseren Stücken vorkommt. Es hat Braunkohlenhabitus, ist aber ganz und gar unit kohlensaurem Kalk imprägnirt.

Betrachtet man den Quiriquina-Sandstein im Dünnschliff u. d. M., so sieht man mehr oder weniger eckige Qnar\%stïckchen und Glaukonitkörner' in einem 'T'eig von kuhlensaurem Kalk liegen. Ferner findet sich in geringer Menge grüner, stark pleochroitischer Glimmer, wenig Muscovit, Plagioklas mit Zwillingsstreifung und gemeine Hornblende, alies Mineralien, die ihren Ursprung in den Graniten und krystallinen Schiefern haben, welche das Ufer des Senonmeeres an dieser Stelle bildeten und auf denen sich die Quiriquina-Schichten absetzten. Diese letzteren erweisen sich somit in jeder Hinsicht als küstennahe Flachseebildung. Mikroskopische Organismen, insbesondere Foraminiferen, felılen ganz.

Die Molluskenschalen bestehen zumeist aus späthigem Calcit. Sie sind daher vielfach sehr zerbrechlich und nicht leicht aus dem Gestein herauszupräpariren. Selten freilich ist das Gestein so hart, dass die Präparimadel gar nichts auszurichten vermag. Mit einiger Geduld liessen sich die Schlösser der Lamellibranchiaten gut freilegen. Diese Arbeit erschien um so nothwendiger, als sich in dem Phitrpr'schen Werk kaum eine einzige Abbildung eines Bivalvenschlosses aus der Kreideformation findet und bei ihm die Genera nur nach der äusseren Form der Schale bestimmit sind. Auch vom rein palaeontologischen Standpunkt aus sind diese gut erhaltenen Schlösser nicht olme Interesse. Selbst dite äussere Gestalt mancher Formen, so des Leitfossils der QuiriquinaSchichten, des Cardium acuticostutum D'Okв., war bisher noch ganz unbekannt. 
186 O. Wilckens, Revision der Fauna der Quiriquina-Schichten.

\section{Beschreibung der Arten.}

Vertebrata.

Pisces.

Einige wenige Haifischzähne sind die einzigen Wirbelthier'reste, die das Duses'sche Material enthält.

Lamna sp. (Taf. XVII Fig. 1, 1a). Schlanke, schwach s-förmig gebogene, etwas gewundene Zähne mit schneidenden Rändern. Die Seitenzähne sind schlecht erhalten, sie sind sehr klein. Die Wurzel ist zweitheilig; etwas ungleichseitig und scheint noch einen kleinen Höcker auf der Flanke gehabt zu haben. - Die Vorderansicht des Zahnes ist nach 2 Exemplaren ergänzt.

Höhe: $18 \mathrm{~mm}$.

Fundort: Quiriquina (3 Exempl.).

Odontaspis constrictus EaERToN ${ }^{1}$ hat etwas Ähnlichkeit mit unserer Form, doch lagen EGERTon auch schlechte Exemplare vor und seine Zeichnung ist offenbar mangelhaft ?

Ausser diesen liegt noch ein kleiner Zahn vor,

$$
\text { Otodus AG. sp. }
$$

Taf. XVII Fig. 2

mit zwei grossen Seitenzacken. Die Höhe beträgt 7,5 , die Breite $55 \mathrm{~mm}$.

\section{Mollusca.}

\section{Cephalopoda.}

\section{Nautilus Breyn.}

\section{Nautilus subplicatus PhILIPPI.}

1895. Nautilus subplicatus Phis. Steinmans, Ceph. d. Quir.-Schicht., dies. Jahrb. Beil.-Bd. X. p. 65̃. Taf. IV Fig. 1-3.

Ein grösseres Exemplar, das vollständig etwa $130 \mathrm{~mm}$ Durchmesser haben würde. Es ist schräg abgerollt. Die

${ }^{1}$ Egerton, On fossil fishes from Southern India. Trans. Geol. Soc. of London. 7. Part III. 18t6. p. 95.

${ }^{2}$ Der Unterschied der Zähne ron Odontaspis gegeniiber Lamna ist von Agassiz (Rech. sur les poiss. foss. 3. p. 288) so definirt, dass Odontaspis mchr cylindrische, stärker gewundene Zähne hat, deren Nebenspitzen stärker und spitzer sind. Zittel (Grundziige der Pal. p. 538) sagt dagegen, dass Lamna grössere Seitenspitzen hätte. 
Wohnkammer fehlt, von der Schale sind einige Partikelchen erhalten, die die feine Streifung erkennen lassen. Ein anderes Stïck besteht aus wenigen inneren Windungen und ist wie das erste Steinkern. - Fundort: (Quiriquina 2 Exempl.).

\section{Cf. Ilolcodiscus gemmalus Hepes.}

185.4. Ammonites gemmatus Huré, Gay's Hitt. Chile. 8. 35. Tat. 1 Fig 3. 1895. Holcouliscus gemmatus (HüE) Strisma.s, Ceph. d. Quir.-Schicht, dics. Jahrb. Beil.-Bd. X. p. 68. Taf. VI Fig. 2 a, b.

Ein Stück einer Windung scheint dem 'Typus anzugehïren, den Sternmax a. a. O.. 'Taf. VI Fig. 2 a, b abbildet und den er als jüngere Windungen vou Holcodiscus yemmatus Hupe auffasst. Das Stïck bietet wegen seiner schlechten Erhaltung keine Anhaltspunkte für eine genamere Bestimmnng.

Fundort: Quiriquina (1 Exempl.).

\section{Phylloceras ramosum MeEk.}

1857. Ammonites (Scaphites?) ramosus MeFi, 'Trans. Alb. Inst. 4. p. 45. 1864. " rumosus Gianb, Geol. Surv, of Calif. Pal. 1. 1. 6.j. Taf. 11 Fig. 12. 12a; Taf. 12 Fig. 12 b.

1876. Phylloceras(?) ramosus MEek, Bull. U. S. Geol. Geogr. Surv. of Territories. 2. p. 371. Taf. V Fig. 1, $1 \mathrm{a}, 1 \mathrm{~b}$.

1879. Ammonites Velleclae Whitsaves, Geol. Surv. of Canada. Mles. Foss. 1. Part II. p. 103.

1895. Phylloceras ramosus (ЈЕeк) Steinuas, Ceph. d. Quir.-Schicht., dies. Jahrb. Beil.-Bd. X. p. 80. Taf. V Fig. 4 a, 4 b.

Gekammertes Stiick einer Windung mit schlecht erhaltener Lobenlinie. Das Exemplar ïbertrifft das von Stensasx abgebildete an Grösse. - Fundort: San Vicente.

\section{Lytoceras Varunu Forbes.}

1846. Ammonites Varuna Forees, Trans. Geol. Soc. Lond. 7. p. 107. Taf. s Fig. อे.

1865. " $"$ (Forkes) Stoliczka, Cret. Fauna of South. India. Ceph. p. 111. Taf. 58 Fig. 1.

1895. Lytoceras . ,

(Forbes) Stemanas, Ceph. d. Quir.-Schicht., dies. Jahrb. Beil.-Bd X. p. 65. Taf. V Fig. 2a, 2 b. (Gaudryceras) Varuna (Forbes) Kossmat. Unters. üb. d. suidind. Kreideform. Beitr. z. Geol. It. Pal. Üsterr.-Ung. u. d. Orients. 9. p. 130. Taf. 16 Fig. 4; Taf. 17 Fig. 8.

Ein Stiickchen einer Windung mit Loben. F'undort: 'T'omé. 


\section{Lytoceras Kayei Forbes.}

1816. Ammonites Kayei Forbes, Trans. Geol. Soc. Lond. 7. p. 101. Taf. 8 Fig. 3.

1865. " " (Forbes) Stoliczka, Cret. Fauna of South. India. Ceph. p. 156. Taf. 77 Fig. 1.

1895. Lytoceras

(Forbes) Steinmann, Ceph. d. Quir.-Schicht., dies. Jahrb. Beil.-Bd. X. p. 86. Taf. V Fig. 5 a, 5 b.

(Forbes) Kossmat, Unters. üb. d. siidind. Kreideform. p. 124. Taf. XVI Fig. 5 a, 5 b.

Von San Vicente liegt ein ziemlich gut erhaltener Steinkern vor, dem ein Restchen Schale anhängt. Das Stück ist nicht so gross wie Steinuans's Exemplar. Von der Wohnkammer ist nichts erhalten. Der äussere Umgang zeigt die Furchen, deren es nach Sternmans $4-5$ auf jeder Windung giebt.

Die inneren Windungen eines Ammoniten, die von Tomé vorliegen, dürften mit grösster Wahrscheinlichkeit zu dieser Art gehören.

Fundorte: San Vicente (1 Exempl.), Tomé (1 Exempl.).

\section{Baculites vagina Forbes.}

1846. Baculites vagina Forbes, Trans. Geol. Soc. Lond. 7. p. 114. Taf. I Fig. 4.

Forbes. DARIIIN, South America 1851. p. 126. Taf. V Fig. 3.

\begin{tabular}{|c|c|c|}
\hline & & $\begin{array}{l}\text { Lyelli D'Orbigny, Voy. Pol Sud. Géol. Taf. } 4 \text { Fig. 3-7. } \\
\text { ornatus D'Orbigny, daselbst Taf. } 6 \text { Fig. } 3-6 .\end{array}$ \\
\hline & & $\begin{array}{l}\text { ornatus DORBIGNY, daselbst Tat. } 6 \text { Hig. 3-6. } \\
\text { vagina (ForBEs) D'ORBIGNY, Prodr. 2. p. } 215 \text {. No. }\end{array}$ \\
\hline & & Lyelli D'Orbigni, Prodr. 2. p. 215. No. 72. \\
\hline 1865. & & $\begin{array}{r}\text { ragina (Forbes) Stouiczka, Cret. Fauna of South. India. } \\
\text { Ceph. p. 198. Taf. 90 Fig. 14, 15; Taf. } 91 \text { Fig. 1-6. }\end{array}$ \\
\hline 1895 & & $\begin{array}{l}\text { (Forbes) Sternaran, Ceph. d. Quir.-Schicht., dies. } \\
\text { Jahrb. Beil.-Bd. X. p. 89. Taf. VI Fig. } 4 \text { a-e. }\end{array}$ \\
\hline$\pi$ & & $\begin{array}{l}\text { (Forbes) Kossmat, Unters. i } \\
\text { form. p. 15̄. Taf. XIX Fi }\end{array}$ \\
\hline
\end{tabular}

Es giebt von Baculites vagina verschiedene Varietäten. vou denen nur zwei besondere Namen erhalten haben (Otacodensis Stol. (nach Steinatans eine besondere Art) und simplex Kossu.). Auch die Baculiten aus den QuiriquinaSchichten zeigen, obwohl sie alle dem Baculites vagina angehören, manche Verschiedenheiten, namentlich in der Stärke der Berippung. Einige Exemplare sind kräftig berippt, andere 
fast glatt. Keiner der Autoren, die diescn Baculiten beschrieben haben, haben diese Unterschiede als artenhegrilindend angesehen. Stourzok erwähnt sie nicht einmal. Sтrmsss: erklärt die Berippung für ein in hohem Matase werhselndms Merkmal.

D'Orbigivy erwähnt den B. anceps, der in Europa len B. vagina vertritt, von Quiriquina ${ }^{1}$. Was fr abbildet (Voy. Pol Sud. 'Taf. 4 Fig. 8-12), diurften vielleicht nur junge B. vagina sein. Die zahlleichen Baculiten ans dem Durs:schen Material gehören alle zu der letzteren Art.

Meist sind die Baculiten zu den sogen. „Baculitenkunllengehäuft. In diesen stecken sie richtungslos durcheinander. Sie finden sich aber auch einzeln, mit Muscheln vergesellschaftet.

Fundorte: Quiriquina (ca. 15 Exempl.), Tomé (ca. 30 Exempl.), San Vicente (ca. 10 Exempl.).

Scaphites constrictus Sow. var. quiriquinensis WrLckens. Taf. XVII Fig. $3-8$.

Scaphit aus der Verwandtschafi des Scaphites constrictu. Sow. mit schmalem, hohem Windungsquerschnitt und eigenartiger Sculptur, die in unregelmässigen Knoten auf der Externseite und in Rippen besteht, die auf dem letzten Theil der' Wohnkammer fast gerade, fein und zahlreich, vorher' aber kräftig geschwungen und stark sind. Die Dimensionen sind gering.

Beschreibung: Das Gehäuse hat eine ovale Gesammtgestalt. Die Jugendwindungen sind weitnabelig und haben einen fast kreisförmigen Querschnitt. Die äusseren Windungen platten sich mehr ab, sie sind im Querschnitt hochoral bis gerundet rechteckig, inmen etwas breiter als aussen, mit mässig gerundeter Externseite (Taf. XVII Fig. 7). Die jüngeren Windungen umfassen mehr die älteren: so dass ansgewachsene Individuen ziemlich engnabelig sind. Das gerade Stiick der Wolnkammer (die etwa $\frac{3}{4}$ des letzten Umganges einnimmt, Taf. XVII Fig. 6) ist nicht lang. Seint innere Kante ist nicht gerade, sondern billet einen kleinen Buckel. Der letzte Umgang biegt sich bald zuriick, so dass

1 Prodr. 2. p. 214. No. 67. 
die Rückenseite der Mündung wieder dem vorhergehenden Ungang anliegt. Bei grossen Exemplaren nimmt der letzte Umgang in seinem letzten Drittel nicht unbeträchtlich an Dicke zu und gewinnt einen weniger hohen Querschnitt.

Die Sculptur der Schale ist auf den ersten Windungen äusserst schwach. Erst anf den späteren tritt sie erkennbar hervor und besteht dann in regelmässigen Rippen. Diese gehen von der Nabelkante aus, krümmen sich zuerst rückwärts, dann vorwärts, dann wieder rückwärts und biegen sich schliesslich, indem sie über die Externseite verlaufen, kräftig: nach vorn. Z. Th. gabeln sich die Rippen, z. Th. vermehren sie sich durch Intercalation von kleineren, die theils in der Nitte der Seiten, theils dem Nabelrande oder der Externseite näher ihren Anfang nehmen. Auf der Externseite sind die Rippen alle gleich stark und gleich weit von einander entfernt. Bei einigen Exemplaren zeigen sie dort, wo sie anf den Externtheil treten, eine leichte Verdickung und sind auf diesem selbst schwächer, so dass er abgeplattet erscheint oder von ganz schwachen Knotenreihen begrenzt ist.

Gegen den gestreckten Theil der Wohnkammer zu ändert sich die Sculptur. Die Rippen werden kräftiger und an der Nabelkante bilden sich 2 oder 3 Anschwellungen. Bei grossen Exemplaren zeigen sich auf der Externseite eigenartige, unregelmässige Knoten, dre theils in der Richtung der Rippen verlängert und an den beiden Enden um einen winzigen Betrag höher als in der Mitte, theils aber von r'undlicher Form und unregelmässig bald auf der einen, bald auf der anderen Seite gelegen sind (Taf. XVII Fig. 3 b).

Noch weiter gegen die Mündung hin tritt ganz unvermittelt abermals eine Änderung in der Sculptur ein. Die starken Rippen, die von den Erhöhungen an der Nabelkante ausgehen, hören plötzlich auf und in ihrer Fortsetzung laufen zahlreiche, sehr feine Rippen über das Gehäuse. Sie sind feiner als die Rippen der jugendlichen Umgänge und vermehren sich theils durch Gabelung; theils durch Intercalation. Dieser eigenthïmliche Wechsel in der Sculptur ist nur hei einem besonders grossen Exemplar von San Vicente beobachtet.

Die Lobenlinie (Taf. XVII Fig. 8) ist folgendermaassen gestaltet: Ein duch einen Mittelsattel zweitheiliger Extern- 
lobus theilt den Externsattel. Jeder Zweig des Externsattels ist zweitheilig und je 3-4lappige. Der erste Seitenlobus ist ebenson tief wie der Externlobus und endigt in vier spitzen. Der erste Sejtensattel ist wieder \%weitheilig und jedter Theil zweilappig. Dann folgt der zweispitzige \%weite Seitenlobus, dessen erste Spitze noch einmal \%weigetheilt ist. mnd hieranf ein \%weilappiger zweiter Seitensattel. Die Lobenlinie hat die grösste Ähnlichkeit mit der von Briknorst ${ }^{1}$ gegebonen Lobenlinie des sic. constrictus.

1)imensioneu einiger Lxemplare in mu.

\begin{tabular}{|c|c|c|c|}
\hline & $\begin{array}{l}\text { Grosses } \\
\text { Exemplar ron } \\
\text { San Vicento }\end{array}$ & $\begin{array}{l}\text { Griisstes } \\
\text { Exemplar } \\
\text { yoll Tumí }\end{array}$ & $\begin{array}{l}\text { Audere. } \\
\text { Exemplar } \\
\text { rou Tom: }\end{array}$ \\
\hline Grösste Erstreckung . & $33=100$ & $27=100$ & $2 \cdot 2,5-110$ \\
\hline Grösste Höhe . . . & $27=82,4$ & $22=81,5$ & $18=80$ \\
\hline Dicke der Wohnkammer. & $11,5=34,8$ & $8, \overline{5}=31, \overline{5}$ & $7 \ldots 31.1$ \\
\hline $\begin{array}{l}\text { Höhe des gestreckten Theiles } \\
\text { Höhe der letzten Wiudung }\end{array}$ & $15=45.4$ & $10, \overline{5}=48,9$ & $8 . \overline{5}=3 \overline{7.8}$ \\
\hline an der Miündung. . . . & $10 . \overline{0}=31.8$ & $9.5=35,2$ & $8.5=3 \bar{\gamma} .8$ \\
\hline Höhe der JIündung. . . & $9=27,3$ & $7=33,3$ & $6 . \check{\partial}=\stackrel{.2 .9}{9.9}$ \\
\hline Nabelweite. . . . & $3,0=9,1$ & $3,3=11,7$ & $3.5=1.5,6$ \\
\hline
\end{tabular}

Fundorte: 'Tomé (30 Exempl.), Quiriquina (3 Exempl.). San Vicente (2 Exempl.); 'T'omé ist also der Hauptfundpunkt für dies Fossil.

Ähnliche Formen: Aus keinem der pacifischen Senongebiete, deren Fauna in erster Linie zum Vergleich mit der Quiriquina-Fauna einladet, liegt ein Scaphit vor, der mit dem soeben beschriebenen ïbereinstimmt. Aus Californien sind Scaphiten wohl erwähnt ${ }^{2}$, aber noch nicht beschrieben. Ans der pacifischen Kreide Canadas ist durch Whiteares der Sc. quutsinocnsis ${ }^{3}$ bekannt geworden. der dem Sc. acqualis

'Binknorst vas nex Bisknorst, Monographie des Gastérupodes et des Céphalopodes de la craie supérieure dn Limbourg. Taf. V d Fig. 6 h.

${ }^{2}$ Anderson, Some cretaceous bels of Rogue River Valley, (Oregon. Journ. of Geol. 3. p. 460.

${ }^{3}$ On some cretaceous fossils from British Columbia, the North West Terr. and Manitoba by Whitedves. Contrib. to Canad. Pal. 1. Part IV. p. 158. Taf. 21 Fig. 2. 
aus dem europäischen Cenoman nahe steht. Aus Südindien fuihrt Kossurat mehrere Scaphiten an, von denen aber nur zwei aus dem dem oberen Senon entsprechenden Theile der AriyalurGroup stammen, während die anderen in der Utatur- und in der 'Trichinopoly-Group liegen ${ }^{1}$. Die beiden senonischen Arten sind:

Scaphites Cunliffei Forbes sp.

Sc. Pavana Forbes sp.

Nach Kossmat ist $S c$. Cunliffei nahe verwandt mit Sc. constrictus Sow. aus den Mucronaten- und Sc. aquisgranensis ScHLÜTER ${ }^{2}$ aus den Quadratenschichten von Aachen. Die Abbildungen, die Forbes ${ }^{3}$ und StoliczkA ${ }^{4}$ von diesem Cephalopoden geben, sind recht verschieden, was besonders in die Augen fällt, wenn man die vergrösserten Figuren (Forbes, Taf. 8 Fig. 2 a und Stoliczka, Taf. L Fig. 3 a) vergleicht. Forbes' Abbildung $2 \mathrm{c}$ ist schlecht. Sie erweckt den Anschein, als sei der Scaphit gekielt. Forbes' Sc. Cunliffei zeigt feine geschwungene Rippen, bei StoLiczka sind diese dagegen gerade. Auch haben die Knoten verschiedene Lage. Wie bei Sc. Pavana handelt es sich ja bei dieser Art um die inneren, regelmässig aufgerollten Windungen eines Scaphiten, und der Vergleich mit einer anderen Form wird, ehe besseres Material vorliegt, stets ein sehr unvollkommener bleiben miissen.

Sc. Pavana unterscheidet sich von dem vorigen dadurch, dass er keine Knoten an der Nabelkante hat. Nach Kossuat's Beschreibung sollte man denken, dass Sc. constrictus var. quiriquinensis mit dieser Art nicht unbedeutende Ähnlichkeit hat. Die geraden Rippen und Knoten des Sc. Cunliffei hat die Form von Quiriquina jedenfalls nicht. Leider erlaubt Forbes' undeutliche Abbildung mir den Vergleich mit Sc. $P a-$ vana nicht in dem Maasse, wie es erwünscht wäre.

1 Das Alter von Scaphites Brahminicus ist ungewiss. Wahrscheinlich stammt er aus der Trichinopoly-Group, was nach seiner Ännlichkeit mit dem Sc. Geinitzi aus dem europäischen Turon sehr wahrscheinlich ist.

${ }^{2}$ Diese beilen Arten unterscheiden sich von einander durch die etwas rerschiedene Berippung, sowie durch die rerschiedene Höbe des gestrecliten Theils der Wohnkammer, welche bei Sc. constrictus beträchtlicher ist.

3 Fornes, Trans. Geol. Soc. Lond. 7. Taf. 8 Fig. 2 a-d.

- Sromiczka, Cret. Famna of South. India. Ceph. Ammonitidae. Taf. j0 Fig. 3. 
Bei weitem am ähnlichsten ist dem Quiriquina-Scaphiten der Sc. constrictus Sow. Man muterscheidet die zahlreichen Varietäten dieser form nicht mit besonderen Namen. Nicht alle gleichen der chilenischen Form. Am nächsten stehen ihn solche Exemplare wie das von Scurëtrer, Taf. 28 Fig. 7 der "Cephalopoden der oberen deutschen Kreide ${ }^{1 /}$ abgebildete oder Stiicke, wie das bei Grossouvre, Les ammonites de la craie supérieme ${ }^{2}$, 'I'af. 31 Fig. 2 a, b und 7 dargestellte. Am besten geeignet, die Zngehörigkeit unseres Scaphiten zum Sc. constrictus darzuthun, sind die Abbildungen dieser Art bei Bixkнors'". Die Variation quiriquinensis steht etwa zwischen den Varietäten Fig. 6 a und Fig. 6 b. Der Verlauf der Rippen, der Buckel an dem Nabolrand des gestreckten Theils der Wohnkammer', die z. 'Th. unregelmässig auftretenden Kinoten, die Lobenlinie stimmen nahe ïberein. Die Eigenart der Variation quiriquinensis gegenüber dem europäischen Sc. constrictus besteht darin, dass seine Windungen stärker abgeplattet und höher sind; die Sculptur ist weniger kriftig, und zwar sowohl die Rippen, als auch die Knoten anf der Banchseite, die auch noch mehr nach aussen gerückt sind. Endlich erreicht die chilenische Form niemals die Grösse der emropäischen".

${ }^{1}$ Palaeontographica. 21. - Ich wandte mich an das Berliner geologische Institut, mu das Original zu dieser Figur zu erhalten, und Herr Dr. Solger hatte die grosse Freundlichkeit, nach demselben zu suchen. Da das Stiick nicht zu finden war, so iibersandte er mir auf meine Bitte möglichst ähnliche Exemplare von Sc. constrichus. Besonders eins derselben, von Orglandes bei Valogne, aus der Sammlung Gerville, stelıt dem Quiriquina-Seaphiten sehr nahe, ist aber treilich etwas grösser als dieser. Ich erlaube mir, Herrn Dr. Solger anch an dieser Stelle für sein freundliches Entgegenkommen herzlichst zu danken.

${ }^{2}$ Recherches sur la craie supérieure. II. partie: Paléontologie. Ans den Ilém. p. s. à l'expl. de la c. géol. dét. de France.

3 J. 'I'. Binkhorst van den Binkinorst, Monographie des Gastíropodes et des Céphalopodes de la craie supérieure du Limbourg. 1861. Taf. Va Fig. 6 a - h.

4 Das unregelmässige Auftreten der Knoten, das fast an pathologische Bildungen erinnert, scheint der ganzen Gruppe eigenthümlich zu sein. Vergl die Abbildungen des Sc. nodosus (der dem Sc. constrictus nahesteht) bei Mьeк, fiep. on the invert. cretac. and tertiary fossils of the upper Missouri Country. (Rep. of U. S. Geol. Surv. of 'Terr. 9. 1876.) Taf. 2う Fig. 2a, 3 a.

N. Jahrbuch f. Mineralogie etc. Beilageband xirll. 
194 O. Wilckens, Revision der Fauna der Quiriquina-Schichten.

\section{Gastropoda.}

Solariella Wood.

Solariella unio PhiL. sp.

1887. Trochus unio Philıppi, Tert. quart. Verst. Chiles. p. 100. Taf. 11

Fig. 23.

Quiriquinae PhIlIPpI, daselbst p. 100. Taf. 11. Fig. 22.

" $\quad$ "Steinmanni PHILIPPi, daselbst p. 100. Taf. 11 Fig. 26.

" $\quad$ insularis PhilippI, daselbst p. 100. Taf. 11 Fig. 21.

Beschreibung: Die Schale ist dünn. Das Gehäuse besteht aus $6-7$ Windungen, die oben abgeplattet sind und unten eine Kante haben. Die letzte Windung ist an der Unterseite ein wenig gewölbt. Die Mündung ist gerundet vierseitig. Die Schale ist glatt, nur auf den ersten Windungen zeigt ein besonders gut erhaltenes Exemplar spirale Streifen. Später treten nur quer verlaufende Zuwachsstreifen auf, die mit der Zunahme der Grösse der Windungen stärker werden. Sie verlaufen rückwärtsbiegend zum Nabel, der von mittlerer Weite ist. Den Nabel fassen an seinem Rande 2-3 spirale Furchen ein, und da diese von den Zuwachsstreifen durchschinitten werden, so entsteht ein gekörnelter Rand um den Nabel herum.

Wegen dieses gekörnelten Randes um den Nabel stelle ich die Art zu Solariella, obwohl diese Gattung meist sculptirte Formen begreift. In ihrer Form ähnelt diese Schnecke sonst einer Margarita.

Dimensionen in mm:

$\begin{array}{cc}\text { Höhe } & \text { Breite an der Basis } \\ 7,5 & 8 \\ 5,5 & 6,2 \\ 6 & 6,5\end{array}$

F und olte: Quiriquina (14 Exempl.), Tomé (4 Exempl.), San Vicente (4 Exempl.).

Bemerkungen: Philjpri hat 7 Trochus-Arten aus den Quiriquina-Schichten beschrieben. Für Trochus Ovallei Phic. ${ }^{1}$ liegt mir kein Material vor. Tr. rotelloïdes ${ }^{2}$ PhIL. halte ich

1 Philippi, Tert. quart. Verst. Chiles. Taf. 11 Fig. 24.

2 Daselbst Taf. 11 Fig. 24. - Ein Trochus rotellö̈des ist übrigens schon von Forbes beschrieben (nach Stoliczka eine Delphinula?) (Forbes in der mehrfach erwähnten Abhandlung über die südindische Famna p. 120. Taf. 11 Fig. 25). 
fül eine Gyrodes euryomplala Pun. sp. (s. u.), jedenfalls nicht fül einen Trochus. Trochus spinula ${ }^{2}$ ist verdächtig. Ich halte iln für weiter nichts als die spitze einer Schneckenschale, etwa eines Fusus difficilis.

Die übrigen 4 Arten sind sich ähnlich, sie sind auf 9 Exemplare gegründet, während mir zur Nachprüfung 22 zur Verfügung stehen. Trochus Steinmunni (auf einen Umgang begriundet!) ist daselbe wie Tr. Quiriquinue, nur ein jüngeres Exemplar, weshalb der Nabel enger ist. Tr. insularis und Tr. unio gleichen sich selır, letzterer ist wieder dem Tr. Quiriyuince ähnlich. Der gekörnelte Nabelrand ist nur von T'r. unio abgebildet. Bei minder guter Erhaltung ist er auch schwer zu entdecken. Unter meinen Exemplaren befindet sich auch noch dies oder jenes, das nicht völlig mit einer der Phisipri'schen Abbildungen übereinstimmt, so dass ich, wenn ich es wie Phicrppi machen wollte, noch mehrere weitere Arten aus der einen machen mïsste.

Ähnliche Formen: aber ron bedentenderer Grösse. sind Solariella radiatula Forbes ${ }^{2}$ aus der südindischen UtaturGroup und Margarita orbiculata StoL. ${ }^{3}$ Gaвb bildet eine, Margaritclla crenulata ${ }^{4} \mathrm{ab}$, die in der californischen TejonFormation, also dem Eocän, vorkommt. Abgesehen davon, dass sie etwas niedriger ist, ist sie unserer Form nicht unähnlich.

\section{Galeropsis Conrad.}

\section{Galeropsis laevis PhiL. sp.}

Taf. XVII Fig. 9 a, b.

1887. Trochita laevis Philippi, Tert. quart. Verst. Chiles. p. 92. Taf. 11 Fig. 3.

Gehäuse rauhschalig. Windungen rasch an Grösse zunehmend. Gewinde verhältnissmässig hoch.

Beschreibung: Das Gehäuse ist von pyramidalem Umriss. Es bestelıt aus etwa 4 IVindmingen, die stark an Grösse

1 Punlippi, 'Tert. quart. Ver'st. Chiles. 'Taf. 11 Fig. 25.

${ }^{2}$ Stoliczka, Cret. fauna of Sonth. India. Gastr. Taf. 24 Fig. 17, 18.

3 Daselbst Taf. 24 Fig. 16.

${ }^{4}$ Geol. Surv. Calif. Palaeont. 1. Taf. 20 Fig. 74. GabB schreibt: „umbilical margin very coarsely creuulated." Das sieht man auf der Abbildung nicht. 
znehmen. Das Gewinde ist hoch und verhältnissmässig schlank. Die letzte WVindung, die eine sehr ruppige Oberfläche hat, ist unten abgeflacht. Leider kann ich keines der wenigen Exemplare freilegen, so dass ich über die Gestaltung der Nabelgegend und der Mündung nichts auszusagen vermag.

Dimensionen in mm: Höhe ca. 40, Breite der letzten Windung 42.

Fund orte: Quiriquina (2 Exempl.), Tomé (1 Exempl.).

Bemerkung: Die Gattung Galeropsis ist für die Calyptraeiden mit hohem Gewinde aufgestellt.

Ähnliche Formen: Galeropsis excentricus ABBB $^{1}$ (emend. ConRAD) aus dem californischen Eocän hat die grösste Ähnlichkeit mit unserer chilenischen Art, allem Anschein nach auch in der Form des Gewindes, das ich leider bei $G$. lacvis nicht freilegen konnte, das aber auf der Fig. 9 a Taf. XVII nach einem Stïck, das leider zerbrach, annähernd richtig. ergänzt sein dürfte.

\section{Natica AdAnson.}

\section{Ampullina australis D'ORB.}

Taf. XVII Fig. 11 a, b, 12.

1842. Natica arancana D'Orbigny, Voy. Amér. Mér. Pal. p. 115. Taf. 12 Fig. 4, 5 .

\footnotetext{
$" \quad$ " australis D'Orbicny, daselbst p. 115. Taf. 14 Fig. 3, 4.

1846. " $"$ D'Orbigny, Voy. Pol Sud. Taf. 4 Fig. 20, 21, 21'.

" Grangeana D'Orbigny, daselbst 'Taf. 4 Fig. 18, 19, 19'.

1850. " araucana D'Orbigny, Prodr. 2. p. 221. No. 198.

" $\quad$ " australis D'Orbigny, daselbst p. 221. No. 199.

1887. " australis (D'Orb.) PhilipPI, Tert. quart. Verst. Chiles. p. 84. Taf. 10 Fig. 7.

" $\quad$ araucana (D'ORB.) PhilipPi, daselbst p. 84. Taf. 10 Fig. 8.

" $\quad$ Gance Philippi, daselbst p. 84. Taf. 10 Fig. 6.

" oliviformis Philippi, daselbst p. 84. Taf. 10 Fig. 5.

" "Grangeana (D'Orb.) Philippi, daselbst p. 87 'Taf. 10 Fig. 212. 1895. Lunatia singularis MörICKe, Gastr. Biv. d. Quir.-Schicht., dies. Jahrb. Beil.-Bd. X. p. 96. Taf. VII Fig. 12, 13.

1 Pal. Calif. 1. p. 136. Taf. 29 Fig. 232, 232 a. (Die Abb. Tat. 20 Fig. 95 ist nicht gut gelungen.)

2 Punuppi giebt Grange als Fundort an. Grange war aber einer der Theilnehmer an der Expedition der Astrolabe.
} 
Beschreibung: Das Gehäuse besteht ans 5 Windungen, von denen die ersten, wie man besonders an jungen Lixemplaren sieht, oben etwas abgeplattet sind. Im Übrigen sind die Windungen convex. Sie sind von kräftigen, nach rückwärts lanfenden Zuwachsstreifen bedeckt. Die Mündung ist von ovaler Form; ilı Umriss steht geneigt gegen die Achse des Gehäuses. Die Innenlippe ist etwas abgeflacht, durch 'Zuwachsstreifen gefurcht und von einer' starken Schwiele bedeckt. Diese verdeckt auch mehr oder weniger, manchmal sogar ganz, den Nabel. Sie wechselt etwas in ihrer Form. wie ein Vergleich der Figuren 11a und 12 auf Taf. XVII ergiebt.

Ich nemne diese Art Ampullina a stralis, weil ein beschalt es Exemplar zuerst unter dies em Namen beschrieben worden ist.

Dimensionen in mm:

$\begin{array}{ccc}\text { Höhe } & \text { Höle der letzten Windung } & \text { Breite } \\ 30 & 25 & 24 \\ 36 & 31 & 29\end{array}$

Fundorte: Quiriquina (ca. 50 Exempl.), San Vicente (9 Exempl.), Tomé (4 Exempl.).

Bemerkungen: D'Orbigny's Abbildungen der Ampullina unstralis im Toy. Amér. Mér. und Voy. Pol Sud stellen kleine Exemplare dieser Art dar. Philippi bildet ron iln als Natica Ganae ein grosses ab. Letztere Abbildung ${ }^{1}$ ist nicht ganz correct. Das Gehäıse ist in Wirklichkeit banchiger und die kräftigen Zuwachsstreifen sind auf der Figur gar nicht zur Darstellung gelangt. D'Orbigny's Abbildung giebt Philippi wieder ${ }^{2}$, ohne dabei zu bemerken, dass es sich um eine Vergrösserung handelt. Die $N$. oliviformis ${ }^{3}$ PhIL. ist eine junge Ampullina australis, bei deren Darstellung die Abplattung der ersten Windungen etwas stark hervorgehoben ist. Wir besitzen ïbrigens ein ganz ähnliches Exemplar aus dem Duscxschen Material.

Die Natica Grangeana D'Orb. ist eine in Bezug auf die Nabelschwiele schlecht wiedergegebene Ampullina austratis.

1 Punlippi, Tert, quart. Verst. Chiles. 'Taf, 10 Fig. 6.

2 Daselbst Taf. 10 Fig. 7.

3 Daselbst Taf. 10 Fig. ว̃. 
Die beiden Furchen auf der Innenlippe, die PhILIPP sich nicht erklären kann, sind zu prononcirt gezeichnete Zuwachsstreifen.

Was endlich Natica araucana D'ORB. anbelangt, so handelt es sich um einen Steinkern der Ampullina australis. Ein solcher Steinkern zeigt natiirlich weder Nabel noch Schwiele. Daher wohl Philippi's Zweifel, ob eine Natica vorliege. D'OrBIGNy will übrigens bei der Beschreibung dieser Form nicht (wie Philippi meint) sagen, dass die Windungen kantig sind. Seine Bemerkung "spira angulosa" ist sinnlos. Jedes Gewinde bildet selbstverständlich einen Winkel, und bei anderen Beschreibungen D'Orbigny's steht an dieser Stelle der Werth des Winkels des Gehäuses.

Was Möricke Lunatia singularis nennt, ist, wie ich mich durch Untersuchung des Originalexemplars ${ }^{1}$ überzengte, ein Steinkern von Ampullina australis mit einigen Schalenresten. Daher das treppenförmige Gewinde und der tiefe Nabel, aus dem der Callus ganz herausgebrochen ist.

Eine ähnliche Form ist $A$. sortita Stou. aus der Ariyalur-Group der südindischen Kreide. Sie stelit unserer Art sehr nahe und unterscheidet sich von ihr fast nur durch die abweichende Gestaltung der Innenlippe. Ortuans vergleicht Natica chilensis PHIL. aus der patagonischen Formation mit N. Ganae (= australis). (Rep. Princ. Univ. Expedit. Patag. 4. II. p. 186.)

\section{Gyrodes ConRad.}

\section{Gyrodes euryomphala PHiL. sp.}

Taf. XVII Fig. 10 a, b.

1887. Natica euryomphala Philippi, Tert. quart. Verst. Chiles. p. 86. Taf. 9 Fig. 21.

[ ? Troclus rotelloïdes Philippi, daselbst p. 99 Taf. 11 Fig. 24.]

Grosse Gyrodes mit niedrigem Gewinde und grossem, tiefem Nabel, der gegen die Innenlippe von einer geraden Kante begrenzt wird.

1 Herr Prof. Dr. Benecke stellte mir die Steinmans'sclie Sammlung von Quiriquina-Fossilien, die sich im geologischen Institut der Universität in Strassburg i. E. befindet, behufs Vergleichnug mit der Dusex'schen in der liberalsten Weise zur Verfügung. Ich spreche Herrn Prof. Benecke. für diese Förderung meiner Arbeit anch hier meinen ergebensten Dauk ans. 
Beschreibung: Das Gehäuse ist dickschalig und von elliptisch-halbkugeliger Gestalt. Es besteht ans 5- 6 Windungen. Das Gewinde ragt wenig herror. Die ersten Windungen sind abgeplattet. Die Umgänge nehmen an Grösse rapide zu; die letzte Windung ist sehr breit. Ihre Vaht senkt sich plötzlich abwärts. Die Anssenlipre ist oben vorgrezogen und weicht dann stark zurïck. Der (ovale) Unmiss der Miindung steht daher seh" schief zur Achse der Windungen. Entsprechend dem Rand der Aussenlippe verlaufen die Zuwachsstreifen, die auf der letzten Windung ziemlich kräftig sind. Der Nabel ist sehr weit und tief, an der Innenlippe wird er von einer geraden Kante begrenzt, so dass seine Umrandung die Form eines Kreisabschnittes hat. Die Innenlippe ist von einem nicht sehr dicken Callus bedeckt.

Dimensionen: Höhe und Breite etwa $40 \mathrm{~mm}$.

Fundorte: 'Tomé (8 grosse, 7 kleine Exempl.), Quiri(quina (14 kleine Exempl.), San Vicente (1 grosses, 4 kleine Exempl.).

Bemerkungen: PhiLiprl's Abbildung ist nicht sehr gut. Sie giebt die trichterförmige Gestalt des Nabels nicht wieder. Auch ist das Gewinde niedriger und sind die Umgänge mehr gerundet.

Ähnliche Formen: Gyrodes tenellus Stor. ${ }^{1}$ aus der sïdindischen Trichinopoly- und Ariyalur-Group ist unserer' Form nicht unähnlich. Doch hat diese Art an der Naht eingesenkte Windungen. Aus der Chico-Formation Californiens beschreibt GABB eine Gyrodes Conratiana ${ }^{2}$, die - soweit man das ja überhaupt nach Abbildungen beurtheilen kann dem $G$. euryomphala nahe $z u$ stehen scheint. Der ganze Habitus ist ein ähnlicher, aber es fehlt allem Anschein nach die gerade Kante am Nabel, die eigentlich für die Gattung Gyrodes charakteristisch ist. Freilich ist dies Merkmal von vielen Palaeontologen vernachlässigt worden, und man hat weitnabelige Natica-artige Schnecken auch olne Nabelkante zu Gyrodes gestellt. So hat alich der Gyrodes excavata, den

${ }^{1}$ Stoliczka, Cret. fauna of Sonth. India. Gastr. 11. 306. 'Taf. ⒉2 Fig. 14.

${ }^{2}$ GabB, Pal. of Calif. 1. p. 107. Taf. 29 Fig. 219. - Es giebt auch eine (nicht identische) Gyrodes Conrudi Mkek (Foss. Upy. Miss. [Geol. Surv. Terr. 9.] p. 310). 
Whiteates ${ }^{1}$ aus der pacifischen Kreide Britisch-Columbiens beschreibt, und der nach Ch. White ${ }^{2}$ zu G. Conradiana GABb gehört, kein e Nabelkante. Dasselbe scheint mit G. depressa Мeer $^{3}$ der Fall zu sein, der einem jugendlichen $G$. euryomphala ähnelt. - Gyrodes ist eine charakteristische Gattung der oberen Kreide.

$$
\text { Gyrodes chilina D'ORB. sp. }
$$

1846. Natica chilina D'Orbigny, Voy. Pol Sud. Taf. 4 Fig. 24, 25, 26.

n auca D'Orbigny, daselbst Taf. 4 Fig. 22, 23, $23^{\prime}$.

1850. " chilina d'Orbigny, Prodr. 2. p. 221. No. 201.

1887. " $"$ (D'Orb.) Philippi, Tert. quart. Verst. Chiles. 1. 86. Taf. 10 Fig. 22.

" $\quad$ auca (D’Orb.) Philippi, daselbst p. 86. Taf. 10 Fig. 23.

" "Darwini Philippi, daselbst 1. 85. Taf. 9 Fig. 28.

"? " Cuadrae PhiLippi, daselbst p. 85. Taf. 9 Fig. 24.

Krleine Gyrodes-Art mit an der Nalit abgeplatteten Windungen und einer in spiralen Streifen bestehenden Sculptur.

Beschreibung: Das kleine Gehäuse ist halbkugelig und besteht aus 4-5 Windungen. Das Gewinde ist niedrig. Die Windungen nelımen rapide an Grösse zu. Sie sind an der Nalit abgeplattet, sonst gerundet. Ausser den Zuwachsstreifen weisen sie noch eine in kräftigen spiralen Furchen bestehende Sculptur auf, die besonders auf der letzten Windung unten, gegen den Nabel zu, kräftig hervortritt. Die Mündung ist hochoval. Der Nabel ist tief; die Innenlippe zeigt eine geringe Verdickung durch eine Schwiele. Eine gerade Kante am Nabel ist vorhanden.

Dimensionen in $\mathrm{mm}$ :

$\begin{array}{ccc}\text { Höhe } & \text { Breite } & \text { Höhe der letzten Windung } \\ 11 & 15,5 & 10 \\ 8 & 8,5 & 7\end{array}$

Fundort: Quiriquina (2 Exempl.).

Bemerkungen: Wie Philippi mittheilt ${ }^{4}$, ist es SteiNMANx nicht gelungen, in Paris die Originale D'Orbigny's für

1 Geol. Surv. Canada. Whiteaves, Mesoz. Fossils. p. 124. Taf. 16 Fig. 2.

2 U. S. Geol. Surv. Bull. No. 51: White, On invert. foss. from the pacif. coast 1889 . p. 45 .

3 MFEk, Report on the geological exploration of the forthieth Parallel.

4. Part I. 1. 159. Taf. 15 Fig. 1, 1 a.

4 Tert. quart. Verst. Chiles. 1) 245. 
die 'Tafeln des Voy. Pol Sud aufzufinden. Die Identificirung der beiden mir vorliegenden Exemplare einer Gyrodes-Art mit den d'Orbigny'schen Natica-Arten ist daher. da nur Abbildungen verglichen werden künnen, nicht absolut zuverlässigr. In ihrer ganzen Gestalt stimmen meine Stïcke mit den $D^{\circ} \mathrm{Or}_{-}$ bicxy'schen Figuren sehr gnt überein. Dass Natica anca und $N$. chilina dasselbe sind, hat schon Philipre richtig erkannt. Dass d'Orbigny selbst schon zu dieser Einsicht gekommen ist. scheint mir aus dem Umstande hervoryngehen, dass el im Prodrome nu $N$. chilina anführt. Phispe irrt sich übrigens. wenn el annimmt (l. c. p. 86), dass $N$. chilina dreimal so, gross sei als $N$. anca. Er hat den Grössenindex (Toy. Pul Sud Taf. 4 Fig. 26) überselien, aus dem ersichtlich ist, dass beide Arten gleich gross sind. Die Abbildungen, die Philıpr von ihnen giebt, sind nicht so gut wie die Originalfiguren. Man sieht 'Taf'. 10 Fig. 23 nichts ron dem Nabel. Da man nun auf D'Orbigny's Abbildungen die For'm des Nabels wegen der darin sitzenden Gesteinsmasse nicht genall sehen hann. so kann man Phrurpe nicht beistimmen, wenn er eine Schnecke, die im Übrigen ganz mit $\Lambda$. chilina übereinstimmt, weil ihr Nabel verschieden sei von demjenigen der D'Orbigry'schen Species, mit dem nenen Namen $N$. Darwini ${ }^{1}$ belegt. Ich halte diese Art für ganz dasselbe wie $N$. chilina. Die Beurtheilung wird freilich durch den Umstand, dass Philippi die Schnecken immer nur von einer Seite zeichnet, erschwert.

Ich bin nicht ganz sicher, ob ich auch $N$. Cuadrae hierher zu ziehen habe ${ }^{3}$. Für eine junge Gyrodes curyomphata ist das Gehäuse zu hoch. Wemn man aber annimmt, dass Phicrppr diese Schnecke ein wenig ron unten gesehen gezeichnet habe. so ist es einfach eine junge G. euryomphala.

Eine ähnliche Form ist der allerdings riel grössere

${ }^{1}$ Eine Natica Darwini ist schon 1886 von Hutton (Trans. N. Zealand Inst. 18. p. 334) beschrieben. PhILIpr's Name fällt also schon ans Grïnden der Priorität weg.

2 Diese Art soll nach PInLmpi eine fast kreisrunde Miundung haben. Das sieht man bei der Figur nicht. - Auf Taf. 9 findet sich bei Philippi der Druckfehler, dass die Natica Cuadrae N. Tcpida genannt ist.

3 Natica distorta Pun, ist ganz zu streichen. Man kennt von dieser kleinen Schnecke nicht den Fundort und damit anch nicht inr Alter. 
G. pansus Stor. ${ }^{1}$ ans der siidindischen Kreide. Die tertiäre Natica Inezana CoNRaD "2, die ähnlich zu sein scheint, ist leider so schlecht erhalten, dass eine Vergleichung unthunlich ist.

\section{Die übrigen Natica-Arten PHILIPPI's.}

Für Natica Rémondi, N. Ferrieri und N. globula lieg̨t mir kein Material vor.

Die beiden Natica, die Philippi Taf. 6 Fig. 13 und 14 abbildet, gehören zu Ampullina australis. Fig. 13 hat die grösste Ähnlichkeit mit Taf. 10 Fig. 6; Fig. 14 ist der Steinkern einer jungen $A$. australis.

Natica ovulum PhiL. Taf. 9 Fig. 25 und N. lepida PhiL. Taf. 10 Fig. 24 sind dasselbe. Aus dem Dusen'schen Material liegen Stïcke vor, die mit den Abbildungen übereinstimmen und alle möglichen Übergänge zwischen ihnen in Bezug auf die Gestaltung des Nabels und seiner Umgebung zeigen. Ich war zuerst geneigt, diese Natica, von der im Ganzen etwa 32 Exemplare vorliegen, als eine besondere Art $z$ betrachten. Ich bin aber doch zu dem Schluss gekommen, dass es sich nur um junge Individuen von Ampullina australis handelt, und zwar hat PhiLippi, glaube ich, Stücke abgebildet, bei denen etwas von der Nabelschwiele abgesprungen ist. Das verändert das Aussehen der Schnecke nicht unbeträchtlich.

\section{Scalaria LAMARCK.}

\section{Scalaria araucana PHIL.}

Taf. XVIII Fig. 1.

1887. Scalaria araucana Philippi, Tert. quart. Verst. Chiles. p. 83. Taf. 9 Fig. 16.

Beschreibung: Das Gehäuse ist länglich-thurmförmig; gross und nimmt langsam an Dicke zu. Die Windungen tragen etwa 15 kräftige Querrippen. Eine andere Sculptur ist nicht sichtbar. Die Mündung fehlt dem mir vorliegenden Exemplar, das so fest im Gestein liegt, dass man es nicht herauspräpariren kann. Das Stiick ist 26,5 $\mathrm{mm}$ lang und zeigt 7 Win-

1 Stoliczka, Cret. famna of South. India. Gastr. p. 305. Taf. 2.2 Fig. 9-13.

"Rep. of expl. Surv. to asc. the most etc. route for a railroad to the pac. ocean. 7. p. 195. Palaeontology Taf. 10 Fig. 5, 6. 
dungen, von denen die letate, grüsste, etwa so gross wie die drittletzte der Philupr'schen Figu' ist.

Fundort: Quiriquina (1 Exempl.).

Bemerkungen: Phurpr meint, dies müsse ihrer ganzen Form nach eine tertiäre Scalaria sein und führt sie deshalb) unter den tertiären Arten auf, obwohl als Fundort 'T'umbe\% (eine der Localitïten, wo die Quiriquina-Schichten entwickelt sind) angegeben ist. Das vorliegende Exemplar stimmt sehr g'ut mit Phis.ppi's Fig'ur überein.

Einige Ähnlichkeit zeigt die eocäne Scalaria Muthensonii GABB (Pal. Calif. 1. p. 212. Taf. 32 Fig. 278).

Scalaria Steinmanni Mör.

1895. Scalaria Steinmanni Jöricke, Gastr. Biv. d. Quir.-Schicht., dies. Jahrb. Beil.-Bd. X. p. 96. Taf. VII Fig. 14.

Von dieser Art, deren Beschreibung wir Möricke verdanken, lieg't ein ziemlich vollständiges Exemplar von San Vicente vor. Es ist $18,5 \mathrm{~mm}$ lang; die Breite der letzten Windung beträgt $7 \mathrm{~mm}$.

Fundorte: San Vicente (1 Exempl.), Quiriquina (2 Bruchstücke).

Bemerkungen: Der am meisten in die Augen fallende Unterschied gegen die vorige Art ist die viel schneller eintretende Verjüngung des Gehäuses.

Scalaria anca D'Orb. ${ }^{1}$ halte ich für identisch mit Sc. Steinmanni. Was D'Orbigny abbildet, ist ein schlechtes Exemplar. das zu sehr verändert ist, als dass es noch die feine Sculptur der Schale zeigte. Dieselbe kanm ja auch rom Zeichner übersehen sein. Ich halte es fïr praktischer, den Namen Sc. ancu ganz aus der Liste der Quiriquina-Versteinerungen zu streichen

1 Seal aria a uc a D'ORBIGNY.

1846. Scalaria auca D'Orbigny, Voy. Pol Sul. Taf. $₫$ Fig. 16, 17.

1850 .

1857. $\leadsto$ (D'OrB.) Philippi, Tert. quart. Verst. Chiles. 1. 8.?. d'Orbigny, Prodr. 2. p. 217. No. 109. Taf. 9 Fig. 29.

Philippi vergisst anzugeben, dass die Grösse seiner Fig. 29 auf Taf. 9 (in der Tafelerklärung fehlt die 29 ganz) nicht die natiirliche ist, sondern dass diese nach D'Orbigny's Grössenindex nur 11, giebt Philippi $13 \mathrm{~mm}$ an. - Für Sc. chilensis D'Orb. und fiir die Gabb'sche Sc. chilensis (= Sc. Gabbi PunL.) liegt mir kein MIaterial vor. Letztere ist wohl identisch mit Sc. Steinmami. 
und den auf ein gutes Stück gegründeten Namen Sc. Steinmanni beizubehalten.

Ähnliche Formen: Die südindische Ariyalur-Group birgt Scalarien, die der chilenischen Form offenbar nahestehen. Namentlich ist dies mit Scalaria subturbinata D'Ors. ${ }^{1}$ der Fall. Nur ist diese etwas schlanker und weniger gross als Sc. Steinmanni. (Eine älnnliche Sculptur zeigt Sc. Dupiniana D'OrB. ${ }^{2}$ aus dem Gault. Mit dieser Art vergleicht D'Orbigny seine Sc. chilensis ${ }^{3}$ )

\section{"Chenopus?" fenestratus PHIL. \\ Taf. XVIII Fig. 4.}

1887. Chenopus? fenestratus Philippi, Tert. quart. Verst. Chiles. p. 3 j. Taf. 1 Fig. 2.

Ein Steinkern mit Schalenresten gehört zu dieser Art; von welcher leider auch Philippr nur ungenügende Reste vorlagen. Die letzte Windung des Steinkernes trägt eine Sculptur. Sie scheint einen Kiel besessen zu haben, und man nimmt spirale Rillen mit punktförmigen Grübchen wahr, deren Zahl der von Phicippi angegebenen entspricht. Ausserdem treten tiefe, orale, quergestellte Gruben auf, die auch Philippis Figur deutlich wiedergiebt. Der Kiel auf den Windungen scheint sehr kräftig zu sein. Man erkennt noch etwas daron an den Schalenresten, die am Gewinde erhalten sind. An letzterem zeigt sich eine feine spirale Streifung unterhalb und eine leicht rückwärts gebogene Zuwachsstreifung oberhalb des Kieles. Die Mündung ist nur zum kleinen 'Theil erhalten, der Ausguss ist kurz.

$\mathrm{Zu}$ welcher Gattung diese Schnecke gelıört, ist, bis besseres Material rorliegt, nicht zu entscheiden, zu Aporrhais aber wohl jedenfalls nicht. Einstweilen mag sie den alten Namen Chenopus? tragen. Philippi neunt sie später in seinen Fossillisten Pugnellus. Dass aber keine Pugnellus rorliegt, folgt aus der Gestalt des Ausgusses.

Dimensionen in mm: Höhe 30, Breite 17.

Fundort: Quiriquina (1 Exempl.).

1 Stoliuzka, Cret. fauna of Soutl. India. Gastr. p. 232. Taf. 18 Fig. 2, 3, 4.

${ }^{2}$ Pal. fr. Terr. crét. 2. 1. 54. Atlas. Taf. 154 Fig. 10.

3 Voy. Amér. Jlér. Pal. p. 114. 


\section{Pugnellus Cosian.}

Pugnellus tumidus GarBs.

'Taf. XVIII Fig. ’2a, b.

1860. Pugnellus tumidus (ialsis, Proc. Nat. Śc. Phil. 1860. 1) 197. 'T'af. :3 Firg. $13,14$.

1887.

(Gafis) Punllp1, Tert. quart. Verst. Chiled p. 34. Taf. 1 Fig. 3.

1895.

(Gaвв) MüııскE, Gastr. Biv. Quir.-Sclichten, dies. Jahrb. Beil.-Bd. X. 1. 96. 'Taf. VII Fig. 15, 16.

Gehäuse von schwiehiger Kalkmasse mehr oder weniger ïberzogen. Ausguss nach innen gekrümmt. Aussenlippe flïgelartig verlängert, in einem dicken Knopf endigend.

Beschreibung: Die plumpe Schale ist im grossen Ganzen von dreieckigem Umriss. Sie besitzt ein mittelhohes Gewinde von 5-6 Windungen, die eine kielartige Erhebung tragen. Auf letzterer befinden sich auf dem letzten Umgang 3 Knoten, die schräg nach vorn und abwärts gezogen sind. Die Naht ist nicht scharf. Die längliche Mündung ist ziemlich weit. Die Innenlippe überzieht nach oben ein Drittel der Oberfläche des Gewindes bis fast an die Spitze; seitlich bildet sie einen Wulst, der sich bis dahin, wo er an den Kiel der zweitletzten Windung tritt, scharf abhebt, inden anssen neben ihm eine Rinne verläuft. Diese vertieft sich da, wo sie in die Naht zwischen del letzten und der vorletzten Windung tritt, zu einem Grübchen. Nach unten zu ist die Innenlippe ganz um die Spindel herumgeschlagen und bildet einen verdickten Rand, der zusammen mit dem Rande der Aussenlippe den Ausg'uss bildet.

Die grosse Aussenlippe ist in sehr charakteristischer Weise flügelartig entwickelt. Ihre Grösse wechselt etwas bei den einzelnen Exemplaren. Betrachtet man sie g'egen die Rückseite, so erscheint auf ihr ein dicker (innen concaver) Wulst, der von der vorletzten Windung des Gehäuses ansgeht. Er hat oben eine Einbuchtung; bilaet nach hinten einen Buckel, krümmt sich damn nach vorn und endigt in einem dicken Knopf von oblonger Gestalt, dessen Form kleinen individuellen Schwankungen unterliegt. Unterhalb dieses Wulstes ist die Anssenlippe, abgesehen ron dem rerdichten Rand, dünn. Sie verschmälert sich plötzlich, indem sie eine 
rechtwinkelige Einbuchtung bildet und zieht sich, immer schmäler werdend nach dem Ausguss hin, an dessen Bildung: sie theilnimmt.

Der Ausguss ist ziemlich lang. Er kriimmt sich (gegen die Innenseite gesehen) etwas nach links und am Ende stark (fast rechtwinkelig) nach innen. Auf der Innenseite weist er eine tiefe, gegen das Ende zu immer seichter werdende Rinne auf, auf der Aussenseite eine Mulde zwischen den verdickten Rändern.

Dimensionen in mm: Höhe 37, Breite über der Aussenlippe 27.

Fundort: Quiriquina (10 Exempl.).

Bemerkungen: Eine etwas ansführliche Beschreibung: dieses seltsamen, auch in kleinen Bruchstïcken leicht erkennbaren Fossils ist hier gegeben, weil diejenige Mörrcke's nur kurz ist und diesem Autor kein so gut präparirtes Exemplar zur Verfügung stand wie uns.

Philippi's Abbildung ist sehr unvollkommen. Er hatte nur unvollständige Stïcke. Gabb's Abbildung ist zu schlank. MörickE's Abbildung ist besser, nur zeigt sie die Krïmmung des Ausgusses nicht richtig und der Wulst auf der Aussenlippe ist nicht gut gezeichnet.

Ähnliche Formen: Die Gattung Pugnellus ist sehr charakteristisch für die obere pacifische Kreide. Das Merkwïrdigste an diesem Typus ist, dass das Thier aus der Schale heraus- und diese umwächst. Das Gehäuse wird dadurch mehr oder weniger, manchmal sogar ganz, von einer unförmlichen Kalkmasse überzogen. Es entstehen dann Formen, wie Pugnellus hamulus GABB (Pal. Calif. 2. Taf. 27 Fig. 42).

Die ersten Pugnellus-Arten treten in der Colorado-Group Nordamerikas auf ${ }^{1}$. Andere Arten finden sich in der californischen oberen Kreide der pacifischen Region (Chico-Group): nämlich $P$. hamulus GABB ${ }^{2}$ und $P$. mamubriatus GABB ${ }^{3}$. Noch näher sind mit der chilenischen Form die indischen Arten verwandt, namentlich $P$. gramuliferus Stou. ${ }^{4}$ aus der Ariyalur-

1 Pugnellus fusiformis МЕeK sp.

2 Gaвb, Pal. Calif. 1. p. 124. 'T'af. 20 Fig. 81; Taf. 18 Fig. 48. 2. Taf. 27 Fig. 42.

${ }^{3}$ Gabr, daselbst. 1. p. 125. Taf. 29 Fig. 229.

4 Stoliczka, Cret. fauna of South. India. Gastr. p. 21. Taf. 3 Fig. 7, 8. 
Group. Immerhin weicht diese Art von I'. tumidus im einzelnen ziemlich stark ab. Auch aus Balutschistan beschreibt Nötuag mehrere Pugnellus-Arten ${ }^{1}$. Verwandt mit Pugnellus ist eine Art aus der Upper Waipara-Formation Neu-Seelands: Conchothyra parasitica Mc Cor, von der das geologische Institut der Freiburger Universität zwei Exemplare besitzt. Das eine ist Taf. XVIII Fig. 3a, b zun Vergleich mit der Gattung Pugnellus abgebildet. Man sieht, dass auch bei Conchothyro das eigentliche Gehäuse von dicken Lagen schwieliger Kalkmasse incrustirt ist?

\section{Pugnellus uncalus Foribs sp.}

1846. Strombus uncatus Forbes, Foss. Invert. of South. India. Trans. geol. soc. Lond. II. Ser. 7. Part III. 1. 129. Taf. 13 Fig. 16.

semicostatus d'Orminx, Voy. Pol Sul. 'Taf. j Fig. 38, 39. 1850. Colombellina semicostata D'Orbignx, Prodr. 2. p. 231. No. 427.

1860. Pugnellus semicostatus (D'Orb.) GabB, Proc. Nat. Sc. Phil. 1860. p. 198. 1864. Colombellina uncata (Forbes) Picter, Foss. St. Croix. 3ième Sér. p. 67. 1868. Pugneilus uncatus (Forbes) Stoliczka, Cret. fama of South. India. Gastr. 1. 22. Taf. 3 Fig. 9-13.

1887. Strombus uncatus (Forbes) Philippi, Tert. quart. Verst. Chiles. p. 34. T'af. 1 Fig. 7.

1895̃. Pugnellus uncatus (Forbes) Möricke, Gastr. Biv. Quir.-Schicht., dies. Jahrb. Beil.-Bd. X. p. 97.

1897. $\leadsto$ (Forbes) Kossnat, The cret. depos. of Pondich. Rec. Geol. Surv. Ind. 30. 1. 87.

Nur GabB giebt an, dass diese Pugnellus-Art in denselben Ablagerungen wie Pugnellus tumidus vorkomme. Weder Philipi noch Mörıcke hat sie vorgelegen, und in dem reichen Dusex'schen Mraterial fehlt sie ebenfalls. Ich halte es daher nicht fïr ausgeschlossen, dass es sich hier um eine Verwechselung oder um eine fasche Deutung eines Fossils handelt. Nach GabB's Ausdrucksweise vermuthe ich, dass er die Angabe nach D'Orbigny gemacht hat und dass auch ihm dies Fossil nicht vorgelegen hat. Vielleicht ist GABB darauf gekommen, den Strombus semicostatus fiir ein Fossil von Quiriquina zu halten, weil er auf einer 'Tafel in Voy. Pol sud abgebildet ist, auf der sich soust ganz vorwiegend QuiriquinaFossilien finden. Ehe man den Pugnellus uncatus anf Quiriquina von Neuem findet, glanbe ich nicht an sein Vorkommen auf dieser Insel.

${ }^{2}$ Leider vermag ich nicht anzugeben, wo Mc Cor diese höchst merkwürdige Schnecke beschrieben hat. Sie soll in der Waipara-Formation Neu-Seelands sehr häufig sein. Eine (kaun kenntliche) Abbildung ron ihr findet sich in dem Hector'schen Katalog der neuseeländischen Fossilien der Colonial exhibition in London 1886. p. 58. 
Struthiolariopsis n. g.

Struthiolariopsis Ferrieri PHIL. sp.

\section{Taf. XVIII Fig. 5.}

1887. Fusus Ferrieri PhiLippI, Tert. quart. Verst. Chiles. p. 43. Taf. 2 Fig. 6.

Beschreibung: Das Gehäuse ist kurz-spindelförmig. Zahl der Windungen? Das Gewinde nimmt etwa die Hälfte des ganzen Gehäuses ein. Die Windungen tragen Knotenreihen, die bei der letzten Windung auf der Mitte liegt. Bei den ersten Windungen liegen die Knoten dicht über der unteren Naht (die vorletzte Windung weist 12 Knoten auf). Die Knoten sind in verticaler Richtung etwas in die Länge gezogen. Die Windungen sind oberhalb der Knotenreihe etwas eingesenkt, unterhalb derselben convex. Ihre Sculptur besteht in spiralen Rippen, die auch über die Knoten laufen. Auf der letzten Windung ist diese spirale Berippung unterhalb der Knotenreihe sehr kräftig. Die Zuwachsstreifen treten deutlich hervor. Sie zeigen auf dem eingesenkten Theil der Windungen eine nach rückwärts gerichtete Bucht. Über die Mündung, die Innen- und Aussenlippe, sowie den Ausguss lässt sich leider nichts aussagen, da nur unvollständige Exemplare vorliegen.

Fundorte: Quiriquina (2 Exempl.), Tomé (1 Exempl.).

Bemerkungen: Ehe besseres, ansreichendes Material von dieser Schnecke vorliegt, ist es unmöglich, sie ins System einzureihen. Auch PhiLipPI hat nur mangelhafte Stücke gehabt. Ich hielt sie Anfangs für Hindsia nodulosa Whiteaves ${ }^{1}$, die in den senonen Nanaimo beds von Vancouver Island vorkommt. Die canadische Form besitzt aber Varices, die der chilenischen fehlen.

Das charakteristische Merkmal der Schnecke ist die sehr starke Spiralstreifung auf der unteren Hälfte der Windungen. Herr Prof. Steinuan, der mich bei meinen Untersuchungen unermïdlich mit Rath und That unterstïtzt hat, machte mich darauf aufmerksam, dass eine ganz ïbereinstimmende Sculptur bei der tertiären Struthiolaria chilensis Pril. von Navidad auftritt (die Abbildung, die Philips 'Taf. I Fig. 4 seines

1 Whiteaves, Mesozoic fossils. 1. p. 125. Taf. 15 Fig. 6, 7. 
Werkes von dieser Art gielst, ist allerlings \% schlecht, lim dies dentlich zu zeigen). Die Übereinstimmugr ist so auffallend, dass der Gedanke an verwandtschaftiche Beriehungen nahe liegt und wem ich es anch für verfiuht halte, dieselben bei den ungenïgenden vorliegenden Resten (vor Allem miss-te erst Mündung und Ausguss bekannt sein) bestimmt zu behaupten, so glanbe ich doch der grossen Ähnlichkeit mit Struthiolaria Ausdruck geben zu diurfen, indem ich die schmecke Struthiolariopsis nenme. Die Knoten, die spirale Streifung, die im unteren 'Theil der Windung so besonders kräftig ist, sowie anch der ganze Habitus sprechen sehr für enge Beziehungen. Die lebenden Struthiolarien leben auch in der. pacifischen Region.

\section{Triton MonTF. \\ Triton Luisue n. sp. \\ Taf. XVIII Fig. 7 a, b.}

Kleiner 'Triton mit mässig hohem Gewinde. Hinter dem Mundsaum 4 Grübchen.

Beschreibung: Gehäuse länglich-oval, aus $4-5$ Windungen bestehend, die in ihrem oberen Theil gekielt sind. Oberhalb dieses Kieles sind sie eben bis leicht concar, unterhalb desselben convex. Sie tragen spirale Rippen, die oberhalb des Kieles weniger kräftig sind als unterhalb. Unterhalb treten ausserdem Querwülste auf, über welche die spiralen Rippen hinüberlaufen. Die letzte Windung ist ebenso hoch wie das Gewinde. Sie zieht sich gegen die Mündung hin in die Höhe, so dass sie fast bis an den Kiel der vorhergehenden Windung heranreicht. Dies ist iiberall da der Fall, wo im Wachsthum der Schnecke periodisch ein Mundsaum stehen geblieben ist. An den ersten Windungen verwischen sich die stehen gebliebenen Mündungsränder, auf den letzten sind sie deutlich. Auf dem abgebildeten Exemplar ist nur ein alter Varix zu sehen.

Die Mündung ist rundlich rechteckig. Die Aussenlippe. ist verdickt, abgeplattet und immen grob gekerbt. Hinter ihrem Aussenrande finden sich 4 Grïbchen in den Zwischenräumen zwischen den spiralen Rippen. Die Innenlippe ist 
von spiralen Streifen bedeckt. Ein ganz vollständiger Ausguss liegt leider nicht vor. Er kann nicht gross gewesen sein.

Dimensionen in mm: Höhe 21, Breite 14.

Fundorte: Tomé (1 Exempl.). San Vicente (1 grösseres, aber schlecht erhaltenes Exemplar und 1 Spitze von einem kleinen).

Eine ähnliche Form ist Tritonium gravidum SToL. ${ }^{1}$ aus der indischen Ariyalur-Group.

\section{Fusus Lan.}

Fusus difficilis D'ORB.

Taf. XVIII Fig. 6 a, b.

1842. Fusus difficitis D’Orbigny, Voy. Amér. I'ér. Pal. p. 118. Taf. 12 Fig. 11, 12.

1846. " \# D'Orbigny, Voy. Pol Sud. Taf. 4 Fig. 27, 28.

" "chilinus D'OrbignT, daselbst Taf. 4 Fig. 29, $29^{\prime}$.

1850. " difficitis D'Orbigny, Prodr. 2. p. 229. No. 374.

$" \quad " \quad$ chilinus D'Orbigny, daselbst p. 229. No. 376.

" dubius Hupé, GaY's Hist. Chile. 8.

1887. " difficilis (D'Orb.) Philippr, Tert. quart. Verst. Chiles. p. 42. Taf. 3 Fig. 2.

chilinus (D'Orb.) PhilipPI, daselbst p. 42. 'Taf. 3 Fig. 3, 24, 25.

(Auch Fusus laevis PhiL.)

Buccinum Hupeanum Philippi, daselbst p. 64. Taf. 6 Fig. 7.

1895. Fusus difficitis (D'Orb.) MörIcke, Gastr. Biv. d. Quir.-Schicht., dies. Jahrb. Beil.-Bd. X. p. 97.

Gehäuse bauchig, Gewinde mittelhoch, meist abgerieben. Feine Spiralstreifen auf dem unteren Theil der Umgänge. Canal gekrümmt.

Beschreibung: Das dickschalige Gehäuse ist von länglich-ovaler Form und besteht aus ca. 5 Windungen, von denen die ersten scliwach gewölbt sind, während die letzte gross und bauchig ist ${ }^{2}$. Das Gewinde ist mittelhoch, aber nur bei jungen Individuen gut erhalten. Bei den grösseren Exemplaren ist es meist stark abgerieben. Es giebt etwas schlankere und gedrungenere Varietäten; bei ersteren ist das Gewinde etwas höher. Die Windungen sind mit leichten, schwach

1 Stoliczka, Cret. fauna of Sonth. India. Gastr. p. 136. Taf. 11 Fig. 14, 14 a.

2 Das Strassburger Institut besitzt ein sehr grosses Exemplar, dessen letzte Windung eine Einsenkung ziemlich nahe minterhalb der Naht besitzt. 
gebogenen Zuwachsstreifen bedeckt. Auf der letzten Windung sieht man gegen die Tnnenlippen zn ganz feine spirale Streifen. Bei jungen Individuen reichen diese etwa bis zm Mitte des Umgangs (s. 'Taf. XVIII Fig. 6a, b). Die Miindung ist oral, die Aussenlippe leicht ausgebuchtet. Die Imnenlippe und der Ausguss sind nit einer leichten Schwiele bekleirlet. Letzterer ist etwas nach hinten und (gegen die Mündung gesehen) nach links gekrümmt. Einzelne Vorkommnisse ron Steinkernen mit spiraler Streifung beweisen, dass die Innenseite der Aussenlippe manchmal gefurcht war.

Dimensionen in mm:

$\begin{array}{cc}\text { Höhe } & \text { Breite } \\ 45 & 28,5 \\ 45 & 31\end{array}$

Fundorte: Quiriquina (ca. 60 Exempl.), 'Tomé (20 Exempl.), San Vicente (2 Exempl.).

Bemerkungen: D'Orbigny's Abbildungen dieses in den Quiriquina-Schichten besonders häufigen Fossils sind resht gut. Die ron 1842 ist insofern besser als die von 1846, als letztere (Fig. 27) eine Falte in der Nähe des Canals zeigt, die in Wirklichkeit nicht rorhanden ist. Dagegen giebt die spätere Figur besser den Verlauf der Zuwachsstreifen wieder als die Abbildung von 1842. PhiLippi stellt die Zuwachsstreifen auch nicht ganz richtig dar. Dieselben stehen nicht so vereinzelt wie auf der Figur an weitesten rechts ron seiner Fig. 2 auf 'Taf. 3. (Diese Figur ist übrigens offenbar nach D'Orbigny (Amér. mér.) copirt.)

Der Fusus chilinus D'Orb. ist auf einen Steinkern g'egründet, den ich für denjenigen eines jungen $F$. difficitis halte. Philippr hat sodann die Unterschiede des $F$. chilinus gegenüber dem $F$. difficilis so präcisirt, dass erstere Art schlanker gebaut sei, ein höheres Gewinde und einen geraden Ausguss habe. Er bildet zwei Exemplare $a b^{1}$ und wiederholt die D'Orbigny'sche Abbildung, die el noch etwas ver'grössert ${ }^{2}$. Auf seinen Figuren hat der $F$. chilinus aber keinen geraderen Ausguss als $F$. difficitis, und aus dem Dusex'schen Material

1 Tert. quart. Verst. Chiles. Taf. 3 Fig. 3 u. 24.

2 Länge $30 \mathrm{~mm}$. D'Orbignr's Figur misst 27,5 mm, der Grössenindex dazu ist $19 \mathrm{~mm}$ larg. 
geht hervor, dass $F$. difficilis bald etwas schlanker, bald gedrungener entwickelt ist. Ausserdem sagt PhiLipPI selbst, dass das Gewinde der grösseren Individuen immer angefressen oder abgeschliffen sei. Er hat sich also die Form der oberen Windungen ergänzen müssen.

Mörıcke, der auf die Form des Canals anscheinend kein Gewicht legt, führt ${ }^{1}$ als neues Unterscheidungsmerkmal auf, dass $F$. chilinus auf dem unteren Theil der Schale eine feine Spiralstreifung zeige. Wenn Philspr diese auch nicht erwähnt, so ist sie doch auf seiner Fig. 3 von Taf. 3 angedeutet. Diese Spiralstreifung ist ja nun bei gut erhaltenen und bei jungen Exemplaren von $F$. difficilis - manchmal freilich nur bei günstiger Beleuchtung - wahrzunehmen. Bei jungen Individuen reicht, wie gesagt, diese Streifung bis zur Mitte der Windung und womöglich noch etwas darüber hinaus. Auch Möricke hat eine Spiralstreifung auf der letzten Windung von Steinkernen beobachtet, ohne aber einen Schluss auf die Gestaltung der Aussenlippe daraus zu ziehen.

d'Orbigny und Möricke vergleichen den $F$. difficilis dem Liosioma bulbiforme Lam. ${ }^{2}$ aus dem Pariser Grobkalk. Diese Ähnlichkeit erstreckt sich ganz besonders auch auf die Sculptur. L. bulbiforme hat auch die feine Spiralstreifung unten auf der Schale und ebenso treten auf der Innenseite der Aussenlippe manchmal Furchen auf, die sich natiurlich auf dem Steinkern abzeichnen müssen. Es handelt sich also bei Fusus chilinus nur um gut erhaltene oder vielleicht etwas variirende Exemplare von $F$. difficilis ${ }^{3}$.

Ähnliche Formen: Ausser dem Liostoma bulbiforme dürften zwei californische Neptunea-Arten unserer chilenischen Form nahestehen. Eine genauere Vergleichung nach den $\mathrm{Ab}$ bildungen, die auch in GABB's Palaeontologie Californiens keineswegs immer tadellos sind, ist freilich unthunlich. $\mathrm{Nep}$ tunea curvirostris $\mathrm{GABB}^{4}$ aus der Chico-Group scheint mit

${ }^{1}$ Gastr. Biv. d. Quir.-Schicht, dies. Jalırb. Beil.-Bd. X. p. 98.

2 Deshayes, Descript. des coq. foss. des environs de Paris. 1837. Atlas. 2. Taf. 78 Fig. 5-10, 15-18.

${ }^{3}$ Nach dem, was Philippl (Tert. quart. Verst. Chiles. p. 64) iiber Fusus dubius Horé und Buccinum Hupeanum PHiL, sagt, halte ich diese heilen Arten fïr identisch mit Fusus difficilis.

${ }^{4}$ Pal. of California. 1. p. 88. Taf. 18 Fig. 37. 
Fusus difficilis verwandt zu sein, mehr noch ähnelt ihm Neptuneu cretucea GABB ${ }^{1}$ aus der T'ejon-Group (Eocän). Bei let\%terer ist nur der Canal etwas mehr gekrümmt und das Geliäuse etwas weniger bauchig.

Die Unterscheidung der einzelnen Untergattungen von Fusus, ein Gebiet, in dem besonders Coxrad durch die Aufstellung vieler schlecht charakterisirtel Untergattungen viel Velwirung angerichtet hat, ist noch selw unvollkommen. Liostoma gehört nach Triox zu den Bucciniden, Fischer stellt es dagegen zu den Fusiden. Neptunea wird von Stouiczka den Fusiden, von Fischer und Trryos den Bucciniden zugerechnet. Es ist danach wohl an und für sich nicht unstattlaft, Neptunea-Arten mit Fusıs difficitis zu vergleichen?.

\section{Fusus Metzdorfi PhiL.}

1887. Fusus Metzdorfi Phimpr, Tert. quart. Verst. Chiles. 1. 43. Taf. 3 Fig. 1.

Es liegt von dieser Schnecke eine letzte Windung vor. Es ist ein Steinkerm mit der inneren Schicht der Schale. Er' bietet keinerlei Anhaltungspunkte, um über diese Art etwas Genauteres auszusagen.

Fundort: Tomé.

\section{Pyropsis Conrad.}

Pyropsis Hombroniana D'Orb. sp.

Taf. XVIII Fig. 8, 9.

1842. Pyrula longirostra d’Orbigny, Voy. Amér. Mér. Pal. p. 119. Taf. 12

Fig. 13.

1846. " " D’Orbigny, Voy. Pol Sud. Taf. 4 Fig. 30.

" "Hombroniana D'ORBIGNy, daselbst Taf. 4 Fig. 31.

[" ? F'usus Durvillei D'Orbigny, daselbst Taf. 5 Fig. 1.]

1850. Fusus longirostra D'ORBianr, Prodr. 2. p. 229. No. 375.

Hombroniana D'Orbigny, daselbst p. 299. No. 377.

[" ?" " Durvillei D'ORBIGNY, daselbst p. 229. No. 378.]

1854. Pyrula dilatata Hupé, Gay's Hist. Chile. 8. 179. Taf. 2 Fig. 2 (teste Philippi).

1867. Perissolax Hombroniana Rénosur, Ann. Univ. (Chile. 1867. 29. p. 125 (teste Philippi).

1 Pal. of California. 2. p. 146. Taf. 26 Fig. 24.

2 In Tryon's Manual of Conchology. 3. p. 225. Taf. Sá Figg. 577 findet sich eine Schnecke Mazzalina pyrula Cosn., die ebenfalls dem Fusus difficitis ähnelt. Wo dieselbe von ConRat beschrieben ist, weiss ich nicht. 
1887. Pyrula Hombroniana (D'Orb.) Phibirpi, 'Tert. quart. Verst. Chiles. 1. ว3. Taf. 4 Fig. 3.

nodulifera (D'Orb.) Philippi, daselbst p. 53. Taf. 4 Fig. 4.

[" ?" "Durvillei (D'Orb.) Philippi, daselbst p. 54. Taf. 4 Fig. 11.] 1895. Pyropsis Hombroniana D'Orв. sp. MörICKe, Gastr. Biv. d. Quir.Schicht., dies. Jahrb. Beil.-Bd. X. p. 99.

Gehäuse gross, kugelig, mit langem, gekrïnmtem Canal. Die späteren Windungen überragen die früheren. Sculptur: spirale Rippen und Knotenreihen. Letztere vermehren sich mit zunehmendem Alter auf 4.

Beschreibung: Das Gehäuse erreicht bedentende Grösse. Es ist kugelig, oben abgeplattet und unten in einen langen gekrümmten Canal ausgezogen. Die Zahl der Windungen beträgt 5. Das Gewinde ist sehr niedrig und die späteren Windungen überragen die vorhergehenden, so lass die Naht in einer Rille liegt. Bei jungen Individuen scheinen die Windungen glatt zu sein, vielleicht ist eine Kante vorhanden. Mit dem Älterwerden tritt auf den Windungen eine Sculptur auf, die, abgesehen von immer kräftiger werdenden Spiralstreifen und Zuwachsstreifen, aus Knotenreihen besteht, von denen die erste auf der ursprünglich vorhandenen Kante beginnt. Etwas unterhalb der ersten beginnt dann bald eine zweite Knotenreihe. Dann wächst aus einer der Spiralrippen eine dritte, dann aus einer anderen eine vierte Knotenreihe heran. Jedesmal beginnt die neue Reihe unterhalb der vorhergehenden ${ }^{1}$. Mehr als 4 Knotenreihen bilden sich nicht aus. Die spiralen Rippen werden schliesslich sehr kräftig; wie das PhilıppI's Figur deutlich zeigt. Die Mundöffnung ist halbkreisförmig bis hochoval. Die Innenlippe wird ron einer starken Schwiele bedeckt, die die Sculptur des Gehänses z. Th. unsichtbar macht. Hinter dem äusseren Rand der Innenlippe läuft eine tiefe Rinne herunter (Taf. XVIII Fig. 9). Über Mündung und Aussenlippe vermag ich nach dem nir rorliegenden Material nichts auszusagen. Der Canal ist lang und ziemlich stark gekrümmt. Die Seite der Innenlippe ist dick, die der Aussenlippe dünner.

Fundorte: T'omé (3 Exempl.), Quiriquina (2 Exempl.).

${ }^{1}$ Bei Punump's Pyrula nodulifera (1. c. Taf. 4 Fig. 4) schiebt sich die vierte Knotenreihe zwischen die zweite und dritte ein. Ich halte dies Merkmal für unwichtig. 
Bemerkungen: Die Abbildung von Pyiopsis Hombroniuna von nombasy (Voy. Pol Sud. Taf. 4 Fige. 31) stellt ein grosses Exemplar olne Canal und grösstentheils im Zustand eines Steinkerns dar. Man sieht abor gut, wie das Gewinde von der letzten Windung iiberragt wird. PHндpr bildet ein vorziiglich erhaltenes Exemplar ab, grebt aber die Zuwachsstreifen nicht richtig wieder. Auch ist der Canal umrichtig ergänzt. PHuspres Pyrulı noduliferce ist ein junger Pyropsis Hombroniana.

Nicht ganz mit Recht sagt Möracke, dass diese Art schon wiederholt beschrieben ist. Puntrpe kn kure lateinische Diagrose ist (von den chilenischen Schriften abgesehen) die einzige existirende Beschreibung und keine der Abbildungen ist ganz genügend. Deshalb ist diese Schnecke an dieser Stelle noch einmal beschrieben und abgebildet, das kleinere Exemplar besonders, um die Form des Canals zu zeigen.

Ob Fusus Durvillei D'Orb. Wirklich zu Pyropsis Homlroniana gehört, ist mir zweifelhaft. Keinem der späteren Antoren hat diese Form vorgelegen. Dagegen glaube ich Pyrula longirostra D'Orb. unbedenklich als junge Fyropsis Hombroniana ansprechen zu dürfen. Sehr verschieden ron der Originalabbildung der Pyrula longirostra ist Philippis Fig. 12 auf 'Taf. 4, die denselben Namen trägt.

Ähnliche Formen: Auf die verwandten Formen in der siidindischen Kreide hat schon Möricke ${ }^{1}$ hingewiesen. Es sind dies Rapa cancellata Sow. sp. ${ }^{2}$ und $R$. nodifera Stol. ${ }^{3}$ Viel grössere Ähnlichkeit mit der chilenischen Art haben aber Formen aus den Fox hill beds ron Missouri, Pyropsis Bairdi Meen et H. sp. ${ }^{4}$ und die Varietät rotula Mesk ${ }^{5}$. Die Übereinstimmung mit $P$. Hombroniance ist in der ganzen Gestalt sowie auch in derjenigen der Windungen ziemlich gross, doch erheben sich die späteren Windıngen nicht ïber die rorher-

1 Gastr. Biv. d. Quir.-Schicht. p. 99.

2 Stoliczia, Cret. fama of Scuth. India. Gastr. p. 154. 'Taf. 12 Fig. 12-16; Taf. 13 Fig. $1-4$.

${ }^{3}$ StoliczKa, daselbst p. 153. Taf. 12 Fig. 10. 11.

4 MeEk, Rep. on the invert. cret. and tert. foss. of the upper Miss. ('ounty (Rep. U. S. Geol. Surv. Terr. 9. 1876) 1) 369. 'Taf. 31 Fig. 10 a-c.

5 Daselbst p. 371. Fig. 47. 
gehenden. Schon in der Colorado-Formation kommt eine ähnliche Schnecke, $P$. coloradoensis Stanton ${ }^{1}$ vor. Die Gattung findet sich auch in den lower marl beds (mittlere obere Kreide) ron New Jersey ${ }^{2}$. Auch in Europa fehlen ähnliche Formen nicht ganz. Man vergleiche Tudicla quadricarinata MÜLl. sp. ${ }^{3}$ und T. subcarinata STURM. ${ }^{4}$

v. Iherisg " hat schlecht erhaltene Reste einer Schnecke aus dem patagonischen Tertiär als Pyrula cf. Hombroniana bestimmt. Ortuana ${ }^{6}$ bezeichnet diese Bestimmung als wahrscheinlich umrichtig. Ich glaube, man darf sagen: sie ist sicher unrichtig. Es war r. Ihering wohl gar nicht bekannt, dass P. Hombroniana eine cretacische Art ist, sonst hätte er es doch schwerlich unterlassen, auf die grosse Bedeutung hinzuweisen, die es haben würde, wenn man eine und dieselbe Art in den Quiriquina-Schichten und im patagonischen T'ertiär fände. Das Fossil, das ihm vorlag, war offenbar in kläglichem Zustand, und auf die Unrichtigkeit seiner Bestimmung muss deshalb noch einmal entschieden hingewiesen werden, weil hier sonst vielleicht ein Anlass vorliegen könnte, die alte irrige Behauptung, die Quiriquina-Schichten seien tertiär, wieder aufzunehmen.

\section{Pyrula rugosa PhiLipri.}

1887. Pyrula rugosa Philippi, Tert. quart. Verst. Chiles. p. 5t. Taf. 3 Fig. 20.

Drei schlecht erhaltene Exemplare einer Pyrula-Art gehören wohl zu der von Philippi beschriebenen P. vugosa. Sie unterscheiden sich durch ihre Kleinheit und ihre ruppige Sculptur von der vorhergehenden Art.

Fundolte: San Vicente (2 Exempl.), Tomé (1 Exempl.).

1 Colorado formation and its invert. fauna by STANToN. U. S. Geol. Surv. Bull. No. 106. p. 154. Taf. 32 Fig. 7, 8.

2 Whitfield , Gastr. and Cephal. of the rariton clays and Greensd. marls of New Jersey. Taf. 1. (U. S. Geol. Surr. MIonogr. 18.)

3 Holzapfel, Aachener Kreide. Palaeontographica. 34. Taf, 11 Fig. 14.

4 Jahrb. k. prenss. geol. Landesanst. f. 1900. 21. p. 71. Taf. 5 Fig. 7. Es handelt sich hier freilich um eine ganz lileine Form.

5 r. Inkring, Die Conchylien der patagonischen Formation. Dies. Jahrlb. 1899. II. p. 30 .

${ }^{6}$ Princeton University Expl. Exped. Patag. 4. Part II. T'ert. Inrertebr. p. 263. 
Surcula A».

Surcula araucana bंÖB. Sp).

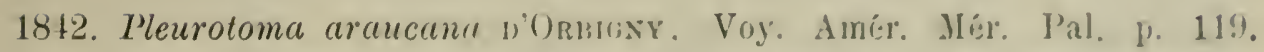

Taf. 14 Figr. 10, 11.

1846.

l'Orbuiny, Voy. Pol Sud. 'Taf. 4 Fig. 35, 36, 36'.

1850 .

I’Orbigny, Prodr. 2. p. 230. No. 395.

1868.

araucurie Stoliczks, Cret. fama of South. India. Gastr.

p. 68.

1887. „ araucana (I'Orn.) Phimipre, Tert. quart. Verst. Chiles. p. 37. Tarf. 1 Fig. 13.

Kleine Surcula nit gekielten und spiral gestreiften Windurgen und einigen Knoten auf dem Kiel der beiden letzten IVindungen.

Beschreibung: Das thurmförmige Gehäuse besteht aus 5(?) Windungen. Diese haben einen Kiel. Oberhalb desselben sind sie concav, unterhalb convex. Sie sind mit spiralen Streifen versehen. Die Zuwachsstreifen sind auf der letzten Windung kräftiger ausgebildet. Sie bilden oberhalb des Kieles eine rundliche, nach rïckwärts gerichtete Bucht. Wo die Zuwachsstreifen iiber den Kiel lanfen, entstehen auf der vorletzten und vorvorletzten Windung einige schief gezogene Knoten. Die Mündung ist länglich, der Canal lang, gerade. Die Aussenlippe ist scharf(?) und zeigt die Bucht, wie sie die Zuwachsstreifen haben. Die Innenlippe trägt eine kräftige Schwiele.

Dimensionen: Höhe?, Breite $7 \mathrm{~mm}$.

Fundort: Quiriquina (1 Exempl., dem der obere Theil des Gewindes und ein grosser Theil des Canals fehlt).

Bemerkungen: D'Orbigny erwähnt die Spiralstreifung nicht, obwohl sie auf seiner Abbildung deutlich hervortritt. Seine Figur ist etwas schematisirt. Das Exemplar ans dem Dusen'schen Material ist etwas grössel als dasjenige d Orbigry's. Die Krümmung des Canals, die man bei n'Orbigny (Toy. Pol Sud. Taf. 4 Fig. 35) sieht, ist an meinem Stïck nicht zu entdecken. (Dasselbe ist genügend erhalten, um sie zu zeigen, wenn sie bei der Art vorhanden wäre.) Die PhiLIpri'sche Abbildung: ist eine mässige Copie nach D’Orbignx (Toy. Amér. Mér.). Es ist nicht einmal dabei angegeben, dass es sich um eine Vergrösserung handelt. 
Ähnliche Formen liegen aus den anderen Gebieten pacifischer Kreideablagerungen nicht vor. Surcula suciensis Whiteaves ${ }^{1}$ ist schlanker und weniger scharf gekielt. Mehr Ähnlichkeit zeigt Turris minor E. u. S. sp. ${ }^{2}$, doch ist die letzte Windung bei dieser Art schlanker und mehr gerundet. Surcula claytonnensis GABB $^{3}$ aus dem californischen Eocän zeigt nur wenige Punkte der Übereinstimmung, insbesondere sind die Windungen nicht so stark convex wie diejenigen der chilenischen Kreideform ${ }^{4}$.

\section{Eriptycha MeEk.}

\section{Eriptycha chilensis D'ORB.}

Taf. XVIII Fig. $10 \mathrm{a}, \mathrm{b}$.

1846. Avellana chitensis D'Orbigny, Voy. Pol Sud. Taf. 4 Fig. 32, 33, 345. 1850 .

1887. Cinulia $\quad$ (D'ORB.) PhiLipPI, T
Taf. 11 Fig. 11.

i'Orbigni, Prodr. 2. p. 220. No. 177.

1895.

(D'ORB.) MörICke, Gastr. Biv. d. Quir.-Schicht., dies Jahrb. Beil.-Bd. X. p. 99. Taf. VII Fig. 3, 4.

Gebäuse kugelig, Gewinde kaum hervorragend. Ebene der Mündung schief zur Axe des Gehänses. Innenlippe mit zweispitzigem, bogenförmigem Zahn.

Beschreibung: Das Gehäuse ist kngelig und besteht aus 4 Windungen. Das Gewinde ragt wenig herror. Nur zuletzt senkt sich die Naht etwas, so dass es hervortritt. Die Sculptur besteht in spiralen Linien, die nach unten und oben enger stehen. Auf der letzten Windung sind es 24. Diese Linien sind punktirt, was nur an sehr gut erhaltenen Stiicken zu sehen ist. Die Mündung ist bei jungen Individuen ziemlich weit, oval, bei älteren enger, spitz-oval. Sie steht schief gegen die Axe des Gehäuses. In ihrer Umrandung zeigt sich

${ }^{1}$ Geol. Surv. Canada. Mesoz. Foss. 1. p. 115̆. Taf. 15 Fig. 1.

2 Мекк, Rep. on invert. cret. etc. upper Miss. Co. (Rep. U. S. Geol. Surv. Terr. 9) p. 384. Taf. 31 Fig. 9 a, 9 b, 9 c. MEEK bemerkt selbst selır richtig, dass dies wohl eine Surcula, keine Pleurotoma (= Turris) ist.

3 Pal. Calif. 1. p. 92. Taf. 18 Fig. 46.

${ }^{4}$ Für die anderen von PhiLıP a as den Quiriquina-Schichten angrefiihrten Pleurotomen liegt mir leider kein IIaterial vor.

5 Abbildung 34 fehlt auf dieser Tafel D'Orbigry"s. 
unten eine leichte Bucht. Die Schale ist an dieser Stelle diunner. Die Aussenlippe ist innen glatt. Aussen ist sie durch einen kräftigen Wulst verdickt, auf dem Zuwachsstreifen sichtbar sind. Die Innenlippe ist schwiclig und trägt eine Falte oder einen Zahm, der bogenfürmig und meist zweispitzig ist und mit seiner convexen Seite der Schwiele anliegt. Dieser Callus wird mit zunehmendem Alter immer kräftiger und seine Gestalt umregelmässiger. Exemplare, die die Grösse ron 'Taf. XVIII Fig. 10 erreicht haben, haben einen viel stärkeren Callus und eine viel engere Miindung, als sie diese (vergrösserte!) Figur zeigt.

Dimensionen in mm: Hölie und Breite 12.

Fundorte: Quiriquina (21 Exempl.), 'Tomé (5 Exempl.), San Vicente (12 Exempl.).

Bemerkungen:

Die Abgrenzung ron Cinutia und Avellana ist etwas unsicher. Nach Zitrel (Grundziige 1895) ist Cinulia das Genus und Avellana das Subgenus. Nach Fischer (1887, Jan. de Conch.) ist Avellana das Genus, Cinutia ein Subgenus. Avellana soll mehrere (2-3) Spindelfalten haben, Cimulia eine. Erstere hat eine immen gezähnelte Aussenlippe, letztere nicht. HoLzAPFEL ${ }^{1}$ beschreibt (1887) als Cinulia Humboldtii eine Art ans der Aachener Kreide, bei der die Zahl der Spindelfalten sehr wechselt. Es scheint auf dies Merkmal kein grosses Gewicht gelegt zu werden diirfen. Ebenso wenig aber unterscheidet das Merkmal der vorhandenen oder fehlenden Zähnelung auf der Innenseite der Aussenlippe in genügender Weise, demn die Avellana Humboldtii begreift wenigstens Formen mit und ohne innere Zähnelung der Aussenlippe. Nach Cosswasx ${ }^{2}$, der noch andere Unterscheidungsmerkmale angiebt, ist die Art von Quiriquina eine Eriptycha, und seine Abbildungen der Eriptycha Humboldti Taf. 3 Fig. 10, 11 ähneln der $\mathbb{E}$. chilensis nicht unbedentend.

Die D'Orbigny'sche Figur zeigt keine Zähne oder Falten an der Spindel, ist auch zu kugelig und giebt die Bucht an der Basis der Mündung nicht wieder. Ebensowenig befriedigt die Abbildung bei Mörrcke, die zwar den Gesammthabitus des Gehäuses gut darstellt, aber das Detail der Mündung schuldig bleibt. Das in Strassburg befindliche Exemplar Möricke's ist ein junges Exemplar, dessen Spindelzähne nicht heranspräparirt, sondern noch durch Gesteinsmasse bedeckt sind. Philippr's

1 Aachener Kreirle. Taf. 6 Fig. 19-22.

${ }^{2}$ Essai de Paléoconchologie comparée. p. 118 ff. 
Figur soll zweifellos dieselbe Art darstellen, ist aber wenig genall.

Ähnliche Arten: Möricke hebt mit Recht die Ähnlichkeit des Eriptycha chilensis mit Cimula pusilla Whiteaves ${ }^{1}$ hervor. Von dieser Art, die iibrigens nicht aus den obersten Kreideschichten, sondern aus den "lower shales and sandstoues" (Gruppe C, Dawsor) stammt, war aber die Beschaffenheit der Spindel Whiteaves unbekannt. Auf der Figur zeigt der äussere Wulst der Aussenlippe dieselbe Spiralstreifung wie das Gehäuse. Das ist wohl ein Zeichenfehler ${ }^{2}$.

Aus der indischen Kreide beschreibt STouiczka 3 Eriptychen, ron denen die freilich bedeutend grössere Eriptycha. larvata ${ }^{3}$ der chilenischen Art ähnlich ist. Cimula Humboldti MÜLLER ${ }^{4}$ aus der Aachener Kreide ist sehr variabel. Die Bucht an der Basis der Mündung scheint ihr zu fehlen. Diese zeigt dagegen $C$. obliqua GABB ${ }^{5}$ aus der Chicoformation, die ïberhaupt der Eriptycha chilensis sehr nahesteht, so nahe. dass wirkliche Unterschiede kaum herauszufinden sind.

\section{Cylichna Lovéx.}

\section{Cylichna chilensis D'OrB. sp.}

1846. Buila chilensis D'Orbigny, Voy. Pol Sud. 'Iaf. \& Fig. 13, 14, 15.

1850. " " ग'Orbigsi, Prodr. 2. p. 223. No. 453.

1887. " " (D'Orb.) Philippi, Tert. quart. Verst. Chiles. p. 109. Taf. 13 Fig. 23.

Kleines Gehäuse mit gänzlich umhülltem Gewinde. Sculptur: spirale Streifen, die oben und unten dichter stehen als in der Mitte.

Beschreibung: Das Gelüuse hat cylindrische Gestalt. Das Gewinde ist gänzlich umhüllt. Auf dem letzten Umgang. zeigen sich spirale Streifen, von denen meist immer ein etwas feinerer zwischen zwei stärkeren liegt. Nach oben und unten

1 Geol. Surv. Canada. Ilesoz. Foss. 1. 1. 217. T'af. 28 Fig. 5.

${ }^{2}$ Die Tafeln 25-32 des Wirtentes'schen Werkes sind, nebenbei bemerkt, sehr schlecht lithographirt.

${ }^{3}$ Stoliczka, Cret. fanna of South. India. Gastr. p. 426. Taf. 26 Fig. 6.

${ }^{4}$ s. auch die Abb. bei Sturur, Jahrb. d. k. preuss. geol. Landesanst. f. 1900. Taf. 5 Fig. 8. 8 a.

5 Pal. ('alif. 1. p. 111. Taf. 19 Fig. 64, 64a, 64 b. 
zu stehen die Streifen dichter. Zur genauen Untersuchung der feineren Gestaltung dieser Sculptur ist die Schale nicht gut genug erhalten. Gegen die Aussenlippe zu bemerkt man auch einige feine Zuwachsstreifen. Die Mïndung ist spaltförmig, unten etwas weiter als oben. Die Aussenlippe ist scharf, die Innenlippe etwa von der Mitte abwärts verdickt.

Dimensionen in mm: Höhe 9,5, Breite 6,5.

Fundorte: Quiriquina (1 Exempl.), San Vicente (1 Exempl.).

B emerkungen: Unser Exemplar ist etwas breiter und die Aussenlippe gerundeter als die Bulla chilensis auf D'OrBrgny's T'af. 4. Doch sind diese Abbildungen ja nicht immer ganz genau, und die beiden Stïcke sind die einzigen ans dem Duswasschen Material, die eine spiral gestreifte Bullicle repräsentiren. SToLrczis ${ }^{1}$ rechnet die chilenische Art mit Recht zu Cylichna. Übrigens ist die Unterscheidung der Gattungen der Bulliden, ja auch der Familien, so der Bulliden und Scaphandriden sehr schwer, besonders bei fossilem Material.

Ähnliche Formen: Ob mar Bulla chilensis mit der von Whiteaves ${ }^{2}$ beschriebenen Haminea Hornii GabB aus dem pacifischen Senon Canadas vergleichen darf, scheint mir nicht ganz sicher. Leider ist diese Art nur ron einer Seite abgebildet und ihre Bestimmung als Haminea scheint mir ebenso zweifelhaft wie ihre Identificirung mit der Bulla Hornii GABB ${ }^{3}$, soweit man darüber urtheilen kann, ohne die Stïcke zur Hand zu haben. Ähnlicher ist Cylichna costata GABB ${ }^{4}$, die freilich viel grösser ist als C. chilensis. Es muss jedoch hervorgehoben werden, dass hier sehr conservative Formen vorliegen, die nach $\mathrm{S}_{\text {TAnton }}{ }^{5}$ von der Kreide ins 'Tertiür übelgehen und daher selu wenig charakteristisch sind. Es erklärt sich auch aus diesem Umstand, dass Whiteares eine Schnecke aus der Nanaimo-Group mit einer Art aus der Tejon-Group identificirt hat.

1 Cret. fauna of South. India. Gastr. p. 430.

2 Geol. Surv. Canada. Mesoz. Foss. 1. p. 132. Taf. 16 Fig. 8, 8 a, 8 b.

3 Pal. Calif. 1. p. 143. Taf. 29 Fig. 235.

4 Daselbst p. 143. 'Taf. 21 Fig. 107.

${ }^{5}$ Stanton, The fumbl relations of the Eocene and Cretaceons on the pacific coast. 17. Amm. Rep. U. S. Geol. Surv. 1896. p. 1032. 
Bulla ḰLein.

bulla subglobosa Phil.

Taf. XVIII Fig. 11.

1857. Bulla subglobosa Pinlipre. 'I'ert. ıuart. Verst. Chiles. 1. 108. Taf. 13

Fig. 2a. b.

Philine chitensis Philippi, daselbst p. 110. 'Taf. 13 Fig. 4.

Kleine Bulla. Kräiftige Zuwachsstreifen, Innenlippe stark schwielig, abgeplattet.

Beschreibung: Das Gehämse ist aufgeblasen, kugelig. eingerollt und besteht aus etwa $t$ Windungen. Das Gewinde ist etwas eingesenkt. Es treten kläftige Zuwachsstreifen auf der letzten Windung auf, die etwas hervorragt und seitlich und unten ger'undet ist. Die Aussenlippe ist scharf, die Imnenlippe stark schwielig und abgeplattet. Bei grossen Exemplaren zeigt sich neben der Schwiele eine kleine Ritze. Die Mïndung ist oben winkelig. unten gerundet.

Dimensionen in mm:

$\begin{array}{cc}\text { Höhe } & \text { Breite } \\ 21 & 18 \\ 16 & 12 \\ 13 & 10\end{array}$

Fundort: Quiriquina (15 Exempl.).

Bemerkungen: Dass Philine chilensis nichts Anderes ist als Bulla subglobosa. geht aus den Abbildungen dentlich hervor. Philupre giebt an. die Philine chilensis habe 4 Windungen. Phitine hat aber wohl kaum jemals so viele TVindungell.

Ob Bulla hualpensis Phit. und B. nesaca PHIL. selbstständige Arten oder junge Individuen von $B$. subglobosa sind. wage ich nicht zu entscheiden.

Scaphopoda Brows.

Dentalium L.

Inentalium chilense dorr.

Taf. XTIII Fig. 12.

1846. Dentalium chilense d Oringsi. Voy. Pol Sud. Taf. 4 Fig. $37,38$. 186s. Antale a (D) ORr.) Storiczks, Cret. fimma of South. India. Giastr. 1. 444.

1EST. Dentatium - ( $0^{\circ}$ Onis.) Phunpur. Tert. quart. Verst. Chiles. 1. 10). Tat. 12 Fig. 20. 
Die Schale ist schwach grekrümmt, riemlich dün und nimmt langsam an Dicke zu. Der Querschnitt ist fast kreisrund. Unten besitzt die Schale eine feine Längsstreifung. die weiter oben aufhiort.

Diese Längsstreifung ist nu bei guter Erhaltung der Schale sichtbar. D'Orbiciry's Abbildung zeigt sie nicht. Entweder hat ihm also ein mässig erhaltenes Exemplar vorgelegen, oder die Zeichnung ist nicht genau. Ein glattes Dentrilum von dieser Form kommt in den Quiriquina-Schichten nicht vor. Storiczka theilte nach der d Origry'schen Figur das Dentatium chilense seiner Gattung Antale zu. Nach der Abbildung durfte er das thun, es liegt aber ein echtes Dentalium vor.

Man findet meistens nur die unteren, dünnen Enden dieses Dentalium mit der mehr oder weniger gut erhaltenen Längsstreifung und auderseits Stïcke mit grösserem Durchmesser, mit fehlendem dïnneren Ende, glatter Oberfläche und '/uwachsstreifen, die schräg zur Axe der Schale stehen. Es liegen aber einige Stiicke vor, die zeigen, dass das Dentalium chilense gegen das dickere Ende zu seine Längsstreifung verliert ${ }^{1}$, und ich betrachte daher die eben beschriebenen Stiicke als die dickeren Enden des $D$. chilense. Ob noch eine weitere Dentalium-Art in den Quiriquina-Schichten vorkommt, möchte ich bezweifeln. Allerdings liegt noch ein Stiick eines Dentalium vor, das ziemlich gross ist und doch Längsstreifung zeigt (Taf. XVIII Fig. 13).

Philipp standen nur 3 Stiicke ron Dentalium aus der Gegend von Concepcion zur Verfügung, das Dusex'sche Material ist daran sehr reich. Phicippr führt noch 2 Arten auf, Dentalium dilatatum und D. subcylindricum. TVie weit denselben Berechtigung zukommt, rermag ich nicht zu entscheiden. $D$. dilatatum möchte ich für dasselbe wie $D$. chilense halten.

Fundorte: Tomé (häufig), Quiriquina (weniger häufig).

Ähnliche Formen: Auch im californischen, canardischen und sïdindischen Senon kommen Dentalien vor, von

1 Dentalien, die ihre Längsstreifung gegen das dicke Ende hin rerlieren, sind u. a. Dentalium decussatum Sow. aus dem Gault (Pal. franç. Terr. crét. Taf. 236 Fig. 1), sowie die recenten Arten D. vulgare DA Costa (Tryon, Man. of Conch. 17. Taf. 9 Fig. 533) und 1). semistrictum Turtor (Tryon, daselbst 'Taf. 16 Fig. 5̇3). 
denen aber keine Art der chilenischen besonders nahe steht. Der stratigraphische Werth dieses conservativen Molluskentypus ist ja sehr gering.

Lamellibranchiata.

Pecten KLein.

Pecten granulatus D'ORB.

1846. Pecten gramulatus d’Orbigny, Voy. Pol Sud. Taf. 5 Fig. 29, 30, $30^{\prime}$. 1850 . d'Orbigni, Prodr. 2. p. 25̃3. No. 874.

1887. " " " $\quad$ (D'ORr.) Philippi, Tert. quart. Verst. Chiles. p. 209. Taf. 46 Fig. 3.

delicatulus Philippi, daselbst p. 209. Taf. 46 Fig. 5.

" " Larenasi Philippi, daselbst p. 209. Taf. 58 Fig. 16.

"? araucanus Philippi, daselbst p. 209. Taf. 46 Fig. 7.

Beschreibung: Schale klein, dünn, fast kreisrund. Die linke Klappe ist gewölbt und trägt radiale Rippen, die etwas gekörnelt sind. Die Rippen zeigen sich auch an der Innenseite der Schale. Es tritt dort aber auch eine concentrische Streifung auf, die sich auf dem Steinkern bemerkbar macht. Die Ohren sind schlecht erhalten, das vordere scheint grösser als das hintere zu sein.

Dimensionen in mm: Höhe uud Breite 19.

Fundorte: Tome (6 Exempl.), Quiriquina (4 Exempl.), San Vicente (1 Exempl.).

Bemerkungen: D'Orbigny's Figur halte ich in Bezug auf die Ohren für unrichtig restaurirt, doch sind die vorliegenden Stïcke zu schlecht erhalten, als dass man darüber ein sicheres Urtheil abgeben könnte. Aus demselben Grunde ist es unmöglich, die Art einer der Untergattungen ron Pecten zuzuweisen. Bei D'Orbigny erscheint die Kömelung der Rippen zu stark; ganz besonders ist dies aber bei PhiLıpp der Fall. wo sie sehr iibertrieben ist. In Wirklichkeit sieht der Pecten granulutus aus wie die Figuren einer der folgenden Puilippr'schen Arten.

Pecten delicatulus PHI. ist ein junger P. gramulatus. Nach Phimpri soll die Schale schief sein; aber es ist nur eine schief zerbrochene Schale und Pnumpr hat sie verkehrt ergïnzt. 
Pecten pencanzis PHis. soll sich von $P$. delicutulus dadurch unterscheiden, dass er , erhabene, strahlenförmige Linien" aufweist. Hiervon ist auf der Figur nichts "zu sehen. Die Schale hat einfach Rippen. Übrigens heisst es in der Diagnose beider Arten: "lineis elevatis radiantibus." Auch zwischen den Abbildungen ist kein Unterschied wahrzunehmen, so dass also anch $P$. pencume $=$ gromulatus ist.

Der untere Pecten der Fig. 16 auf 'Taf. 58 bei Phimirpi, ist Pecten Larenasi PInL. genannt. Es ist ebenfalls $P$. granulatus. Der obere gehört vielleicht zu IP. chilensis. Dass beide Klappen zu einem Individum gehören, ist nicht bewiesen.

Pecten araucanus PHIL. lialte ich für einen seitlich abgeriebenen $P$. gramulatus. Vielleicht scheint es gewagt, aus der Abbildung diesen Schluss zu ziehen; aber es ist bei Philrppl's Bestreben, neue Arten anfzustellen, nicht unwahrscheinlich.

Ähnliche Formen: Ein ähnlicher, fast kreisrunder Pecten ist $P$. verdachellensis Forbes ${ }^{l}$ aus der Utatur-Group. Aus dem pacifischen Senon liegen ähnliche Formen nicht ror.

$$
\text { Pecten ehilensis D'OrB. }
$$

1846. Pecten chilensis D'Orbigny, Voy. Pol Sud. Taf. j Fig. 31, 32, 32'. 1850 D'Orbigny, Prodr. 2. p. 25̌3. No. 875.

1887. $\quad$ (D'Orw.) Philippi, Tert. quart. Verst. Chiles. p. 208. Taf. 46 Fig. 6 a. b.

1895. " (Amusium?) chilensis (D'ORB.) Mörrcke, Gastr. Bir. d. Quir.Schicht., dies. Jahrb. Beil.-Bd. X. p. 100.

Eine Beschreibung der Art findet sich bei Möricke, dem 2 Exemplare von Quiriquina vorlagen. Ich habe in dem Dusen'schen Material einen Pecten von 'T'omé, der vielleicht hierher gerechnet werden darf. Es ist eine rechte Klappe mit grossem vorderen Ohr. Da die Schale aber allem Anschein nach nicht ganz glatt war, so bin ich nicht völlig. sicher, ob nicht vielleicht eine rechte Klappe von $P$. granulatus vorliegt.

1 Stoliczka, Cret. fauna of South. India. Pelecyp. p. 432. Tat. 31 Fig. 13, 14; Taf. 42 Fig. 7, 8.

N. Jahrbuch f. Mineralogie etc. Beilageband XVIII 


\section{Naiadina Munier-Chalmas.}

Naiadina? ambigua PHIL. sp.

Taf. XIX Fig. 1, 2.

1887. Monopleura ambigua Philippi, Tert. quart. Verst. Chiles. p. 198. Taf. 37 Fig. 12.

L" ? Lyonsia ?vicentina PHILIPPI, daselbst p. 162. Taf. 56 Fig. 4.]

Beschreibung: Die Schale ist ungleichseitig dreieckig: nicht sehr stark gewölbt. Der kurze Hinterrand ist gerundet, der Vorderrand ist etwas concav, der Unterrand convex. Eine kräftige, etwas unregelmässige concentrische Streifung läuft über die Schale. Die Streifen vereinigen sich z. Th. gegen den Hinterrand hin. Die Wirbel ragen wenig hervor. Über das Ligament lässt sich nichts sagen. Schlosszähne sind nicht vorhanden. Anscheinend ist unter dem Wirbel der Schlossrand glatt. In seinem vorderen Theil aber ist er eingekerbt.

Es liegen zwei rechte und eine linke Klappe vor. Die linke Klappe ist etwa so lang wie hoch. Die rechten Klappen sind länglicher. $\mathrm{Ob}$ hier eine Ungleichklappigkeit vorliegt, kann nach dem vorliegenden mangelhaften Material nicht ganz entschieden werden. Ich glaube, dass es sich nur um eine gedrungene Varietät derselben Art handelt.

Der ziemlich grosse Muskeleindruck ist nur an der linken Klappe sichtbar. Er liegt ziemlich weit nach vorn.

Dimensionen in $\mathrm{mm}$ :

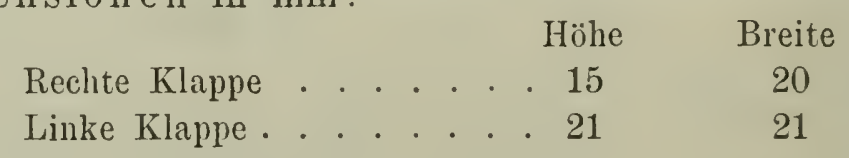

Fundort: Quiriquina (3 Exempl.).

Bemerkungen: Phimipri hat diese merkwïrdige Muschel als Monopleura ${ }^{1}$ ambigua beschrieben. Seine Fig. 12 auf 'Taf. 37 stellt ein grosses Individnum dar. Er war der Meinung, dass das Schloss taxodont wäre. Was PhiLıpp für Schlosszähne gehalten hat, sind aber Einkerbungen der Schale, wie sie bei jungen Austern oft rorkommen, z. B. bei Gryphaea vesicularis ${ }^{2}$.

PhiLippr's Lyonsia? vicentina ist vielleicht dasselbe (?).

1 Der Name Monopleura ist bereits fuir einen Rudisten rergeben.

${ }^{2}$ s. z. B. die Abbildungen des Gryphaea vesicularis in Stoliczki's Pelecypoda (Cret. fauna of South. India) Taf. 45 Fig. 9. 
Ich habe diese Muschel zuenst \%u Chalmasia stellen wollen; sie stimmt aber noch am meisten mit der Nairulina Héberti Mux.-Chalm. aus dem Senon überein, und ich stelle sie deshalb zu der Gattung Naiudina. Besseres Material, besonders solches, das das Ligament dentlich zeigt, ist noch abzuwarten, elıe die Bestimmung als gan\% sicher betrachtet werden darf.

\section{Ostrea sp.}

'Taf. XIX Fig. 3.

Unter dem Sternmann'schen Material des geologischen Instituts der Universität Strassburg i. E. findet sich ein kleiner ovaler Deckel einer Auster. Er ist leicht eingesenkt und zeigt einen länglichen Muskeleindruck. Wenn dieser spärliche Rest auch nicht weiter bestimmbar ist, so darf doch sein Vorhandensein nicht unerwähnt bleiben, da er den einzigen Austermrest aus den Quiriquina-Schichten darstellt.

Modiola Lay.

Modiola araucana D'OrB. sp.

Taf. XIX Fig. 4.

1846. Mytilus araucanus d'Orbignx, Voy. Pol Sud. Taf. う̌ Fig. 27, 28, 28'. 1850 .

d'Orbigny, Prodr. 2. p. 247. No. 745.

1860. Modiola cretacea GABB, Proc. Nat. Sc. Phil. 1860. p. 198. Taf. 3 Fig. 3. 1887. " \# (GABB) PhilipPi, Tert. quart. Verst. Chiles, p. 203. Taf. 44 Fig. 11.

Mytilus araucanus (D'Orb.) Phicippi, daselbst p. 202. Taf. 44 Fig. 2.

Beschreibung: Die Schale ist mässig dick, schmal; in der Nähe der Wirbel laufen die Ränder fast parallel. Der Hinterrand ist convex, der Vorderrand concav. Die Klappen sind hoch gewölbt. Eine Falte läuft vom Wirbel aus schräg* nach dem Hinterrand. Die Wirbel sind umgebogen und ganz nach vorn geriickt, doch ragt die Schale unterhalb ebenso weit hervor. Hinten ist die Sclale gerundet. Es treten kräftige Zuwachsstreifen auf.

Dimensionen in mm: Länge 44, Breite 18.

Fundolt: Tomé (2 unvollständige rechte und 1 linke Klappe [Steinkern mit Schalemresten]).

Bemerkungen: Die Abbildung, welche Purtep von Modiola cretacea GABB ("Von Talcahuano") giebt, stimmt g*ut 
mit den Stücken überein, die uns vorliegen. Es ist ein junges Individuum dieser Art. Als solches betrachte ich auch den IIytilus arancanus D'ORB. Die Schale wächst ja erst später unterhalb des Wirbels so stark nach vorn. Die junge Modiola hat noch einen spitzen Wirbel. Philippi bildet den Mytilus araucanus ab und führt ihn unter seinen tertiären Arten an, indem er als Fundort Arauco angiebt, während D'Orbigny selbst im Prodrome Quiriquina als solchen angiebt.

Als verwandte Form darf vielleicht die sehr ähnliche Villsella Galpiniana MeEk ${ }^{1}$ aus den Fox hill beds angesprochen werden ${ }^{2}$.

\section{Nucula Gray.}

Nucula Cecileana D'OrB. sp.

Taf. XIX Fig. 5.

1842. Mactra Cecileana D’Orbigny, Voy. Amér. Mér. Pal. p. 126. Taf. 1 う Fig. $5,6$.

1846. Nucula Albertina D'Orbigny, Voy. Pol Sud. Taf. 5 Fig. 25, 26, 26 '. 1850. Mactra Cecileana D'Orbigny, Prodr. 2. p. 235̃. No. 495.

Nucula Albertina D'Orbigny, daselbst p. 243. No. 657.

1887. Mactra Cecileana (D’Orb.) Philippi, Tert. quart. Verst. Chiles. p. 148.

Taf. 32 Fig. 8.

Nucula Albertina (D'Orb.) PhlLippi, daselbst p. 194. Taf. 31 Fig. 8. " " apicina Philiprl, daselbst p. 193. Taf. 41 Fig. 19.

Schale gewölbt, fast dreieckig. Wirbel stark nach vorn gerïckt, ziemlich spitz. Muskeleindrücke sehr tief.

Beschreibung: Die Schale ist von annähernd dreiseitigem Umriss und ziemlich stark gewölbt. Die Wirbel sind stark nach vorn gerückt, umgebogen und ziemlich spitz. Der Vorderrand ist concav, del Hinterrand schwach convex, der Unterrand convex. Die Lunula ist scharf abgegrenzt. Die Sculptur besteht in concentrischen Zuwachsstreifen, die aber kaum hervortreten.

Das Schloss liess sich leider aus dem harten Gestein nicht herauspräpariren, doch war es leicht, festzustellen, dass ein echtes Nucula-Schloss vorliegt. An manchen Steinkernen.

${ }^{1}$ MeEk, Inv. Cretac. and tertiary Fossils of Upp. Jiss. Countr. ('Terr. 9.) p. 73. Taf. 28 Fig. 7 a.

${ }^{2}$ Es giebt auch noch Modiola cretacer Conrad (s. Stoliczra, Pelecypoda 1). 374. No. 101), die aber nach Stoliczka 1864 publicirt ist. Die (iABB'sche Art hat also die P'rioritiit. 
denen noch die innere Schalenpartie anhängt, kann man es grut wahrnehmen. Die Muskeleindricke und die buchtlose Mantellinie treten auf dem Steinkern sehr kräftig hervor.

Dimensionen in mm: Breite 2,4, Höhe 18,5), Dicke 1,2.

Fundorte: Quiriquina (ca. 25 Exempl.), 'T'omé (ca. 100 Exempl.), San Vicente (6 Exempl.).

Bemerkungen: Diese zuerst von l'Orbugry als Mractru Cecileana beschriebene Nuculu ist eines der hänfigsten Fossilien der Quiriquina-Schichten, bei T'oné geradezu das häufigste. Sichon D'Orbicisy selbst war die Nuculu-ähnliche Form seiner' Mactra ('coileann anfgefallen und PHisirer spricht die richtige Vermuthung aus, dass es sich um eine Nucula handelt. Er giebt D'Ormaxy's Figur wieder und bemängelt die Incongruenz der Grössenangabe in der Beschreibung und der Grösse der Figur. Ihm selbst scheint diese Nucula nicht vorgelegen zu haben, wenn nicht etwa seine Nucula Ovalle ${ }^{1}$ mit ihr identisch ist. Den Steinkern bildet er als $N$. apricina ab.

Mactra Cecileana D'OrB. Ind Nucula Albertina D'Ors. haben, wemn man die Abbildungen vergleicht, so wenig Ähnlichkeit, dass man beide kaum für dieselbe Muschel halten möchte. Und doch sind sie es. Freilich darf man nicht die Philipri'schen Copien miteinander vergleichen. Bei Philı'pr ${ }^{2}$ ist die Zuwachsstreifung der "N. Albertina", die mehr in Farbenunterschieden in der Schale, als in einer Sculptur auf derselben besteht, zu einer concentrischen Berippung geworden. so dass man eine Vcmus vor sich zu haben glaubt.

Die Abbildung der "Mactra Cecileana" in den Voy. Amér. Mér. ist nicht gut. Der Vorderrand ist nicht conciv, der Hinterrand nicht convex genug gezeichnet, was aber auch z. 'Th. daher rïhrt, dass ein junges Individum von Nucula C'ecileana D'OrB. sp. dargestellt ist. Bei der" "N. Albertina" ist der Vorderrand zu concav und die concentrische Streifung etwas zu grob ausgefallen. Sehr ähnlich sind dagegen die Ansichten gegen die Wirbel von den beiden n'Orbigry'schen Arten (Voy. Amér. Mér. Pal. 'Táf. 15 Fig. 16 und Voy. Pol Sud. 'Taf. 5 Fig. 26). Wenn man geniigendes Material vor'

1 Phicıpr, Tert. quart. Verst. Chiles. p. 193. Taf. 11 Figg. 12.

" Daselbst. Taf. 31 Fig. 8. 
sich hat, kann an der Identität der beiden Arten kein Zweifel bestehen.

Ähnliche Formen: Dieser Nucula stehen die N. Tamulica Stol. ${ }^{1}$ und $N$. indefinita Forbes ${ }^{2}$ aus der AriyalurGroup nahe. Ferner die californische N. solitaria $\mathrm{G}_{\mathrm{ABB}}{ }^{3}$. Von tertiären Formen ähnelt $N$. mixta Desh. ${ }^{4}$

Malletia Desu.

Malletia pencana PHIr. sp.

Taf. XIX Fig. 6.

1887. Nucula pencana PhiL., Tert. quart. Verst. Chiles. p. 192. Taf. 41 Fig. 5.

Scliale mitteldick, flach, querverlängert. Die Wirbel stehen etwa auf $\frac{1}{3}$ der Schalenlänge vom vorderen Ende entfernt und sind stark umgekrümmt, spitz. Vorn ist die Schale gerundet, hinten schräg abgeschnitten, zugespitzt. Eine Falte läuft vom Wirbel gegen die hintere Partie des Unterrandes herab. Die Sculptur besteht ir einer kräftigen, concentrischen Berippung.

Das Ligament ist äusserlich und liegt auf einer langen Nymphe. Das Schloss ist taxodont; die Zähne werden nach innen immer kleiner; die Reihe der Zähne ist unter dem Virbel schwach geknickt.

Die Mantellinie und die Muskeleindrücke zeigt das einzige mir vorliegende Exemplar nicht.

Dimensionen in mm: Höhe 14, Breite 29, Dicke von 2 Klappen 11.

Fund ort: Quiriquina (1 linke Klappe).

Ähnliche Formen sind Malletia ornata Sow. ${ }^{5}$ aus dem patagonischen Tertiär und "Nucula" Volckmami PHIL. ${ }^{6}$ aus der Navidad-Stufe. Ich stehe nicht an, die Malletia pencana der Quiriquina-Schichten für die directe Vorläuferin dieser Arten zu halten.

I Stoliczka, Cret. fauna of South. India. Pelecypoda. p. 328. Taf. 17 Fig. $15,16$.

2 Stoliczka, daselbst. Taf. 17 Fig. 17-19.

${ }^{3}$ Pal. Calif. 2. p. 197. Taf. 32 Fig. 94.

4 Animaux sans vertèbres. 1. 1). 819. Atlas Taf. $6 \pm$ Fig. 1.

${ }^{5}$ Ortmann, Tertiary Invertebrates. Prino. Univ. Experl. Patagonia. 4. Part II. p. 85. Taf. 26 Fig. 4.

${ }^{6}$ 'Tert. quart. Verst. Chiles. p. 194. Taf. 41 Fig. 9. 


\title{
Trigonia Brus.
}

\author{
Trigonia llanetiana i) OrB.
}

1842. Trigonia Haneliana s'Orbigny, Voy. Anér. Jér. Pal. 1) 127. 'Taf. 12 Fig. $11-16$.

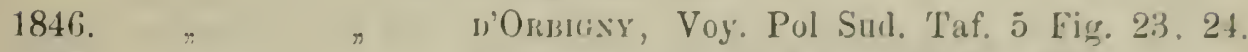

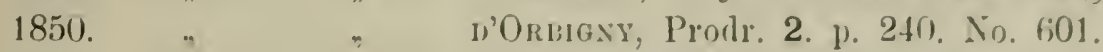

1854., (1)'Orns.) Hupe, Gay's Hist. Chile. 8. 1) 327.

\# n oblusa Hupé, daselbst 1. 32. Taf. 5 Fig. 9.

1887. .. Hanetiana (D'Ori.) P'hilip', T'ert, quart. Verst. Chiles. 1. 199. Taf. 42 Fig. 1, 3.

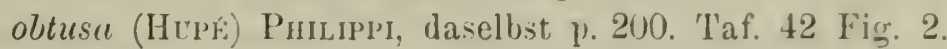
?glabra Philıpe, llaselbst p. 200. Taf. 42 Fig. 4.

1895. Manctiana (D'Orв.) Möricke, Gastr. Biv. d. Qir.-Schicht., dies. Jahrb. Beil.-Bil. X. p. 101. Taf. VII Fig. 8, 9.

Dies Leitfossil der Quiriquina-Schichten ist ron Möricke eingehend beschrieben und gut abgebildet. Die Dusexschen Anfsammlungen sind nicht sehr reich an dieser Muschel. PhiLippi's Abbildungen stellen grosse, etwas abgeriebene Exemplare dar.

Fundorte: Quiriquina (5 Exempl.), Tomé (6 Exempl.), San Vicente (6 Exempl.).

Bemerkungen: Die Trigonia? glabra, die Phitrppi als eine Muschel von "sehr sonderbarer Form" beschreibt, ist eine $T r$. Hanctiana, der die obersten Schalenschichten mit rer ganzen Sculptur fehlen. Es ist nur eine dünne Schicht Schale auf dem Steinkern erhalten. Mir liegt eine solche „Tr. glabra" von San Vicente vol.

Die Ähnlichkeit der chilenischen Art mit der neuseeländischen Tr. sulcata Hector ist schon von Möriche herrolgehoben.

\section{Cardium L.}

Cardium (Ringicardium) acuticostatum ${ }^{1} \mathrm{D}^{*}$ ORB.

Taf. XIX Fig. 7, 8, 9, 10.

1842. Cardium acuticostatum D'Orbigny. Voy. Amér. Jér. Pal. p. 120. Taf. 12 Fig. 19, 20, 21, 22.

1846. „ " 10 Orbigny, Voy. Pol sud. Taf. 5 Fig. 17, $18,19,20$.

australe D'Orbigni, daselbst. Taf. 5 Fig. 21, 22, 22'.

1 Spätere Autoren schreiben acutecostalum. Das Adverb kann aber in zusammengesetzten Worten die Endung i haben, z. B. densistrintus. 
1850. Cardium acuticostatum D'OrbigNr, Prodr. 2. p. 242. No. 636. australinum D'OrBigNi, daselbst p. 242. No. 635.

1854. " " acuticostatum (D'OrB.) Hupé, GaY's Hist. Chile. 8. p. 32 1887. $\#$ acutecostatum (D'Orв.) Phicippi, Tert. quart. Verst. Chiles. p. 174. Taf. 28 Fig. 4 (2 Fig.), 4 b. obliquatum Philippr, daselbst p. 175. Taf. 39 Fig. 1, 2, 14. Diazi Philippi, daselbst p. 175. Taf. 39 Fig. 12. obtusanyulatum Philippi, daselbst p. 175. Taf. 39 Fig. 4. subangulatum Philippi, daselbst p. 176. Taf. 39 Fig. 7. hualpense PHiLipr, daselbst p. 176. Taf. 34 Fig. 5. vicentinum Philippi, daselbst p. 176. Taf. 56 Fig. 5. pencanum Philippi, daselbst p. 177. Taf. 56 Fig. 2. diminutum PhilippI, daselbst p. 177. Taf. 58 Fig. 9.

1895. " " acutecostatum (D'Orb.) MörICKE, Gastr. Biv. d. Quir.-Schicht. p. 103.

Fast kreisrunde Schale, mit 24 hohen, scharfen, z. Th. gekörnelten Rippen und namentlich am hinteren Rande sehr tief eingekerbtem Schalenrand.

Beschreibung: Die Schale ist dick, von fast kreisrundem Umriss und hochgewölbt. Die Wirbel stehen in der Mitte des oberen Randes, sind schwach nach vorn gekrümmt und stark umgebogen. Am Vorderrande ist die Schale gerade abgeschnitten, am Hinterrand springen die ersten tief eingekerbten Rippen etwas ror. Die Sculptur besteht in 24 Rippen. Nahe am Wirbel sind dieselben niedrig; werden aber bald höher und sind nahe am Rande sehr hoch und schmal. Die vordersten sind gekörnelt und etwas breiter, die übrigen sind schärfer und etwas gewellt, da von Zeit zu Zeit eine kleine verdickte Erhöhung auf ihmen auftritt. Sie weisen eine einseitig-fiederförmige Sculptur auf ihren Flanken auf. Die hinteren Rippen stehen etwas weiter auseinander und der Schalenrand ist zwischen ihnen sehr tief eingekerbt. Die 9. Rippe von hinten ist höher und kräftiger als die übrigen. wodurch die Schale eine schwache Kante erhält, die sich selbst manchmal auf den Steinkernen noch angedeutet findet. Die Rippen sind auf der Innenseite leicht gefurcht (s. Abbildung Taf. XIX Fig. 10). Das Ligament ist kurz; es liegt in einer kleinen Furche hinter und unter dem Wirbel.

Das Schloss der rechten Klappe ('I'af. XIX Fig. 8) besteht aus folgenden Elementen: Die beiden Hauptzähne sind zu einem zweihöckerigen Torsprung verwachsen $\left(h_{1}, h_{2}\right)$, unter 
dem sich eine rundlich-dreieckigre Grube $\left(g_{1}\right)$ befindet. Dicht hinter dem hinteren Hanptzahn liegt eine zweite Grube $\left(y_{z}\right)$, welche die erste an Grösse übertrifft. Sie ist länglich-dreieckig. Über ihr biegt sich der Schalenrand etwas nach rorn ïber und ist verdickt $(r)$. An ihrem hinteren, unteren Ende steht ein kleiner, ku\% zapfenförmiger hinterer Seitenzahn $\left(s_{2}\right)^{1}$. Der vordere Seitenzahn steht weit vor den Hauptzähnen. Leider ist er an keinen Exemplar erhalten.

Das Schloss der linken Klappe (Taf. XIX Fig. 7) zeigt eine tiefe, dreieckige Grube für den hinteren Hauptzahn der rechten Klappe. Dann folgt nach vorn ein dreieckiger Hauptzahn, über dem eine kleine Grube für den vorderen Hauptzahn der rechten Klappe liegt. Der vordere Seitenzahn $\left(s_{1}\right)$ liegt weit vor den Hauptzähnen. Er ist gerundet-leistenförmig, und unter ihm liegt eine seichte Grube $\left(g_{3}\right)$ für den vorderen Seitenzahn der rechten Klappe. Der hintere Seitenzahn ist anscheinend ein kräftiger Zapfen und stelıt dicht bei den Hauptzähnen. Oberhalb des vorderen Seitenzahnes ist die Schlossplatte etwas eingesenkt.

Leider ist das Schloss der linken Klappe beim Präpariren grösstentheils zerbrochen, so dass die Figur nur wenig zeigt.

Der Steinkern ist fast kugelig gestaltet, die Wirbel sind spitz. Die Muskeleindrücke sind rundlich, die Mantellinie tritt deutlich hervor. Die Masse; die in den tiefen Einkerbungen des Randes gelegen hat, ist meist abgebrochen. An der Abbildung Taf. XIX Fig. 9, die einen Steinkern aus der Sammlung des geologischen Instituts in Strassburg darstellt, sind zwei solcher Zähne nach einem Freiburger Exemplar ergänzt.

Dimensionen: Höhe und Breite etwa gleich, bis zu $42 \mathrm{~mm}$.

Fundorte: Quiriquina (ca. 70 Exempl.), 'Tomé (ca. 30 Exempl.), San Vicente (ca. 30 Exempl.).

Bemerkungen: Cardium acuticostatum ist das gemeinste Fossil in den Quiriquina-Schichten. Man findet es in allen Altersstufen und Grössen. Die Schale ist sehr spröde und sehr selten gelingt es, gute Präparate ans dem harten Gestein

1 In der Figur zeigt die Linie $s_{2}$ durch ein Versehen des Zeichners nicht auf den hinteren Seitenzahn, sondern auf die erste (abgebrochene) der weit vorspringenden Rippen. 
zu gewinnen. Trotz des reichhaltigen Materials habe ich auch nicht eine einzige vollständige Schale gewinnen können. Die Steinkerne erhält man leicht, doch brechen die feinen Zwischenmassen $z$ wischen den weit vorspringenden Rippen meist ab. Zweiklappige Exemplare liegen mir nicht vor, das Strassburger Institut besitzt einige solche Steinkerne.

Es erklärt sich auf diese Weise unschwer, dass es bisher noch keine Abbildung dieses Leitfossils gab, die seine wahre Gestalt auch nur annähernd wiedergab. Das beschalte Exemplar, das d’Orbigny Voy. Amér. Mér. Pal Taf. 12 Fig. 19 abbildet, ist nach D'OrBigny selbst nicht gut gezeichnet, da die Rippen nicht scharf genug dargestellt sind. Auch fehlen die tiefen Einkerbungen des Schalenrandes. Fig. 21 stellt einen Steinkern (nebenbei bemerkt, unrichtig ${ }^{1}$ ) dar. Diese Abbildung copirt PHiLippi ziemlich schlecht und sagt dazu: "Die D'Orbigry'sche Figur ist eine glïckliche Restauration." (!) Ich verzichte clarauf, die Fehler dieser Abbildungen im Einzelnen zu schildern. Ein Blick auf die Figuren, die dieser Arbeit beigegeben sind, zeigt, wie weit sie von der Wirklichkeit abweichen.

Im Voy. Pol Sud. sieht das C. acuticostatum ganz anders aus als 1842. Hier sind die Rippen zweitheilig. Dies rührt laher, dass ein etwas abgeriebenes Exemplar dargestellt ist. Wenn die Rippen oben abgeschliffen sind, kommt der feine Hohlraum zu 'Tage, der von dem lamellaren Fortsatz des Mantels eingenommen wurde, der die Rippe bildete. Mir liegen Exemplare vor, die mit dieser Abbildung d'Orbignx's ganz übereinstimmen. Sie sind oberflächlich abgeschliffen.

Cardium australinum ${ }^{2}$ D'ORB. ist ein junges abgeschliffenes Exemplar von C. acuticostatum.

Philupp beschreibt eine ganze Reihe ron Cardien. Er ist selbst ${ }^{3}$ nicht immer sicher gewesen, ob es sich wirklich um neue Arten oder um Jugendformen, mechanisch veränderte Schalen oder individuelle Variationen handelte. Seine Arten gründen sich oft nur auf Steinkerne; SToLiczka s ${ }^{4}$ Mahnung

1 Der Steinkern hat keine Rippen.

" oder austrule D'Ors.

3 Tert. quart. Verst. Chiles. p. 175.

${ }^{4}$ Cret. fauma of South. India. Pelecyporla 1). 212. 
„Cast specimens are objectionable to base specific challacter's upon" ist unbeachtet geblieben. Pundre's Arten muissen etwas näher beleuchtet werden.

Cardium obliguatum Pns. Ich habe 3 Exemplare, die anfs Beste mit Punmp's Abbildungen übereinstimmen. Es handelt sich bei dieser "Art" einfach um C. acuticostutum. Die Schalen sind schief dnrchschnitten und abgerollt. Man neige die Muschel (Pinluper 'T'af. 39 Fig. 1) etwas aus dtel' Ebene des Papiers heraus nach links und drehe sie so weit, dass der rechte Rand fast senkrecht steht, damn hat man etwas mehr als die Hälfte eines $C$. acuticostatum vor sich. Die breiten Streifen kommen auf der Muschel folgendermaassen zu Stande: Wemn eine Schale dadurch zum Steinkern wird. dass die Schale nicht abgesprengt oder aufgelöst, sondern alluählich abgerollt wird oder verwittert, so dringt die Verwitterung in den Furchen zwischen den Rippen schneller vor als an den Stellen, wo die Rippen liegen. Tetztere sind dann oft noch von etwas Schalensubstanz bedeckt oder sind ein wenig heller gefärbt als der aus dem dunklen Kalkstein bestehende Steinkeru, auf dem sogar manchmal schwache Furchen entstehen. Man nimmt die radiale Streifung auf den Steinkernen z. 'T'h. nur bei giunstiger Beleuchtung wahr. Dies erwähnt PHuLippi, dem die eben beschriebene Erscheinung nicht erklärlich war, bei der folgenden Art, dem

Cardium vicentinum PhiL. Dies ist ein abgerolltel Steinkern des $C$. acuticostatum. Phıluppi's Diagnose ist iibrigens diurftig und Unterschiede gegen die anderen Cardium-Arten werden nicht. hervorgehoben. Die spitzen Wirbel rles Steinkerns sind bei $C$. acuticostatum ebenso vorhanden.

Cardium Diazi PHu. ist ein C. acuticostatum, das in ähnlicher Weise abgerieben ist, wie "C. obliquatum". Nul ist es nicht schief durchschnitten.

Auch Cardium pencanum PHis. halte ich für weiter nichts als $C$. acuticostutum. PHinipP meint, del Steinkel'n dieser vermeintlichen Art muisste Spuren der Rippen zeigen; aber der Steinkern von $C$. acuticostatum ist ja auch glatt. "C. vicentinum" kann also sehr gut der Steinkeru von „C. pencamum" sein. Er ist es sogar; demn beide sind $C$. acuticostatum. Auffallend sind bei C. pencomm die starken Rippen aut dem 
hinteren Theil der Schale. Sie stehen weiter auseinander als die vorderen. Gerade darin ist ein Beweis dafür zu erblicken, dass C. acuticostatum vorliegt, bei dem ja diese Erscheinung auftritt. PhiLıpri's Ergänzung der Schale ist schwerlich ganz richtig; sie miisste winkliger verlanfen.

Cardium obtusangulatum PhIL. ist ein verquetschtes C. acuticostatum. Mir liegen von letzterem 2 Exemplare von San Vicente vor, die mit Philippr's Figur ganz übereinstimmen.

Auch von Cardium subangulatum PHIs. liegt im Dusex'schen Material ein Stiick, das beweist, dass es sich auch hier nur um ein schlecht erhaltenes $C$. acuticostatum handelt. Man sieht ja auch an PhiLIPy's Zeichnung aufs Deutlichste, dass der Rand dieses Curdium verletzt sein muss.

Cardium diminutum PHL. dürfte ein junges C. acuticostatum sein.

Auch Cardium hualpense PHIL. scheint zweifelhaft zu sein. Die Kerben des Randes sind zwar in der unteren Abbildung von Fig. 5 (Phic. Taf. 39) dentlich gezeichnet, sie fehlen dagegen der oberen. Vielleicht ist es nur ein abgerolltes C. acuticostatum.

Die auffallende Erscheinung, dass in den QuiriquinaSchichten mehrere Cardium-Arten von annähernd gleicher Grösse und gleicher Rippenzahl auftreten sollten, erklärt sich also auf einfache Weise. Mir liegen fast alle diese "Arten" vor und aus dem grossen Material geht mit voller Sicherheit hervor, dass sie alle nur Erhaltungszustände des $C$. acuticostatum sind.

Ähnliche Formen sind aus dem übrigen pacifischen Senon nicht beschrieben. Dass eine gewisse Ähnliclikeit der chilenischen Art mit dem Cardium denticulatum ${ }^{1}$ BaILY aus Natal besteht, ist von Möricke hervorgehoben worden. Sie besteht aber im Wesentlichen nur in del tiefen Kerbung des Hinterrandes der Schale. Diese zeigen auch die tertiären Arten, wie C. Burdigalinum LAм. ${ }^{2}$ aus dem Unteren Miocän. das aber sonst abweichend gestaltet ist. Das ist auch mit

1 Bally, Descr. of some cret. foss. from South Africa. Quart. Jouru. of Geol. Soc. of London. 11. (1855.) p. 460. Taf. 13 Fig. 4 a, 4 b.

${ }^{2}$ Honnns, Fossile Mollusken des Wiener Tertiärbeckens. Biralven. Taf. 27 Fig. 2. 
C. oufalense Conrad ${ }^{1}$ aus den Lower marl beds der mittleren oberen Kreide von New Jersey der Fall. Merkwïrdig aber ist es, dass es ein lebendes Cardium giebt, das mit der senonen Art von Quiriquina nahe übereinstimmt. Es ist das $C$. (Tingicardium Fischer) ringens ${ }^{2}$ Chmms. von Westafrika. Die Ähmlichkeit liegt in rler tiefen Einkerbung der Schale am Hinterrand und im Bau des Schlosses. Die Rippen der recenten Art sind nur auf dem hinteren Theil der Schale scharf, die iibrigen sind platt und alle entbelıren der Körnelung. Auf Taf. XIX Fig. 11 ist eine linke Klappe dieser Art dem C. acuticostatum gegenübergestellt, um die Ähnliclıkeit beider zu zeigen, und weil ich keine gute Abbildung davon in der Literatur fand.

\section{Amathusia Philippi.}

Amathusia veneriformis Hupe sp.

Taf. XX Fig. 1-3.

1854. Crassatella ? veneriformis Hupé, GAY's Hist. Chile. 8. p. 302. Taf. $f$ Fig. 11.

1887.

(Hupé) Philippi, Tert. quart. Verst. Chiles. p. 172. Taf. 38 Fig. 6.

Mactra tumida Philippi, daselbst p. 144. Taf. 30 Fig. 3.

Ferrieri Philippi, daselbst p. 144. 'Taf. 29 Fig. 10.

" d'Orbignyi Phulippi, daselbst p. 144. Taf. 30 Fig. 4. pinguis Philippi, daselbst p. 144. Taf. 31 Fig. 5.

1895. $"$ tumida (Phil.) Möricke, Gastr. Biv. d. Quir.Schicht, dies. Jahrb. Beil.-Bd. X. p. 10 .

Umriss queroval, Wirbel sehr stark vorspringend, stark eingekrümmt. Schale aufgebläht. Schloss in beiden Klappen aus 2 Hauptzähnen und 1 linteren Seitenzahm bestehend.

Beschreibung: Die Schale ist dick, besonder's in der Gegend der Wirbel. Sie besitzt einen querovalen Umriss, wenn man von den weit vorspringenden Wirbeln absielıt ${ }^{3}$. Sie

1 Whitfield, Brachiop. and Lamellibranch. of the rariton clays and greensd. marls of New Jersey. U. S. Geol. Surv. Monogrr. 9. 'T'af. 20 Fig: 7.

2 Martini und Chemnitz, Conchyliencabinet. 10. Abth. 2. p. 71. Taf. 12 Fig. 10 und Taf. 4 Fig. 8.

${ }^{3}$ Es sieht bei den Fig. 1 und 2 auf Taf. XX so aus. als spränge der Wirbel von Fig. 2 viel mehr vor. In Wirklichkeit zeigen beide Stïcke dies Merkmal ganz übereinstimmend. Die Figuren differiren so stark. theils weil die Stellung der beiden Stïcke etwas verschieden ist, theils weil Fig. 1, die auch grösstentheils Steinkern ist, nicht ganz richtig ergänzt ist. 
ist stark aufgebläht. Der Vorderrand ist halbkreisförmig; der Hinterrand scheint ganz ähnlich gestaltet gewesen zu sein. Er ist bei keinem der mir rorliegenden Stücke enthalten; aber man darf es aus PhiLippr's Abbildungen schliessen. Die Schale ist von feinen concentrischen Zuwachsstreifen bedeckt.

Das Ligament liegt auf einer breiten, glatten Nymphe. sowie in einer aussen gelegenen, tiefen, schmalen Furche von nicht unbeträchtlicher Länge (Taf. XX Fig. 3l).

Das Schloss der rechten Klappe (Taf. XX Fig. 1) weist einen stark entwickelten, gerundet-dreieckigen, hornförmigen, aufwärts gekriummten Zahn auf, vor dem sich eine tiefe, rundlich-dreieckige Grube befindet. Vor dieser Grube liegt der zweite Hauptzahn, der rom Schlossrande durch eine seichte Furche nur schwach getrennt ist. Von der grossen glatten Partie des Schlossrandes, die hinter dem hinteren Hauptzahn folgt, und wie gesagt die Ligamentnymphe darstellt, gabelt sich ein hinterer Seitenzahn ab, der schräg abwärts verläuft, aber bald endigt, so dass der untere Rand der Schlossplatte hier mit starkem Winkel nach dem Schalenrand einbiegt. Ein vorderer Seitenzahn ist nicht vorhanden.

Das Schloss der linken Klappe (Taf. XX Fig. 2) ist dementsprechend gebaut. Dem grossen hornförmigen Zahn der rechten Klappe entspricht eine Grube von ähnlicher Gestalt. wie sie in der rechten Klappe auftritt. Auch der davor liegende Hauptzahn ist ähnlich geformt wie derjenige der rechten Klappe. Dann folgt noch die Grube für den vorderen Hauptzahn der rechten Klappe. Leider liegt von der rechten Klappe nur ein zerbrochenes Exemplar vor, so dass ich über den zweiten Hauptzahn und den hinteren Seitenzahn (für den sich in der anderen Klappe eine Grube ïber dem Seitenzahn findet) nichts auszusagen vermag.

Leider kann ich über die Mantellinie ebenfalls nichts mittheilen. Sie hatte jedenfalls keine Bucht. Es liegt nur ein vorderer Muskeleindruck ror, der auf dem Steinkern kräftig hervortritt. Zwischen ihm und dem Wirbel läuft eine Furche herab.

Fundorte: Quiriquina (1 Exempl.), San Vicente (1 Exempl.). 
Bemerkungen: Diese Muschel ist von Hup: Crassatcllu genannt. Hurs lag aber nur ein Steinkern ror, und ilun selbst blieb die generische Bestimmung \%weifellaft. Die Muschel muss daher leider Amuthusia veneriformis Here sp. heissen, obgleich der Artnane so wenig passt, wie nur mügrich.

Phumpr hat sie unter mehreren Namen beschrieben, zunächst ein Exemplar als Mactra tumida, obwoht ihm die Ähnlichkeit mit der Hupe'schen C'russutella? veneriformis nicht entgeht. Ihm scheinen nur zweiklappige Exemplare, die kein Schloss zeigen, vorgelegen zu haben, und el stellt die Muschel nach der änsseren Form zu Mactra, obwohl keine Kante vorhanden ist und Mactra nicht die stark vorspringenden Wirbel besitzt. Einen Steinkern derselben Art nennt er Mactra d'Orbignyi. Den Gedanken an eine Identität von "ML. tumida" und "MI. d'Orbigmyi" weist Phimlpr mit dem Hinweis zuriick, dass der Schlossrand bei jener Art zu beiden Seiten des Wirbels schräg abfalle, während er bei dieser eine gerade Linie bilde. Dieser Unterschied erklärt sich natürlich seln einfach ans dem Umstand, dass ein beschaltes Exemplar mit einem Steinkern verglichen wird, und die Schale von Amathusia gerade in der Gegend der Wirbel ganz besonders dick ist. Ausser diesen beiden bildet PhiLippr noch zwei Muscheln ab, die unter sich die gröosste Ähnlichkeit haben, die er aber mit verschiedenen Namen helegt: Mactra Ferrieri und Mactra pinguis. Beide sind offenbar dieselbe Art, eines die rechte und eines die linke Klappe. Die Beschreibungen beider Muscheln geben keine Unterscheidungsmerkmale an, stimmen vielmehr, soweit dieselben Verhältnisse besprochen werden, wörtlich ïberein. Ich halte diese beiden "Mactren" für identisch mit unserer Amatlusia veneriformis Hupe sp. Sie sind zwar etwas länger als "Mactra tumida" und "MI. d'Orbignyi"; aber man darf nicht rergessen, dass es sich $1 \mathrm{~m}$ Steinkerne handelt, und dass das wahre Bild eines Fossils durch einen ungiunstigen Erhaltungszustand sehr verändert werden kann. Bei „M. Ferrieri" fehlt am Unterrand die Schale, dadurch erscheint die Muschel niedriger als sie ist. Die Abbildungen sind übrigens wenig schön und plastisch.

Die relativen Grössenverhältnisse der 4 PhiLıpr'schen Arten sind (reducirt) folgende: 


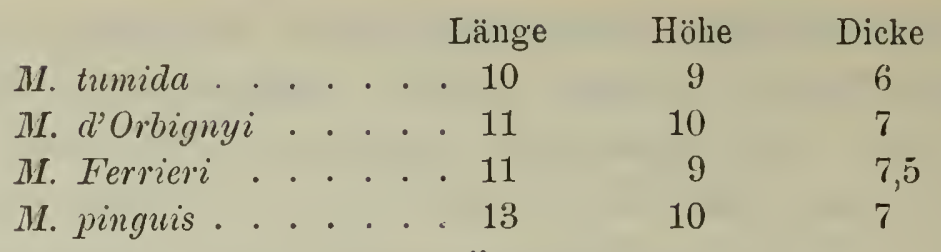

Auch daraus erhellt ihre Übereinstimmung.

Der Steinkern von "Mactra tumida", der Möricke volgelegen hat, ist äusserst schlecht erhalten und konnte keine Anhaltspunkte dafür geben, zu welcher Gattung die Muschel zu stellen sei. Immerhin darf nicht unerwähnt bleiben, dass MöRICKE's Beschreibung unrichtig ist, weil keine Rücksicht darauf genommen ist, dass es sich bei dem Fossil nur um einen abgerollten und entstellten Steinkern handelt. Die Form der Wirbel und die Kanten, wie sie Möricke schildert, sind nur durch die Verwitterung und Abrollung hervorgebracht.

Schon PpiLIPpi hat auf die grosse Ähnlichkeit des Amathusienschlosses mit dem der Gattung Cardium hingewiesen, und Ortmann ${ }^{1}$ hält es für zweifellos, dass eine Verwandtschaft wirklich besteht. Er weist auf die grosse Übereinstimmung zwischen dem Schloss der tertiären Amathusia angulata PHiL. und demjenigen gewisser Cardien, wie z. B. des Cardium laqueatum CONRAD, hin. Ich behalte mir vor, in einer späteren Arbeit über patagonische Kreidefossilien auf diesen Punkt näher einzugehen.

$\ddot{A} h n l i c h e$ Formen sind aus dem chilenischen und patagonischen Tertiär beschrieben worden. PhiLippi hat die Gattung anf die Arten Amathusia angulata und $A$. orbicularis von dem Fundpunkt Navidad gegründet ${ }^{2}$. Diese Arten sind grosse Muscheln mit stark eingekrümmten Wirbeln und an-

1 Rep. of Princeton Univ. Exped. to Patagonia. 4. Part II : Ortuasx, Tertiary invertebrates. p. 135.

2 Auch Mactra Rémondi PhIL. (Tert. quart. Verst. Chiles. p. 150. Taf. 30 Fig. 1), deren Ähnlichkeit mit M. pinguis PhilippI hervorhebt, dürfte eine Amathusia sein. Ebenso vielleicht Fimbria laerigata Sow. sp. (daselbst Taf. 33 Fig. 4), deren Umriss dem einer Amathusia ähnelt. Dass der eine Wirbel etwas höher erscheint, dürfte dadurch zu erklären sein, dass die beiden Klappen etwas gegeneinander rerschoben sind. Ferner dürfte alıch Mactra Ovallei Pinlippl Taf. 29 Fig. 6 sicher eine Amathusiu sein, wahrscheinlich eine junge $A$. angulata. Man darf nicht vergessen, dass cin Steinkern abgebildet ist, der natïrlich niedriger erscheint als ein beschaltes Exemplar. 
nähernd gleichseitigem Umriss. Ihr Schloss gleicht ganz dem der oben beschriebenen Art, die sich somit als ihr cretaceischer Vorläufer darstellt. Übrigens giebt die Abbildung Purıppr's Taf. 25 Fig. 1 eine weniger gute Vorstellung von $A$. angulata als 'Taf. 23 Fig. 1, und man wird, wenn man letztere Figur mit denjenigen der Mactra pinguis, tumida, Ferrieri und d'Orbignyi vergleicht, die grosse Ähnlichkeit in der Form leicht erkennen. Da es nirgends eine gute Abbildung der Amathusia angulata giebt, so gebe ich 'Taf. XX Fig. 4 eine solche in halber Grüsse. Sie ist nach 2 Exemplaren aus dem patagonischen Tertiär gezeichnet, die von Herrn Prof. Hautral an Herrn Prof. Steinmann zur Bestimmung geschickt waren ${ }^{1}$. Herr Prof. Steinmans gestattete mir mit grösster Bereitwilligkeit, dass ich die schönen Stïcke zeichnen liess, wofür ich ihm auch an dieser Stelle herzlichst danke.

Aus anderen Gebieten sind diese eigenartigen Muscheln nicht bekannt.

\section{- Lucina Brug.}

\section{Lucina Grangei D'OrB.}

1846. Lucina Grangei d'Orbigny, Voy. Pol Sud. Taf. 5 Fig. 13, 14, 14'. » Dumoulini D'Orbigny, daselbst. Taf. 5̌ Fig. 15, 16, $16^{\prime}$.

1850. $刃$ Grangei D'Orbigny, Prodr. 2. p. 241. No. 611.

\# Dumoulini D'Orbigsy, daselbst p. 241. No. 612.

1895. Lucina? dubia MIörıcke, Gastr. Biv. d. Quir.-Schicht, dies. Jahrb. Beil.-Bd. X. p. 102.

Kleine Lucina von mittlerer Wölbung der Schale. Wirbel fast mittelständig. Ein vorderer, aber kein hinterer Seitenzahn. In der Nähe des Wirbels concentrische Rippen.

1 Herr Prof. Steinmann machte mich auf die Ähnlichkeit der Amathusia veneriformis mit der $A$. angulata aufmerksam. Das Ligạment der $A$. angulata PHIL. liegt auf den glatten Nymphen und reicht in die tiefen Furchen hinein, die sich ausserhalb des Schlossrandes hinter dem Wirbel finden. Diese Furche erweitert sich sogar nach unten. PHILIPpi zeichuet (Taf. 25 Fig. 1 untere Figur) wohl die Nymphen, aber nicht die Furchen. Das Schloss von $A$. angulata ist von Philippi und Ortwane (Rep. Princ. Univ. Exped. Patag. 4. Part III. Taf. 27 Fig. 9 a, 9 b) abgebildet. Die Darstellungen der beiden Autoren stimmen nicht absolut iiberein. Es lässt sich aber leicht feststellen, dass das Schloss aus denselben Elementen besteht, wie das der A. veneriformis Hupé sp.

N. Jahrbuch f. Mineralogie etc. Beilageband XVIII. 
Beschreibung: Die Schale ist von querovalem Umriss, fast so lang wie hoch und von mittelstarker Wölbung. Die Wirbel stehen annähernd in der Mitte. Der Hinterrand ist leicht gerundet, der Vorderrand etwas concav. Charakteristisch ist die Sculptur. Sie besteht nahe den Wirbeln in einer concentrischen Berippung, während sich gegen den Unterrand zu nur noch schwache Zuwachsstreifen finden.

Nur von der linken Klappe liegt das Schloss vor. Es liess sich leider nicht tadellos präpariren. Unter den Wirbeln liegt anscheinend eine dreieckige Zahngrube, die von zwei divergirenden Hauptzähnen begrenzt wird. Ein vorderer Seitenzahn ist vorhanden, ein hinterer fehlt. Die Ligamentfurche ist ziemlich lang.

Der charakteristische lange vordere Muskeleindruck ist an einem der Stücke sehr gut zu sehen.

Dimensionen in $\mathrm{mm}$ :

$\begin{array}{ccc}\text { Länge } & \text { Höhe } & \text { Dicke ron 2 Klappen } \\ - & 12 & 7 \\ 18 & 18 & -\end{array}$

Fundorte: Quiriquina (5 Exempl.), San Vicente (2 Exempl.), Tomé (1 Exempl.).

Bemerkungen: Lucina Dumoulini scheint mir eine junge L. Grangei zu sein. Daher ihre geringere Grösse und die Erscheinung, dass sie ganz von concentrischen Rippen bedeckt ist.

Die L.? dubia Möricke aus der Sammlung des Strassburger Instituts ist ein besonders grosses Exemplar dieser Art.

Ähnliche Formen: Ob diese Lucina in die Nähe der Lucina fallax Forbes ${ }^{1}$ gehört, ist nach dem vorliegenden Naterial schwer zu ermessen. Jedenfalls ist die Sculptur dieser Art, ebenso wie diejenige der sonst in ihrer äusseren Gestalt ebenfalls nicht unähnlichen $L$. subcircularis $\mathrm{GABB}^{2}$; verschieden.

\section{Dosinia Scopoli.}

\section{Dosinia vicentina PHuL.}

1887. Artemis vicentina Philippr, Tert. quart. Verst. Chiles. 1). 113. Taf. 37 Fig. 11.

'Stroliczka, Cret. fauna of South. India. Pelecypoda. p. 2う6. 'Taf. 13 Fig. 13, 15-17; Taf. 14 Fig. 3-5, 7, 8.

${ }^{2}$ Calif. Pal. 1. p. 176. 'Taf. 24 Fig. 160. 
Schale kreisrund, wenig gewölht, mit feiner concentrischel. Berippung. Wirbel nach rorn eingebogen. Leider lassen sich die diunnschaligen Muscheln nicht präpariren. Das Schloss ist daher nicht sichtbar, ebenso auch nicht Mantellinie und Muskeleindrücke. Die vorliegenden Exemplare stimmen mit Phimrer's Abbildung gut überein, doch giebt diese die Muschel ein wenig zu lïnglich wieder. Ob Artemis Quiriquinae Pнu. wirklich eine. zweite Art ist, scheint mir nicht gan\% sicher.

Dimensionen in mm: Länge und Hüle 21, Dicke einer Klappe 5 .

Fundort: Tomé (2 Exempl.).

Ähnliche Formen: Da nur ein einigermaassen vollständiges Exemplar vorliegt, das aber noch manche Beschädigung zeigt, ist ein Vergleich mit den californischen Dosinia-Arten unthunlich.

\section{Cytherea LaM.}

Cytherea auca D'ORB. Sp.

Taf. XIX Fig. 12-14.

1846. Venus auca d'Orbigny, Voy. Pol Sud. 'Taf. 5 Fig. 9, 10 (nou V. aucu D'Orb., Voy. Amér. Mér. Pal. 1842. p. 122. Taf. 12 Fig. 17, 18 und nou V. Aucasiana D'Orb., 1850. Prodr. 2. p. 237. No. 545).

1854. $\pi \quad$ (D'Orb.) Hupé, GaY's Hist. Chile. 8. p. 341.

1871. $\pi$ (D'Orb.) Stoliczis, Cret. fauna of South. India. Pelecyp. p. $16 \check{.}$

1887. " " (D'ORB.) Phimppi, Tert. quart. Verst. Chiles. p. 11う.

Taf. 17 Fig. 5.

Ferrieri Phrlupi, daselbst p. 116. Taf. 17 Fig. 8 . Nepinele Phinip pi, daselbst p. 117. Taf. 18 Fig. 4. Neomeris Philippi, daselbst p. 118. Taf. 30 Fig 10. rustica Philippi, daselbst p. 118. Taf. 19 Fig. 8. Hallii (Gabr) Philippi, daselbst 1. 118. Taf. 14 Fig. 2. d'Orbignyanus (GabB) Philipri, daselbst p. 118. pencana PHILIPI, daselbst p. 119. Taf. 20 Fig. 2. Steinmanni Philippi, daselbst p. 119. 'Talf. 58 Fig. 1. Diazi Prinlppr, daselbst p. 119. Taf. 18 Fig: 1. hualpensis Punlrppi, daselbst p. 120. Tat, 21 Fig. 6. scalenia Pinlippi, daselbst p. 120. Taf. ¿̇ Fig. 2. compressa Puncipli, daselbst p. 120. Taf. 5̊ Fig. 4.

1895. „ pacifica Mörıcke, Gastr. Biv. d. Quir.-Schicht., dies Jahrb. Beil.-Bl. I. 1. 103. Taf. VII Fig. 7. 
Schale dick, queroval, concentrisch gerippt. In der rechten Klappe die beiden vorderen Hauptzähne verwachsen. In der linken Klappe ein länglicher Lunularzahn.

Beschreibung: Die Schale ist kräftig, dick, von querovalem Umriss und concentrisch gerippt. Die Wirbel sind stark nach vorn umgebogen. Der Hinterrand ist wenig gekrümmt, der Vorderrand unterhalb des Wirbels stark concav. Das Ligament liegt in einer feinen Rille von beträchtlicher Länge (Taf. XIX Fig. 12l,13l).

Die Schlossplatte ist kräftig entwickelt. Es finden sich in der rechten Klappe (Taf. XIX Fig. 12) 3 Hauptzälnne, von denen einer $\left(h_{3}\right)$ länglich und nach hinten gerichtet ist, während dic beiden anderen $\left(h_{2}, h_{1}\right)$ fast parallel nach rorn gerichtet und oben miteinander verwachsen sind, so dass sie wie ein einziger gespaltener Zahn aussehen. Jener ist von den letzteren durch eine dreieckige Grube $\left(g_{2}\right)$ getrennt. Vor den Hauptzähnen liegt die längliche Grube für den Lunularzahn der linken Klappe, oberhalb deren sich ein kleiner Seitenzahn $\left(s_{1}\right)$ vom Rande der Schlossplatte abzweigt.

Das Schloss der linken Klappe (Taf. XIX Fig. 13) zeigt ebenfalls 3 Hauptzähne $\left(h_{1}, h_{2}, h_{3}\right)$, die eine ähnliche Gestalt haben wie diejenigen der rechten. Zwischen dem langen, nach hinten gerichteten hinteren Hauptzahn $\left(h_{3}\right)$ und den beiden fast senkrecht stekenden, etwas divergirenden vorderen Hauptzähnen $\left(h_{2}, h_{1}\right)$ liegt die länglich-dreieckige Grube $\left(g_{3}\right)$ für den hinteren Hauptzahn der rechten Klappe. Vorn ist ein starker Lunularzahn $\left(s_{1}\right)$ von länglicher Form entwickelt.

Der Steinkern (Taf. XIX Fig. 14) zeigt sehr spitze Wirbel. Die Muskeleindrücke sind schwach; die Mantellinie zeigt eine tiefe Bucht.

Die vorliegenden Exemplare sind von verschiedener Grüsse. Sie sind nur z. Th. gut erhalten, und ich habe kein sicheres Urtheil darüber gewinnen können, ob es eine etwas längere und eine etwas kürzere Varietät dieser Muschel giebt.

Fundorte: San Vicente (15 Exempl.), Quiriquina (14 Exempl.), Tomé (7 Exempl.).

Bemerkungen: Eine Venus auca ist zuerst von D'Orbigny in Voy. Amér. Mér. Pal. p. 122 'Taf. 12 Fig. 17, 18 beschrieben und abgebildet. Dann findet sich eine $V$. auca, 
wie oben citirt, im Voy. Pol Sud. Beide gleich benannten Muschehn ähneln sich nicht im Geringsten. 1)ie $V$. anca von 1842 ist überhaupt keine Venus. In d'(Jumaxy's Prorliome. 2. (1850) findet sich keine Venus auca, sondern statt dessen eine $V$. Aucasiana ${ }^{1}$, wie jetzt die $V$. anca des Voy. Amer. Mér. genannt wird. Die $V$. anca des Toy. Pol Sud wird nicht angegeben.

Die Confusion, die bei D'Orbigry herrscht, ist bereits von Stouiczka ${ }^{2}$ aufgedeckt und des Näheren beleuchtet. Er vermuthet - wohl mit Recht - dass D'Orbigry eigentlich die $V$. auca des Voy. Pol Sud im Prodrome anführen wollte (unter dem Namen $V$. Aucasiana), dam aber versehentlich ein falsches Citat zum Namen gesetzt hat.

Philippi liat von $V$. anca (Voy. Pol Sud) nur 1 linke Klappe (auf Quiriquina) gefunden. In seinem Werke erscheinen aber nicht weniger als 19 V'rms-Arten aus den Quiriquina-Schichten der Ungegend ron Concepcion. Diese Arten waren insgesammt in 25 Stïcken vertreten, nämlich von Quiriquina 4, von Tumbez 5, von Hualpen 16. Nur 4 Arten sind auf beschalte Stücke gegründet(!). Die 36 Exemplare, die mir vorliegen, gehören nun seltsamerweise alle (bis auf eines?) nur einer Art an. Es dürfte daher angebracht erscheinen, Philippi's Arten kritisch zu untersuchen. Es ergiebt sich dabei Folgendes:

Venus Ferrieri PHL. ist ein etwas schief gedrücktes Exemplar der Cytherea anca D'OrB. sp.

Venus navicula PhiL. (p. 117. Taf. 19 Fig. 6) ist Mactra araucana (s. p. 259).

Venus Nephele PHIL. soll sich von $V$. auca dadurch unterscheiden, dass sie weniger dick ist. Dieser Dickenunterschied erklärt sich wohl zur Genïge aus dem Umstande, dass ein Steinkern mit einem beschalten Exemplar verglichen ist. Von V. Nephele hatte Phictpp nur einen Steinkern und die Cytherea anca hat eine ziemlich dicke Schale. Venus Nephele ist also zu streichen.

Venus a erea Hupé ist nur beschrieben, aber niemals abgebildet und wird bessel gauz gestrichen.

1 Prodr. 2. p. 237. No. 545.

${ }^{2}$ Stoliczka, Cret. fauna of South. India. Pelecypoda. 1. 165. No. 184. 
Venus Hallii GabB (nach Stoliczka und Pinlippi $=$ Venus d'Orbignyana GABB ${ }^{1}$ ) dürfte trotz der Unterschiede, die GABB angiebt, nur junge Exemplare von Cytherea auca sein. Ein Unterschied liegt eigentlich nur in der Unregelmässigkeit der concentrischen Berippung bei der GABB'schen Art. Doch kann diese sehr wohl die Folge eines schlechten Erhaltungszustandes sein. Die mir vorliegenden Exemplare der $C$. auca zeigen sehr verschieden starke und manchmal unregelmässige Berippung infolge geringerer oder stärkerer Beschädigung durch die Atmosphärilien. Philippi, dem die D'Orbigny'sche Confusion nicht zum Bewusstsein gekommen zu sein scheint, vergleicht die Venus Hallii mit $V$. auca des Voy. Amér. Mér. und kann daher nicht verstehen, dass GabB die beiden Muscheln überhaupt irgendwie ähnlich findet. - Auch diese beiden Arten müssen demnach wegfallen.

$V$ enus Jone PHiL. ist offenbar auf ganz ungenïgende Reste begründet, die nicht einmal eine generische Bestimmung erlauben.

Venus Neomeris PhiL. und

Venus Steinmanni PHIL. sind beide offenbar dasselbe und wiederum nichts als die gewöhnliche Cytherea anca.

Auch Venus rustica PhiL. ${ }^{2}$ glambe ich dieser Art zurechnen zu müssen.

Venus pencana PHIL. ähnelt der $V$. Nephele und ist wie diese ein junges Individuum von Cytherea auca. Phllippi wundert sich darüber, dass der Steinkern die Berippung aufweist, die die Schale gehabt hat. Diese Erscheinung beruht auf gleichmässiger Abwitterung, wie das bereits bei Besprechung des Philippi'schen Cardium vicentinum (s. p. 235) dargethan ist. Mir liegt ein Steinkern und auch ein Exemplar mit ganz dünnem Rest der Schale ror, bei denen aber die concentrische Berippung fast ebenso stark ist, wie auf der vollständigen Schale.

Venus Cuartrae PHIL. ist Mactra araucana D'OrB. (s. p. 258). Man sieht dies ohne Weiteres, wenn man die

${ }^{1}$ Philippi benutzt im T'ext den ersteren, auf der Tafel den letzteren Namen.

${ }^{2}$ Der Name Venus rustica ist schon von Sowerby für eine Venus-Art aus dem Crag gebrancht. 
Muschel anders reconstruirt, als Phurper es gethan hat. Sie ist in Wirklichkeit länglicher.

Venus Diazi Pum. scheint auch nur ein Erhaltungszustand der Cytherea aucu zu sein. Beim Steinkern erscheinen die Wirbel nicht so eingekriimmt. Darin kann kein Unterscheidungsmerkmal gesucht werden.

Venus hualpensis PhiL. ', die Ähnlichkeit mit V. pacifica Möricke (s. u.) liat, ist offenbar von $V$. pencana sehr wenig verschieden, und wie diese eine junge Cytherea ancu.

Venus? nuculiformis PhiL. (p. 120. T'af. 58 Fig. 3) ist entweder sehr schlecht gezeichnet oder das Original erlaubt nicht die Feststellung genauer Merkmale. Diese Muschel gehört einstweilen in die Liste der Dubia.

Venus scalenia PHiL. hat einen anffallend zur Seite gerückten Wirbel. Dies Merkmal verschwindet aber, wenn man die Figur ein wenig nach links dreht. Dann unterscheidet sich diese Art, die nur etwas schief gezeichnet ist, in nichts ron Cytherea auca. - Zu dieser Art ist anch zu rechnen:

Venus compressa PHIL. und

Venus pacifica Mör., die ein junges Individuum der Cytherea auca darstellt ${ }^{2}$.

1 Venus hualpensis auf Taf. 19 Fig. 7 bei Puilipy ist ein Druckfehler für $M$ actra hualpensis.

${ }^{3}$ Von 'Tomé liegt eine Cytherea vor, die grösser als die $C$. auca ist, mit dieser aber im Schloss übereinstimmt (Taf. XIX Fig. 15)). Sie ähnelt sehr der Venus subsulcata PHiL. (p. 115. Taf. 17 Fig. 7) von Algarrobo. Bei der Verschiedenheit der Fauna von Algarrobo und derjenigen der Quiriquina-Schichten in der Ungegend von Concepcion (s. dariber p. 273 ff.) zögere ich etwas, das Stück mit dem Namen der Art von Algarrobo zu belegeu, zumal da von dieser das Schloss nicht bekanut ist. - $V$. subsulcata Phil. und V. alta PhiL. (p. 116. Taf. 20 Fig. 3), beide ron Algirrrobo gleichen sich ïbrigens sehr. Ein Unterschied in der Höhe, wie PullippI ihn angiebt, ist in den Figuren nicht vorhanden. Von $V$. alta hat PurLIPPI ja nur eine unvollständige Klappe vorgelegen, die man anch etwas anders ergänzen kann. Die Berippung, die auf den Abbildungen recht verschieden ist, soll nach dem Text übereinstimmen. $V$. Landbeclii PinL. (p. 116. Taf. 20 Fig. 8) zeigt kaum Verschiedenheiten von diesen beiden Arten. Was MörIcke (Gastr. Biv. d. Quir.-Schicht. p. 104) V. alta nenut, ist ein schlecht erhaltenes Bruchstiick eines Individuums von bedentender Grösse, dessen genauere Bestimmung bei der mangelhaften Erhaltung aber als ein Wagniss erscheint. - Über V. egregia PHIL. vermag ich nichts auszusagen, ebenso wenig über $V$. insuls a Hupé. 
Ähnliche Formen: Aus der Chico-Formation Californiens zeigt Venus varians $\mathrm{G}_{\mathrm{ABB}}{ }^{1}$ einige Ähnlichkeit. Diese Art ist aber etwas höher. Es scheinen anch niedrigere Varietäten vorzukommen. GABB bildet leider kein Schloss ab. Bis zur Identität ähnlich ist der Cytherea anca die C. (Callista) sculpturata Stou. ${ }^{2}$ Es ist dies übrigens auch eine Form, die länglichere und gedrungenere Varietäten aufweist. Sie stammt aus der südindischen Ariyalur-Group.

\section{Tellina L.}

\section{Tellina Largillierti D'OrB.}

1842. Nucula Largillierti D’Orbigny, Voy. Amér. Mér. Pal. p. 128. Taf. 15 Fig. 9, 10.

1846. Tellina „ D'Orbigny, Voy. Pol Sud. Taf. ǰ Fig. 5, 6. 1850. " " D'Orbignt, Prodr. 2. p. 236. No. 509.

1871. $" \quad$ (D'ORB.) StoLiczKA, Cret. fauna of South. India. Pelecypoda. p. 124.

1887. Nucula? " (D’Orв.) Philippi, Tert. quart. Verst. Chiles. p. 194. Taf. 31 Fig. 7.

Die wenigen Exemplare dieser Art, die mir vorliegen, sind Steinkerne mit Schalenresten, deren Präparation unmöglich ist.

Fundorte: Tomé (4 Exempl.), San Vicente (1 Exempl.).

Bemerkungen: D'Orbigny's Abbildung von 1842 zeigt die Muschel zu aufgebläht, in der des Voy. Pol Sud erscheint sie zu niedrig. D'Orbigry hat sie erst Nucula, später aber selbst Tellina genannt. Nach Stoliczka wäre es eine T'ellinella. Philipp führt die Art als Nucula? an. Seine Abbildung weicht von den D'OrBigny'schen, die unter sich schon verschieden sind, ab. Die Ansicht gegen die Wirbel giebt PhiLipp so, als klaffte die Schale. Hätte er wirklich geglaubt, dass die Schale klaffte, so hätte er sie nicht Nucula nennen dürfen; in Wirklichkeit ist aber diese Figur eine Copie nach D’Orbigny aus dem Toy. Amér. Mér. Die Ab-

1 Pal. Calif. 1. p. 161. Taf. 23 Fig. 140, 140a. Diese Art fiudet sich niclit in dem Catalogue of Californian Fossils, compiled by J. G. Cooper (im 17. Jahresber. des State Mineralogist. Calif. State Mining Bureau. Sacramento 1888).

2 StoliczkA, Cret. fauna of South. India. Pelecypoda. p. 173. Taf. 7 Fig. $7-9$. 
bilikung D'Orbigny's ist nun schlecht gedruckt und die Schale scheint zu klaffen. Jass dies nicht beabsichtigt ist, erkennt man aber daran, dass die Naht ganz gezeichnet ist.

Ähnliche Formen: Am meisten ähneln noch dieser Art T'ellina occidentalis MEEK' aus der pacifischen Kreide Canadas und Tellina aequilatercalis ${ }^{2}$ MEEK aus den oberen Foxhillbeds Missouris. Sehr nahe stehen diese Arten aber der chilenischen nicht ${ }^{3}$.

Ceroniola n. g. .

Ceroniola australis GABB sp. ${ }^{4}$

Taf. XX Fig. $11 \mathrm{a}, \mathrm{b}, 12,13$.

1860. Cultellus australis GabB, Proc. Nat. Sc. Phil. 1860. p. 198. Taf. 3 Fig. 8.

1897. Solen [?] (Cultellus) australis (GABB) Philippi, Tert. quart. Verst. Chiles. p. 169. Taf. 34 Fig. 8.

Beschreibung: Die Schale ist länglich, schmal, ziemlich dünn, ungleichseitig. Die Wirbel sind sehr stark nach hinten gerïckt, so dass der hintere Theil der Schale nur $\frac{1}{4}$ der ganzen ausmacht. Der Unterrand ist schwach convex. der vordere Theil des Schlossrandes etwas concav, der hintere ist gerade und fällt ziemlich steil ab. Das hintere Ende ist rundlich-eckig, das vordere gerundet. Die Schale klafit vorn und hintell. Vor und hinter dem Wirbel läuft eine Furche. Die erstere ist lang, die letatere kurz (s. Taf. XX Fig. 13). Ich glaube nicht, dass die letztere eine Ligamentfurche ist. Sie liegt dafür zı weit nach aussen.

1 Geol. Surv. Canada. Whiteaves, Mesoz. Fossils. 1. Taf. 17 Fig. 11.

2 Mék, Invert. Upp. Miss. Country. (Rep. U. S. Geol. Surr. Terr. 9.) p. 196. 'Taf. 39 Fig. 5 b.

${ }^{3}$ A $11 \mathrm{~m}$. Arcopagia (= Tellina) valdiviana D'Orb. (Voy. Pol Sud. Taf. 5 Fig. 7, 8, 8'), nach D'Orbigny voll Quiriquina, wird von Philippi unter seinen tertiären Arten anfgeführt, weil er nach dem Namen der Inschel annimmt, sie sei bei Valdivia gefunden. Mir liegt kein IIaterial für diese Art vor; man möchte fast meinen, es sei eine junge Tellina Largillierti.

- Ich hatte mich bei der Untersuchung dieser Inschel der freundlichen Hilfe von Hern Prof. Dr. G. Bokm zu erfrenen. Hierfür, sowie für seine Rathschläge in nomenclatorischen Fragen danke ich Herrn Prof. BöHм auch an dieser Stelle herzlichst. 
Das Ligament scheint vielmehr innerlich zu sein und auf einer kleinen dreieckigen Fläche unter dem Wirbel zu liegen. Leider erlaubt mir das Material keine absolut sichere Entscheidung dieser Frage. Die Schlösser sind sehr klein und es mögen kleine Verletzungen beim Präpariren vorgekommen sein.

Das Schloss der linken Klappe (Taf. XX Fig. 11 a) zeigt 2 Zähne. Der hintere ist lang und schmal. Er beginnt unterhalb des Wirbels und zieht sich dicht am Schalenrande hin. Der andere liegt ziemlich weit vorn und ist weniger lang. Unter dem Wirbel sind die Verhältnisse leider nicht zu erkemnen. Die rechte Klappe (Taf. XX Fig. 11 b) hat ebenfalls einen vorderen und einen hinteren Seitenzahn, die sich dem Schalenrand nahe anlegen. Unter dem Wirbel findet sich ein ganz kleiner, schräg nach unten vorwärts geneigter Zahn, hinter dem der Platz des Ligamentes ist.

Die Muskeleindrücke sind nur bei grossen Exemplaren einigermaassen kräftig entwickelt. Der vordere ist schwach, länglich und liegt ziemlich weit vom vorderen Ende der Schale entfernt, der hintere stärker, rundlich. Die Mantellinie entspringt an diesem nicht unten, sondern mehr in der Mitte, bildet dann eine rundliche Bucht und biegt nachher sehr scharf nach vorll.

Die Schale zeigt eine feine Zuwachsstreifung.

Trotzdem dass diese Muschel in den Quiriquina-Schichten ziemlich häufig ist, liegt mir auch nicht ein talelloses Exemplar vor, so dass vielleicht der Anblick der Muschel noch ein klein wenig anders ist, als ihn die Figur Taf. XX Fig. 12 darstellt.

F u u d o r te: T'omé (iiber 30 Exempl.), Quiriquina (11 Exempl.), San Vicente (7 Exempl.).

Bemerkungen: GabB hat diese Muschel als Cultellus beschrieben, doch hat dieselbe weder das Schloss dieser Gattung, noch stehen die Wirbel bei Cultellus so weit nach hinten gerückt. Philipp nennt sie Solen [?], was ebensowenig richtig ist. Die Abbildung GabB's und noch mehr die Copie derselben bei Philippi sind unbefriedigend. Dass diese Muschel vielmehr eine Mesodesmatide ist, kann keinem Zweifel unterliegen. Wenn man z. B. Ceronia donacia Desh. mit ihr vergleicht, so springt die grosse Übereinstimmung in der Form, im Schloss 
und in der Gestaltung der Mantellinie aufs Deutlichste in die Augen. (Selbst wenn spätere Untersuchungen zu dem Resultat tühren sollten, dass das Ligament äusserlich wäre, bleibt die grosse Übereinstimmung, und es müsste dann angenommen werden, dass hier ein Vorläufer der Ceronien mit äusserlichem Ligament vorläge.) Die lebenden Ceronien sind übrigens rolwiegend der pacifischen Region eigenthïnlich.

\section{Mactra L.}

Lactra araucanu D ORB.

Taf. XX Fig. $5-7$.

1842. Mactra araucana D’Orbigny, Voy. Amér. Mér. Pal. p. 125. 'Taf. 15 Fig. 3,4 .

1846. d’Orbigny, Yoy. Pul Sud. Taf. 5. Fig. 2, 3, 4.

1850 . d'Orbiany, Prodl. 2. p. 235. No. 494.

1860

(D'Orb. sp. var.) Gabi, Proc. Ac. nat. sc. Plil. 1861. p. 198. Taf. 3 Fig. 12.

1871 (D'Orb.) Stoliczka, Cret. fauna of South India. Pelecyp. p. 56.

1887. „ , (D'Orb.) Philippi, Tert. quart. Verst. Chiles. p. 144. Taf. 32 Fig. 14.

ambigua Philippi, daselbst p. 146. Taf. 27 Fig. 11. oxyrrhyncha Philippi, daselbst p. 147. Taf. 27 Fig. 7. amphirrhyncha PhiLıPi, daselbst p. 147. Taf. 32 Fig. 15. Cuadrae Phin IPpi, daselbst p. 145. Taf. 29 Fig. 4.

Venus Cuadrae Philippi, daselbst p. 119. Taf. 19 Fig. ó. navicula Philippi, daselbst p. 117. Taf. 19 Fig. 6.

? Mactra Quiriquinae PincIPpI, daselbst p. 145 Taf. 29 Fig. 7.

? \# nesaea Philippr, daselbst p. 146. Taf. 32 Fig. 12.

Mactra ? Steinmanni Philippi, daselbst p. 146. Taf. 29 Fig. 12. hualpensis Philippi, daselbst p. 146. Taf. 19 Fig. 7. Gabli Philippi, daselbst p. 145. Taf. 27 Fig. 13, 22. chiliensis (GABB) Philippi, daselbst p. 146. Taf. 32 Fig. 10. dubia Puilippi, daselbst p. 147. 'Taf. 27 Fig. 6. Ganae Philiper, daselbst p. 147. Taf. 27 Fig. 8. Conchae Pulluppi, daselbst p. 145. Taf. 29 Fig. 5. vicentina Philiper, daselbst p. 148. Taf. 36 Fig. 10.

1895. " " hualpensis (PHiL.) Mörıcke, Gastr. Biv. d. Quir.-Schicht., dies. Jahrb. Beil.-Bd. X. p. 10 .

Beneckei Jï̈riune, daselbst p. 104. Taf. VII Fig. 10, 11.

Schale nicht sehr gross, rundlich-dreieckig, ungleichseitig. Eine Falte vom Wirbel zum Hinterrand, eine ganz schwache vom Wirbel zum Vorderrand. Mehr oder weniger regelmässige, 
feine, concentrische Berippung. Schloss in der linken Klappe mit einem dreieckigen Zahn, der von einem feinen, lamellenförmigen Zahı, welcher die Ligamentgrube begrenzt, durch eine schmale Furche getrennt ist.

Beschreibung: Die Schale ist von länglicher, rundlichdreieckiger Gestalt und ungleichseitig. Nach vorn verschmälert sie sich und bildet fast eine Ecke. Der Vorderrand ist gegen die Wirbel zu concav, der Hinterrand leicht convex, der Unterrand bogenförmig. Die Wirbel springen wenig vor; sie sind eingekrümmt und ziemlich spitz. Eine Kante läuft von Wirbel nach vorn und vor der Kante eine Furche. Beide sind sehr schwach, bringen aber eine deutliche Unterbrechung in der \pm regelnässigen concentrischen Streifung (oder feinen Berippung) hervor, mit der die Schale bedeckt ist. Ebenso verlänft vom Wirbel nach hinten eine Falte, die viel mehr hervortritt als die vordere. Die Furche liegt vor der Kante. Die concentrische Streifung ist zu beiden Seiten des Wirbels und in den jüngsten Theilen der Schale am kräftigsten.

Das Ligament liegt innerlich in einer tiefen, grossen, dreieckigen Grube, die etwas hinter der Spitze des Wirbels beginnt und sich schräg nach hinten und abwärts erstreckt (T'af. XX Fig. 6l, $7 l$ ). Über der Ligamentgrube ist in der Schale eine kleine Lücke.

In der linken Klappe ('Taf. XX Fig. 7) wird die Ligamentgrube nach hinten durch einen Wulst begrenzt $(w)$, über dem eine Furche hinläuft. Nach vorn bildet eine scharfe Lamelle $\left(h_{2}\right)$ die Grenze (bei dem abgebildeten Exemplar lädirt), vor der eine tiefe schmale Grube liegt, die diesen Zahn von dem nun folgenden grossen dreieckigen Zahn trennt. Dieser ( $h_{1}$, gleichfalls etwas lädirt), ist unten etwas ausgebuchtet, aber durchaus nicht eigentlich zweitheilig. Vor ihm liegt wieder eine tiefe, dreieckige, schräg nach unten vorn gerichtete Grube, und dann folgt der lange, schmale, vordere Seitenzahn $\left(s_{1}\right)$, über dem sich eine lange, schmale Grube befindet. Der hintere Seitenzahn $\left(s_{2}\right)$ ist ebenfalls diun, lang und leicht gebogen. Oberhalb von ihm biegt sich der Schalenrand etwas nach innen um $(r)$. Der Raum zwischen dem hinteren Rande der Ligamentgrube und dem hinteren Seitenzahn ist ziemlich gross. 
In del rechten Klappe ('Taf. XX Fig. 6) ist die Ligamentgrube vorn von einem leistenförmigen 'Jahn $\left(h_{2}\right)$ begrenzt ${ }^{1}$, dann folgt die grosse dreieckige Grube (g) für den Dreieckszahn der linken Klappe. Dann kommt ein leistenförmiger Zahn $\left(h_{1}\right)$, der mit dem vorigen divergirt und der durch eine Furche vom Schalenrande getrennt ist. Hintere Seitenzähne $\left(h s_{1}, h s_{2}\right)$ sind zwei vorhanden, und zwar ein langer, kräftiger ind ein kleinerer nahe am Schlossplattenrand. Beicle sind durch eine tiefe Grube voneinander getrennt. Ebenfalls sind zwei vordere Seitenzähne $\left(v s_{1}, v s_{2}\right)$ vorhanden, die ganz ähnlich angeordnet sind wie die hinteren.

Der Steinkern (Taf. XX Fig. 5) ist schlanker als die beschalte Muschel. Er zeigt die beiden Muskeleindrïcke, ron denen der vordere bogenförmig begrenzt ist, sich allmählich erhebt und 'in seiner' Längserstreckung etwa senkrecht steht, während der hintere mehr rund ist und kräftiger hervortritt. Die Furche, die vom Wirbel nach hinten verläuft, zeichnet sich auf dem Steinkern deutlich ab. Die Mantelbucht ist gleichmässig gerundet und reicht bis unterhalb des Wirbels.

Bei den ungemein verschiedenen Erhaltungszuständen bietet diese Muschel - eine der lıäufigsten in den Quiriquina-

1 Ich glaube, dass dieser Zahn in die schmale, scharfe Grube fasst, die längs des Dreieckszahnes der linken Klappe verläuft. Das Schloss dieser MIactra-Art, sowie das der weiter unten beschriebenen $M$. colossea sind vom palaeontologischen Standpunkt aus sehr interessant. Der gespaltene Zahn in der linken Klappe recenter Mactren, z. B. der M. stultorum, tritt hier als ein einziger ungetheilter Zahn auf. Die scharfe Lamelle, die sich hinter ihm bei $\boldsymbol{M}$. araucana erhebt, fehlt bei $\boldsymbol{H}$. colossea, die iiberhaupt den einfachsten Typus darstellt. Dagegen zeigt sie sich sowohl bei der tertiären $\boldsymbol{M}$. contradicta als auch bei $\boldsymbol{M}$. stultorum, bei letzterer freilich nur ganz klein und dicht an den Spaltzahn angeschmiegt. Ihr Vorhandensein bei $M$. stultorum beweist aber, dass nicht etwa aus den (Taf. XX Fig. 17) mit $h_{1}$ und $h_{2}$ bezeichneten Zähne der linken Klappe ron M. araucana die beiden divergirenden Zähne (der Spaltzalın) der linken Klappe von $M$. stultorum hervorgegangen ist, sondern dieser Spaltzahn ist bei jener noch ein ungetheilter einfacher Zahn. Daraus ist dann ja auch klar, warum bei späteren Arten der Grube zwischen diesen beiden Zähnen kein Zahn in der anderen Klappe entspricht. Das Schloss der rechten Klappe von $\boldsymbol{M}$. colossea zeigt sehr viel Übereinstimmung mit demjenigen von $\boldsymbol{M}$. stultorum.

Die Mactren aus der Kreide, deren Schloss sich abgebildet findet, sind zu zählen. PhuLippi bildet von seinen vielen Mactren kein einziges ab. 
Schichten - einen sehr wechselnden Anblick. Die concentrische Streifung tritt bald deutlich hervor, bald - wenn nämlich die oberste Schalenschicht abgerieben ist - fehlt sie ganz. Im letzteren Fall entdeckt man sie meistens noch in der Gegend der Wirbel, wo sie gegen schädigende Einflüsse am besten geschützt war. Vollends erkennt man die ILactra araucana dann nicht immer als solche, wenn Exemplare vorliegen, die theilweise der Schale beraubt sind. Fehlt z. B. am vorderen Theil des Schlossrandes ein Stück Schale, so erscheint die Muschel viel schlanker, als sie in Wahrheit ist. Ferner ist bei Steinkernen sorgfältig darauf zu achten, ob nicht abgeriebene Stiicke vorliegen, die zu geringes Dickenmaass haben. Wir werden auf diese Punkte noch bei der Besprechung der PhiLIPPi'schen Mactra-Arten zurückzukommen haben. Zweiklappige Exemplare sind in dem Dusev'schen Naterial fast gar nicht vorhanden, während das Strassburger Institut deren mehrere besitzt.

Dimensionen: Es kommen Exemplare von verschiedenem Alter und dementsprechender Grösse vor, die kleinsten sind $24 \mathrm{~mm}$, die grössten $53 \mathrm{~mm}$ lang. Hier einige Masse:

$\begin{array}{ccc}\text { Länge } & \text { Höhe } & \text { Dicke ron 2 Klappen } \\ 48 & 32 & 24 \\ 47 & 34 & 20 \\ 53 & 36 & 23 \\ 45 & 28 & 17 \\ 50 & 34 & 21\end{array}$

Die Verhältnisse schwanken zwischen folgenden Zahlen:

$$
\begin{aligned}
& 6: 4: 3 \\
& 5: 3: 2,2 \\
& 9: 6: 4
\end{aligned}
$$

Ich hatte erst geglaubt, es liesse sich vielleicht eine etwas gedrungenere Varietät von einer länglichen unterscheiden. Doch habe ich dies nicht durchführen können.

Fund or te: Quiriquina (ca. 60 Exempl.), Tomé (24 Exempl.), San Vicente (17 Exempl.).

Bemerkungen: Nachdem D'Orbigny die Mactra araucana $1842 \mathrm{im} \mathrm{Voy.} \mathrm{Amér.} \mathrm{Mér.} \mathrm{beschrieben} \mathrm{hat,} \mathrm{giebt} \mathrm{er} 1846 \mathrm{im}$ Voy. Pol Sud neue Abbildungen von ihr, die von den ersten so wesentlich abweichen, dass man nicht geneigt ist, beide Figuren für solche einer Species zu halten. Zwar stimmen 
die beiden Ansichten gegen die Wirbel ${ }^{1}$ ïberein, aber in der seitlichen Ansicht zeigt die M. araucana von 1842 nur auf dem vorderen 'Theil der Schale eine Kante, während die Hinterseite gleichmässig gerundet ist. Taf. 5 Fig. 2 des Voy. Pol Sud ist dagegen eine vorzügliche Abbildung der M. araucana. Kleine Ungenauigkeiten fehlen zwar auch hier nicht ganz. sind aber unwesentlich. (Die vordere Partie der Schale ist etwas zu weich gezeichnet und die Ausbiegung des vorderen Schlossrandes nach oben ist ein wenig zu stark. Die vordere Kante auf der Schale kommt nicht genügend zum Ausdruck, und der Winkel, den die concentrische Streifung an ihr macht, ist nicht ganz richtig wiedergegeben, indem die Verbindungslinie der Scheitel der Winkel zı horizontal liegt, während sie sich in Wahrheit schräg nach dem Wirbel emporzieht.) Die M. aruucana von 1842 ist auch unter etwas anderem Gesichtswinkel, nämlich etwas mehr auf die Wirbel gesehen. gezeichnet. Auffallend an ihr ist die sehr regelmässige concentrische Streifung.

Schon StoliczkA ${ }^{2}$ ist der Widerspruch zwischen den Abbildungen der beiden D'Orbignv'schen Werke aufgefallen, und el hat darauf hingewiesen, dass die Figuren, falls sie correct wären, zwei verschiedene Species darstellten. Wenn man ein sehr grosses Material zur Verfügung hat, ist es jedoch nicht schwer, zu constatiren, dass es sich bei der $M$. araucana ron 1842 nur um eine schlechte Zeichnung handeln muss. Die Quiriquina-Fossilien sind auch sonst auf den T'afeln des Voy. Pol Sud besser dargestellt als anf denjenigen des Toy. Amér. Mér. Man vergleiche nur die Abbildung der Trigonia Hanetiana in beiden Werken! In dem Fall, der uns hier beschäftigt, hat der Zeichner die Falte auf der Hinterseite der Schale ïbersehen und die Regelmässigkeit der concentrischen Streifung ein wenig übertrieben.

Phicippi beschreibt dann 1887 nicht weniger als 23 MactraArten aus den Quiriquina-Schichten. Er betrachtet die beiden M. araucana D'Orbignr's als 2 Arten und nennt die von 1846

1 Voy. Amér. Mér. Pal. Taf. 15 Fig. 4; Voy. Pol Sud. Taf. 5 Fig. 3. Diese Figuren sind nicht ganz correct. Die Wirbel sind zu sehr in die IItte gerückt.

2 Cret. fauna of South. India. Pelecy\}. p. 56. 
14. ambigua ${ }^{1}$. Im übrigen ist es nicht leicht, in jedem Fall mit voller Sicherheit festzustellen, welche von seinen Arten wirklich Daseinsberechtigung haben. Die Originalexemplare stehen mir nicht zur Verfügung, und Philippi's Abbildungen sind nicht immer ganz zuverlässig.

Von M. araucana giebt Philippi eine Copie nach dem Voy. Amér. Mér. Dieselbe ist aber schlecht ausgefallen, und der Unterschied dieser Figur (Philıpr, Taf. 32 Fig. 14) gegen das wirkliche Aussehen der $M$. araucana ist enorm.

Mactra ambigua PHIL. ist die M. araucana D'ORB. (1846). Diese Art fällt also weg.

Zwischen Mactra oxyrrhyncha PнIт. ${ }^{2}$ und der vorhergehenden kann ich weder nach der Abbildung, noch nach der Diagnose einen Unterschied entdecken. PHILIPPI erwähnt kein trennendes Merkmal. Die "Kante, die vom Wirbel nach der hinteren Extremität geht", ist ja auch bei $\boldsymbol{M}$. "ambigua" (= araucana) vorhanden, ebenso die "Furche, die vom Wirbel nach dem vorderen Ende verläuft". Auch diese Art kann also nicht aufrecht erhalten werden.

Mactra amphirrhyncha PHIL. ist ein Steinkern von M. araucana.

Mactra Cuadrac PHIL. halte ich auch für einen abgeriebenen, schlecht erhaltenen Steinkern voll $\boldsymbol{M} \boldsymbol{I}$. araucana (grösseres Exemplar).

Mactra Quiriquinae PHL. ist auch auf Steinkerne begrïndet. Der Unterschied gegen die vorige besteht in der gerundeteren Form des Vorder- und Hinterrandes. Ich halte anch dies nicht für eine selbständige Art. Die Steinkerne sind offenbar sehr schlecht erhalten, man müsste sonst doch etwas von den Muskeleindrïcken sehen. Ich glaube, dass es sich wieder nur um II. araucana handeit.

1 Philippi bemerkt bei der Figur dieser seiner Art: "nach D'Orbigsy". Seine Abbildung stellt aber eine Muschel mit verletzter Schale dar und stimmt mit der D'OrBIGsy'schen Figur von 1846 wenig überein. Ich denke mir, Philippi wollte seine Abbildung der M. araucana von 1842 als Copie nach D'ORBIGNY bezeichnen und bat diese Bemerkung versehentlich an einen verkehrten Platz gestellt.

${ }^{2}$ Die Mraasse, die Philippi für $\boldsymbol{M}$. oxyrrhyncha giebt, decken sich nicht mit den Maassen der Figur. 
Mactra nesaea PHIL. hat mit der vorhergehenden Art viel Ähnlichkeit. Ich zweifle nicht daran, dass dies auch ein Steinkern von $M$. aruucana ist. Es ist, nebenbei bemerkt, sehr auffallend, dass all diese vielen Mactren gleiche Grösse haben. Philıp ist bei diesem Genus ebenso kritiklos vorgegangen wie bei Curdium und Cytherea (Venus).

Mactra Steinmanni PHI. ist ein Steinkern von M. araucana, der gut die Mantellinie und die Muskeleindriicke zeigt ${ }^{1}$.

Mactra hualpensis PHIL. ${ }^{2}$ ist eine M. araucana, bei der sich die concentrische Streifung auf dem Steinkern eingegraben hat, während die Falte auf dem hinteren Theil offenbar sehr schwach erhalten ist. Schon oben ist auseinander gesetzt, wie man sich den Vorgang der Übertragung der Schalensculptur auf dem Steinkern zu denken hat. Aus dem Dusex'schen Material liegt ein ganz ähnliches Stiick vor. Der Umriss ist von Phibippi nicht ganz gliicklich ergänzt.

Die M. huclpensis, die Möricke anführt, ist, wie ich mich durch Prüfung des Strassburger Exemplars ïberzeugen konnte, der Steinkern einer jungen $M$. aruucana.

Mactra chiliensis GABB hat PHILIPP nicht vorgelegen. Das Dusen'sche Material enthält ein Stiick, aus dem hervorgeht, dass sich unter diesem Namen eine $M$. araucancerbirgt, deren angewitterte Schale einige stark heranstretende Zuwachsstreifen zeigt. Auch diese Art muss fallen.

Mactra Gabbi PhiL. nennt PhiLippi die von GabB als M. araucana var. beschriebene Muschel. Nach PhiLipp soll der Hauptunterschied gegen letztere in der weniger grossen Regelmässigkeit der concentrischen Streifung bestehen. Dies Merkmal ist unzuverlässig. Die meisten Exemplare von M. araucana, die mir vorliegen, sind durch Verwitterung ${ }^{3}$ u. s. w.

1 Diese Alt (Philtppi, Taf. 29 Fig. 12) soll Ähnlichkeit mit Venus navicula PHIL. (Taf. 19 Fig. 6) haben. Wenn man die Seitenansichten vergleicht, versteht man schwer, worin diese Ähnlichkeit bestehen soll. Die Figur unter Taf. 19 Fig. 6 hat freilich Ähnlichkeit mit der Figur iiber Taf. 29 Fig. 12. Da $V$. navicula auch weiter nichts als Mactra araucana ist, so hat PhiLipri iibrigens mit seiner Bemerkung recht, wenn sie auch nach seinen Zeichnungen nicht $\mathrm{zu}$ verstehen ist.

${ }^{2}$ Anf der Tafel versehentlich Venus huulpensis genannt.

${ }^{3}$ Die Verwitterung und Beschädigung, die hier so oft erwähnt wird, findet sich z. Th. an Stücken, die am Mecresstrande geesammelt sind, z. 'Th.

N. Jahrbuch f. Mineralogie etc. Beilageband Xvir. 
sehr unregelmässig gestreift. Dass die $M$. Gabbi verhältnissmässig höher ist, erwähnt PHILIPPI gar nicht. Dazu zeigt Philiper's Abbildung Taf. 27 Fig. 13 gar nicht die hintere Falte, die auf GabB's Abbildung (Philippi Taf. 27 Fig. 22) so kräftig hervortritt und die doch sicherlich für die Art charakteristisch sein muss. Ich glaube bestimmt, dass GıBB die Muschel, die ihm vorlag, mit Recht als $M$. araucana bestimmt hat ${ }^{1}$, und dass PhiLippi's Fig. 13 auf Taf. 27 eine wenig gelungene Abbildung einer grossen $M$. araucana ist.

Die Mactra Gabbi, die Möricke (Gastr. Biv. Quir.-Sch. p. 105) erwähnt, halte ich nach Prüfung des Exemplars für den Steinkern einer grossen Cytherea auca D'OrB. sp.

Mactra dubia PHI. soll sich von M. oxyrrhyncha durch ungleichseitige Form, sowie dadurch unterscheiden, dass sie im vorderen Drittel mehr aufgetrieben ist. Ich glaube gleichwohl, dass beide Arten identisch und $=M$. araucana sind. Philippi lag nur ein Steinkern mit der inneren Schalenschicht vor. Wenn man die Figur (PhiLrppi Taf. 27 Fig. 6) links unten etwas ergänzt (es fehlt dort offenbar ein Stïck von $2-3 \mathrm{~mm}$ Breite), so stimmt der Umriss ganz mit dem von M. oxyrrhyncha.

Mactra Ganae PHIL., von der vorigen der Beschreibung nach kaum zu unterscheiden, dürfte eine am Hinterrande lädirte junge $1 I$. araucana (Steinkern) sein.

Mactra Conchae PHIL. In dem vorliegenden Material findet sich nichts Ähnliches. Die Gleichseitigkeit der Schale ist sehr auffallend. $\mathrm{Ob}$ nicht auch hier eine $M$. araucana vorliegt, die durch irgendwelche Verletzungen unkenntlich ist? Ich wage es nicht $\mathrm{zu}$ entscheiden.

Mactra vicentina PHIL. ist auf einen verdrückten Steinkern begründet. Derselbe muss stark lädirt sein. Man elkennt daran Reste einer concentrischen Streifung, die Mantelbucht und den Platz der Muskeleindrücke: aber für die Begründung einer Species ist dieser Rest doch nicht genügend.

Venus Cuadrae PHIL. muss anders ergänzt werden (so dass die Muschel länglicher wird). Man hat damn ohne

sind es aber Beschädigungen, welche die Schalen schon bei ihrer Einbettung in die z. Th. groben Sande zur Senonzeit erfahren haben.

1 Übrigens ist aber GABB's Abbildung keineswegs schön zu nennen. 
weiteres ein grosses Exemplar von Mactra uraucana vor sich. Die Ähnlichkeit mit

Venus navicula PHI. springt in die Augen. Auch diese Art muss gestrichen werden, weil es ein Synonym für die Mactra araucance ist.

Endlich wäre noch Mactra Benecliei Mor. zu besprechen. Die Figuren Mörıcke's sind, wie der Vergleich mit den Originalen ergab, ein wenig idealisirt. Es muss aber vor Allem darauf hingewiesen werden, dass ron dieser Art 3 Steinkerne vorliegen, was Möricke gar nicht erwähnt. Es sind aber freilich nicht reine Steinkerne, denn man sieht nichts von den Muskeleindrücken und der Mantellinie. I)ie Schale ist ganz gleichmässig weggewittert und dann hat die Verwitterung den Steinkern ergriffen. Daher sieht man eine gewisse concentrische Sculptur. Die Wirbel sind abgerieben. Die Falte hinten und die Kante vorn haben sich seln scharf markirt. Die Muschel erscheint viel schlanker, als sie in Wirklichkeit gewesen ist. Sie stimmt im Übrigen ganz gut mit M. arucuna überein und ich kann mich nicht entschliessen, sie für etwas Anderes als den Steinkern dieser Art zu halten.

Ähnliche Arten: Inwieweit Mactra Ashburnerii GABB ${ }^{1}$ aus der Chico-Group der californischen Kreide und der Nanaimo-Group ron Vancouver und Lucia Island verwandtschaftliche Beziehungen zu M. araucana aufweist, ist bei Mangel von Vergleichsmaterial schwer zu sagen. Das Schloss gleicht in den Elementen und der Anordnung derselben entschieden etwas, doch ist die ganze Muschel höher und die Ligamentgrube liegt mehr oben auf der Schlossplatte, nicht in dieselbe eingesenkt, was GaBB speciell hervorhebt?

Nach Whiteaves passt GabB's Beschreibung der II. Ashburnerii anf alle Mactra-Arten der nordamerikanischen Kreide. Besonders ist er nicht mit der Vereinigung concentrisch ge-

1 Pal. Calif. 1. p. 15̄3. Taf. 22 Fig. 127; 2. p. 181. Taf. 29 Fig. 69, 69 a. Whiteares, Mesoz. Fossils. (Geol. Surv. Canada) 1. p. 141. Taf. 17 Fig. S. White, Invert. foss. of the pac. coast. (U. S. Geol. Surr. Bull. No. 51) p. 42.

2 Auffallend ist an der GaBB'schen Figur des Schlosses, dass keine Üffnung für das innere Ligament nach anssen vorhanden ist. JEEk (Tert. a. cretac. Inrert. upp. Miss. Country. (Rep. U. S. Geol. Surv. Terr. 9.) p. 210) hält dies für einen Fehler der Zeichnung. 
streifter und \pm glatter Formen einverstanden ${ }^{1}$. M. Warrenana M. u. H. ${ }^{2}$ soll der M. Ashbumerii ähnlich sein. Doch ist es eine kleinere Form. Ihr Schloss ist nicht bekannt.

Nit $M$. Ashburnerii ist nach Whiteaves die $M$. tripartita Forbes ${ }^{3}$ aus der sïdindischen Trichinopoly-Group verwandt. STOLiczka's Abbildungen ${ }^{4}$ dieser Art sind nicht sehr deutlich, besonders das Schloss. Eine Falte anf dem hinteren Theil der Schale ist vorhanden (schwach angedeutet in Stouiczis s Fig. $8^{5}$ ), ebenso eine Furche oder Kante auf dem vorderen. Auch die indische Art ist aber höher als die chilenische.

Nähere Beziehungen zur $\boldsymbol{M}$. araucana finden sich bei einigen tertiären Formen, so bei $M$. contradicta Desh. ${ }^{6}$ aus dem mittleren Lutétien. Allerdings hat $\boldsymbol{M}$. arancana eine etwas länglichere Gestalt, aber die Schlösser der beiden Arten sind sehr ähnlich. Bei der tertiären Art ist der Dreieckszahn der linken Klappe tiefer getheilt. Hinter ihm erhebt sich aber in derselben Weise wie bei der cretaceischen Art die kleine scharfe Lamelle, und auch die Seitenzähne sind ähnlich. Nur der hintere Rand der Ligamentgrube ist bei $\boldsymbol{I}$. contradicta verwischt, während $M$. araucana hier einen kräftigen Wulst hat. Auch die Schlösser der rechten Klappen stimmen sehr nahe überein, nur ist der Hinterrand der Ligamentgrube auch hier bei der tertiären Art weicher und der obere hintere Seitenzahn ist etwas mehr vom Rande getrennt.

Auch das Schloss von M. semisulcata LaM. ${ }^{7}$, einer der M. contradicta nahe verwandten Art, ist dem der $\boldsymbol{M}$. araucana sehr ähnlich.

1 Ob es sich hier vielleicht auch um verschiedene Erhaltungszustände handelt?

${ }^{2}$ Vergl. die Abb. bei MEek, Terr. 9. Taf. 30 Fig. 7 a, 7 d. (Die Abbildungen zeigen eine concentrische Streifung, die diese Art gerade nicht haben soll.)

${ }^{3}$ Forres in Trans. Geol. Soc. London. 7. p. 142. Taf. 15 Fig. 17 ; Taf. 18 Fig. 8.

${ }^{4}$ Cret. famma of South. India. Pelecyl). Taf. 5 Fig. 8-11.

5 Whiteaves sagt mit Unrecht, sie wäre auf der Abbildung nicht vorhanden. Auch Forbes Abb. Taf. 15 Fig. 17 zeigt sie deutlich.

${ }^{6}$ Deshayes, Descr. des animaux sans vertèbres déc. dans le bass. de Paris. 1. p. 288. 'Taf. 18 Fig. 19, 20, 21

7 Deshayes, Coq. fuss. des environs de Paris. 1837. p. 11. Taf. 4 Fig. 10; Animaux sans vertèbres. 1. p. 288. 


\section{Mactra colossea Phis.}

Taf. XX Fig. 8, 9.

1887. Mactra colossea P'nu1', Tert. quart. Verst. Chiles. p. 143. 'Taf. 28 Fig. 1; Taf. 29 Figr. 2.

Schale gross, dreieckig. Höhe und Länge ungefähr gleich. Schloss mit grossen innerlichen ligamentgruben. In der linken Klappe ein grosser Dreieckszalın, in der rechten ein lamellenförmiger Zahn und ein kleiner, vom Schlossrande kaum lısgegliederter. Nur ein vorderer Seitenzahn in der rechten Klappe.

Beschreibung: Die riesige Schale ist dick, von annähernd dreieckigem Umriss, ungleichseitig, das vordere Ende länger als das hintere. Die Wirbel sind stark umgebogen. Der Vorderrand ist concav, der Hinterrand schwach convex. fast gerade. Eine ziemlich scharfe Kante verläuft vom Wirbel nach dem Hinterende der Schale, so dass der hintere Theil ziemlich steil abfällt. Nach dem Vorderende verläuft eine weniger stark ausgebildete Kante. Die Lmula ist gegen die Wirbel hin tief eingesenkt, aber die Schalenränder heben sich stark. Die Area ist älnnlich beschaffen. Die Sculptur der Schale besteht nur in feinen Zuwachsstreifen.

Das Ligament ist innerlich. Es liegt in der linken Klappe (Taf. XX Fig. 8) in einer tiefen, dreieckigen, schräg nach unten hinten gerichteten Grube. Vor dieser erhebt sich ein kräftiger, dreieckiger Zahn $\left(h_{1}\right)$, über dessen Gestalt das mir vorliegende Material keinen Aufschluss giebt. Bei dem abgebildeten Exemplar ist viel von ihm abgebrochen. Unten scheint er etwas ausgebuchtet zu sein. Über der Ligamentgrube liegt (in beiden Klappen) eine glatte Fläche $(f)$. Hinter der Ligamentgrube, die hinten von einer ziemlich scharfen Kante $(k)$ begrenzt wird, liegt ein sehr kräftiger, schräg nach abwärts gerichteter, länglicher Seitenzahn $\left(s_{2}\right)$ ron bedentender Höhe. Der vordere Seitenzahn $\left(s_{1}\right)$ ist lang und schmal. Er wird durch eine tiefe, lange Grube von dem scharfen Schalenrande getrennt.

In der rechten Klappe (Taf. XX Fig. $9^{1}$ ) befindet sich

${ }^{1}$ Dies ist eine Klappe von einem bedeutend jüngeren Exemplar als dasjenige, das Taf. XX Fig'. 8 darstellt. Der Vergleich der beiden Klappen 
vor der Ligamentgrube ein lamellenförmiger Zahn $(m z)$, der die dreieckige Grube für den Dreieckszahn der linken Klappe von der Ligamentgrube trennt. Nit ihm convergirt ein kleiner Zahn $\left(h_{1}\right)$, der sehr nahe am Schalenrande liegt, so dass zwischen diesen und ihm nur eine kleine Furche bleibt. Es scheint nur ein vorderer Seitenzahn $(s v)$ vorhanden zu sein, dagegen zwei hintere, von denen der eine sich dicht an den Schalenrand anschmiegt $\left(s h_{1}\right)$, so dass nur eine seichte Furche zwischen beiden bleibt, während der andere $\left(s h_{2}\right)$ kräftig entwickelt ist und in bogenförmigem Verlauf die kräftige Grube für den hinteren Seitenzahn der linken Klappe umschliesst.

Der Steinkern zeigt den mässig grossen vorderen Muskeleindruck von ovaler Form und den hinteren Muskeleindruck, der rundlich oval und auch relativ klein ist. Die Mantelbucht ist einfach und nicht sehr tief.

Dimensionen in $\mathrm{mm}$ :

$\begin{array}{ccr}\text { Höhe } & \text { Länge } & \text { Dicke von } 2 \\ \text { ca. } 105 & \text { ca. } 112 & \text { ca. } 64 \\ \text { » } 87 & \text { " } 98 & \text { \% } 62\end{array}$

Fundorte: Quiriquina (1 rechte, 1 linke und 1 unvollständige linke Klappe), 'Tomé (1 rechte, 1 linke Klappe), San Vicente (1 linke Klappe, Steinkern).

Bemerkungen: Philipp giebt 2 Abbildungen dieser Muschel. Die Taf. 28 Fig. 1 ist besser gelungen als Taf. 29 Fig. 2. Bei letzterer ist der Wirbel zu breit und rund und nicht geniigend umgebogen. Tadellos ist allerdings Taf. 28 Fig. 1 anch nicht; denn es sieht so ans, als liefe vom Wirbel zum hinteren Ende nicht eine Kante, sondern eine Furche.

Ähnliche Formen von so beträchtlicher Grösse kommen im pacifischen Senon nicht vor. Die Grösse dieser Art steht einzig da. Auch die grössten recenten Arten, Mactra byronensis Gray und M. MLurchisoni Desh., kommen ihr nicht gleich. Das Schloss hat viel Ähnlichkeit mit dem von $M$. araucana, ist aber etwas einfacher. Vor Allem scheint der lamellenförmige Zahn vor der Ligamentgrube der linken Klappe zu fehlen. Ferner hat der vordere Hauptzahn der rechten Klappe eine

wird (abgesehen von den vielen Verletzungen) durch diesen Grössenunterschierl etwas erschwert. Die Abbildung steht anch ein wenig schief auf der Tafel. 
andere Lage und endlich scheint nur ein vorderer Seitenzahn vorhanden $\%$ sein. M. alta MEEK ${ }^{1}$ hat ein ähnlich gebautes Schloss. Auf die Ähnlichkeit des Schlosses mit demjenigen von $M$. stultorum ist oben schon hingewiesen worden.

Panopea MExard.

Panopea simplex Hupe.

Taf. XX Eig. 10.

1854. Panoper simplex Huré, Gay's Hist. C'hile 8. p. 37t. Taf. 6 Fig. 7. 1887.,$\quad$ (Hứ) PInLIPI', Tert. quart. Verst. Chiles. p. 166. Taf. 34 Fig. 4.

1895. „ " (HuPE) Mörıcke, Gastr. Biv. d. Qnir.-Schicht., dies. Jahrb. Beil.-Bd. X. p. 104.

sp. Möricke, daselbst p. 104.

Es liegen zwei Exemplare mit geringen Schalenresten vor. Sie zeigen, dass die von Phibippi copirte Abbildung HuPE's wenig correct ist. Charakteristisch ist der kreisbogenförmig umgrenzte Vorderrand. Bei dem einen Stiick sind die Wirbel verschoben, das andere zeigt nur die linke Klappe. Die Mantelbucht ist schmal und tief. Concentrische Zuwachsstreifen treten deutlich hervor.

Die von Möricke als Panopea sp. aufgeführte Muschel ist wohl kaum eine besondere Art, sondern nur ein grosses Exemplar der $P$. simplex. Es zeigt eine vom Wirbel herablaufende Furche.

Fundort: Quiriquina (2 Exempl.).

Ähnliche Formen: Ähnliche Panopea-Arten finden sich im patagonischen Tertiär.

Corbula Brug.

$$
\text { Corbula chilensis D'OrB. }
$$

1846. Corbula chilensis D'Orbigny, Voy. Pol Sud. 'Taf. 5 Fig. 11, 12, 12'. 1850. „ „ D’Orbigny, Prodr. 2. p. 238. No. jł9.

1861. Thracia corbulopsis Gabi, Proc. Nat. Sc. Phil. 1860. p. 198. Taf. 3 Fig. 1. 1871. Corbula chilensis (D'OrB.) Stoliczka, Cret. fauna of South. India. Pelecyp. p. 41. No. 47.

1887. \# " (D'Orв.) Philippi, Tert. quart. Verst. Chiles. p. 162. Taf. 28 Fig. 3.

n Thracia corbutopsis (Gabı) Pinlippı, daselbst p. 161. Taf. 28 Fig. כ́.

1 Tert. a. cret. invert. upp. Miss. Co. (Rep. U. S. Geol. Surv. Terr. 9.) p. 210. Taf. 37 Fig. 2 a. 
Schale klein, wenig ungleichklappig, hintere Hälfte der Schale verschmälert sich. Schloss? Mantelbucht kaum angedeutet.

Beschreibung: Die kleine Schale ist rundlich dreieckig, ziemlich stark aufgebläht, ungleichklappig. Doch ist der Grössenunterschied der beiden Klappen unbedentend (die rechte ist etwas grösser als die linke). Die Wirbel krümmen sich nach hinten. Eine Kante läuft vom Wirbel nach dem Hinterende. Die hintere Hälfte der Schale verschmälert sich, ist aber nicht länger als die vordere. Concentrisch angeordnete Rippen bedecken die Schale.

Leider gelang es nicht, das Schloss zu präpariren.

Die Mantellinie prägt sich auf dem Steinkern sehr deutlich ab. Eine Mantelbucht ist kaum angedeutet.

Dimensionen in $\mathrm{mm}$ :

$\begin{array}{ccc}\text { Höhe } & \text { Länge } & \text { Dicke von } 2 \text { Klappen } \\ 6,5 & 7,5 & 6 \\ 4,5 & 6 & 4,2\end{array}$

Fundorte: Tomé (7 Exempl.), Quiriquina (3 Exempl.), Sau Vicente (3 Exempl.).

Bemerkungen: D'Orbigny's Abbildung dieser Art stellt eine linke Klappe dar. Die Figur ist im Verhältniss reichlich lang. Philıppr's Figmr wird den wirklichen Grössenverhältnissen besser gerecht. Noch besser ist die Copie der GABB'schen Thracia corbulopsis, die offenbar dasselbe wie D'Orbigny's Corbula chilensis ist. Der Kiel der Schale ist aber zu scharf gerathen.

Ähnliche Formen: Corbula exulans StoL. (Cret. fama S. Ind. Pelecypoda, p. 45. Taf. 1 Fig. 16; Taf. 16 Fig. 1) ist eine ziemlich nahestehende Art ans der Ariyalur-Group. Sie ist ein wenig grösser als C. chilensis.

\section{Teredo chilensis PhIL. sp.}

1887. Teredina chilensis Phimpp, Tert. quart. Verst. Chiles. p. 172 Taf. 42 Fig. 6.

In dem Dusen'schen Material befindet sich ein Stiick fossilen Holzes, das von Bohrmuschelröhren ganz durchsetzt ist. Die Röhren sind an einer Seite geschlossen. Nach der anderen Seite verengern sie sich und man findet die Schale der Muschel an diesem Ende. Es lässt sich aber immer nur eine Klappe freilegen. Die Muschel hat die charakteristische kugelig-dreilappige Gestalt und zeigt die vom Wirbel nach 
dem Unterrand laufencle Furche. Fon der Sculptur ist nicht viel wahrzunehmen; sie scheint in einer concentrischen Berippung zu besiehen.

Die Art zu Teredina zu stellen, liegrt kein Grund vor.

Fundort: 'T'umé.

\section{Liste der in dem DusEN'schen Material enthaltenen Fossilien aus den Quiriquina-Schichten.}

\section{a) Pisces.}

Lamma sp.

Otodus sp

b) Cephalopoda.

Nautilus subplicatıs Pris. cf. Holcodiscus gemmatus Hupe Phylloceras ramosum MEEK

Lytoceras Vamona Forbes Kayei Fonises

Baculites vagina Forues Scaplites constrictus Sow. var. quiriquinensis WILCK.

$$
\text { c) Gastropoda. }
$$

Solariella unio PHIL. sp. Galeropsis laevis PHIL. sp. Ampullina australis D'ORB. Gyrodes curyompliala Pнш.. sp. chilina D'ORB. sp. Scalaria araucana PHIL. "Steinmanni Mör. "Chenopus?" fenestratus Pнiц. Pugncllus tumidus GABв Struthiolariopsis Ferrieri PHIr. sp. Triton Luisae WILCK.

Fusus difficilis D'ORB. Metzdorfi PhiL.

Pyropsis Hombraniana D'OrB. Pyrula rugosa Phir.
Surcula arazcana I)'Oris. sp. Eriptycha chitensis n'Oпв. Cylichna chilensis n Orrs. sp. Bulla subglobosa Pint..

d) Scaphopoda.

Jentalium chilense D'Ons.

e) Lamellibranchiat a.

Pecten gramulatus n'ORIs. chilensis J ${ }^{\circ} \mathrm{ORr}$.

Naiactina? ambigua Phis. sp.

Ostrea sp. IVILCK.

Modiola arancana D ORB. sp.

Nucula Cecileana D'ORs. sp.

Mralletia pencana Pris. sp.

'Trigonia Hanetiana D'Oris. Cardium acuticostatum D'ORr. Amathusia reneriformis Hepés sp. Incina Grangei D Orus. Dosinia vicentina Prin. Cytherea auca D'Oisis. sp. Tellina Largillierti n'ORn. Ceroniola australis GABE sp. Mactra araucana D OHB. $"$ colossea Phir.

Panopea simplex Hùé. Corbula chilensis D'ORB. 'Teredo chilensis Pini.. sp.

\section{Uebersicht über die Entwickelung der Kenntniss der Quiriquina-Fauna ${ }^{1}$.}

Da die Listen, die Philipri auf p. 3-5 in seinem Werke giebt, mancherlei Versehen enthalten, sind im Folgenden noch

1 Von den Cephalopoden wird im Folgenden abgeseinen. 
eimmal die Arten aus den Quiriquina-Schichten zusammengestellt, wie sie von den bisherigen Autoren beschrieben sind.

D'Orbigny beschrieb 1842 aus den nach seiner Meinung: tertiären Schichten von Quiriquina:

Fusus difficilis

Scalaria chilensis

Pyrula longirostra

Pleurotoma araucana

Natica araucana

$"$ australis

Nucula Largillierti
Arca araucana

Mactra araucana

Cecileana

Cardium acuticostatum

aıca

Venus anca

Trigonia Hanetiana.

Dies sind 14 Arten. Von ihnen ist Cardium auca zu streichen und ebenso Arca araucana, weil beide tertiäre Arten sind ${ }^{1}$. Pyrula longirostris $=$ Pyropsis Hombroniana, Natica araucana $=$ Natica (Ampullina) australis. (Für Scalaria chilensis liegt uns kein Material vor, ebenso wenig für die "Venus" auca von 1842.) Es bleiben also 10 Arten.

1846 bildet sodann D'Orbigny im Atlas zur Voy. Pol Sud $a b$ :

$\begin{array}{cl}\text { Bulla chulensis } & \text { Mactra araucana } \\ \text { Scalaria auca } & \text { Tellina Largillierti } \\ \text { Natica Grangeana } & \text { Arcopagia valdiviana } \\ " \quad \text { australis } & \text { Conus auca } \\ " \quad \text { auca } & \text { Lucina Grangei } \\ \text { Fusus difficilis } & " \text { Durdium acuticostatum } \\ " \quad \text { Durvillei } & \text { " chilina australe } \\ \text { Pyrula longirostra } & \text { Trigonia Hanetiana } \\ \text { " Hombroniana } & \text { Nucula Albertina } \\ \text { Avellana chilensis } & \text { Mytilus araucanus } \\ \text { Pleurotoma araucana } & \text { Pecten granulatus } \\ \text { Dentalium chilense } & \text { " chilensis. }\end{array}$

Diese Arten finden sich alle 28 mit der Fundortsangabe "Quiriquina" im Prodr. 2, allerdings z. Th. mit anderen GenusNamen, aufgeführt. Neun von diesen Arten sind schon 1842

1 Über Cardium auca s. Steismasw, Auftreten und Alter der Quiriquina-Schichten, dies. Jahrb. Beil.-Bd. X. p. 22. Diese Art wird ron D'Orbigny selbst in Prodr. 3. p. 120. No. 2262 muter dem Falunien angefülnt. Ebenso Arca araucana (s. Prodr. 3. p. 125. No. 2356). Es ist daher wobl begreiflich, dass PhilipPI, der diese beiden Jinscheln mit unter den Kreidearten anführt, „nicht so glücklich war, anf diese Art zu stossen." 
beschrieben ', von denen Pyrula longirostra wegfällt. Sieben Namen fallen als Synonyma fort, so dass folgende 12 Arten iibrig bleiben, im welche dies Werk die Liste der QuiriquinaFossilien vermehrt:

Bulla (= Cylichna) chilensis

Scalaria auca (= Stcinmanni)

Natica (= Gyrodes) chilina

Pyrula (= Pyropsis) Hombroniana Avellana (= Eriptycha) chilensis Arcopagia valdiciana (? = Tellina Largillierti)
Dentralium chilense

Corbula chilensis

Lucina Cirangei

Mytilus araucanus (= Mrodiola araucana)

P'ecten granulatus chilensis

Mit den $10 \mathrm{im} \mathrm{Voy.} \mathrm{Amér.} \mathrm{Mér.} \mathrm{beschriebenen} \mathrm{Arten}$ sind dies $22^{2}$.

1854 verzeichnet Hupt in Gay's Hist. Chile. 8 folgende Arten von Quiriquina:

Fusus dubius (= difficilis)
Pyrula dilatata (= Hombroniana)
Triton armatum
Panopea simplex
Trigonia obtusa (= Hombroniana)
Venus insulsa

Vonus acrea

"subalbicans

Lutraria cuneiformis

Crassatella (= Amathusia)

veneriformis.

Leider steht mir Hupé's Werk nicht zur Verfïgung, und ich habe diese Liste nach den zerstreuten Angaben bei Philippi zusammengestellt. Venus subalbicans und Triton armatum sind tertiäre Arten. Drei Namen fallen als Synonyma fort. Lutraria cuneiformis ist in Philippi's Liste (PhiL. p. 4) als von Coquimbo aufgeführt, im Text erscheint sie aber als eine Art aus den Quiriquina-Schichten (Phil. p. 112). Nach Philıppl's Abbildung (Taf. 33 Fig. 9) zu schliessen, ist die Muschel schlecht erhalten. Vielleicht liegt Panopec vor? Vemus aerea haben wir gestrichen (s. p. 245), es bleiben also nur Venus insulsa (s. p. 247 Anm.), Amathusia veneriformis und Panopea simplex, so dass sich also nur $z$ wei sichere neue Arten ergeben. Das wären insgesammt 24 Arten.

1 Von der Confusion mit "Venus auca" ist dabei abgesehen.

${ }^{2}$ Philippi giebt als Fundort bei allen Arten des Voy. Pol sud Port Famine (Puerto del Hambre) an, indem er sicl nach einer Angabe von GRANGE richtet. Bei Puerto del Hambre kommen aber keine QuiriquinaSchichten vor (s. PhilipPI, Tert. quart. Verst. Chiles. 1. 245). Der Prodrome muss Philippi nicht zur Verfïgung gestanden haben. 
Es folgt nun die Arbeit GaBB's in den Proc. of the Academy of Nat. Sc. Philadelphia 1860. p. 197, 198. Er fiihrt folgende 16 Species an:

Pleurotoma arata
$\quad$ d'Orbignyana
Pugnellus tumidus
Scalaria chiliensis
Strombus semicostatus (= Pug-
$\quad$ nellus uncatus)
Eulima seminosa
Patella auca
Trigonia Hanetiana
Anomia parva

Cultellus (= Ceroniola) australis Mactra araucana

" chiliensis $(=$ arancana $)$

Modiola cretacea $(=$ araucana)

Pinna minuta

Thracia corbulopsis ( = Corbula chitensis D'ORB.)

Venus d'Orbignyana $(=$ Cytherea auca).

Es ist auffallend, dass gar keine nähere Fundortsangabe gemacht wird. Es heisst nur bei Eulima seminosa: "from a greyish brown limestone from Chili, in connection with Trigonia Hanetiana D'ORB. U. S. W. Bei den folgenden Arten ist dann kein Wort mehr uiber den Fundort verloren. Sollten vielleicht Anomia parva und Patella auca gar nicht von derselben Fundstelle sein?

Vier von diesen Namen fallen weg als Synonyma (Venus d'Orbignyana $=$ Cytherea auca). Das Vorkommen von Strombus semicostatus (= Pugnellus uncatus Forb. sp.) ist sehr zweifelhaft. Scalaria chiliensis ist wahrscheinlich $=$ Sc. Steinmanni. Es bleiben also folgende 8 Arten als neu:
Plenrotoma arata
Patella arca
Pugnellus tumidus
Eulima seminosa
Anomia paria
Cultellus (ECroniola) australis
Pinna minuta.

Mit ihnen zeigt die Liste der Quiriquina-Fossilien 32 Arten.

Es wäre sodann Philippi's grosse Liste ron 1887 (Tert. quart. Verst. Chiles. p. 242, 243) zu besprechen. Wir streichen aus dieser Liste zunächst alle diejenigen Arten, welche sich nur bei Algarrobo gefunden haben, weil es nicht völlig sicher ist, ob die Fossilien von diesem Fundpunkt demselben Horizont angehören wie die Quiriquina-Schichten in der Umgebung von Concepcion. Aus diesem Grunde ist auch bisher in dieser Arbeit von Algarrobo immer ganz abgeselien. Wir entfernen ausserdem aus dieser Liste alle Synonyma und alle Arten, die ungenügend begrïndet sind, soweit das oben auseinander- 
gesetzt ist. Es ergeben sich dann folgende neue Arten, die auf den vorhergehenden Seiten besprochen oder doch erwähnt sind:

Trochus (= Solariclla) unio Orallei

Trochita (= Galeropsis) laevis

Natica Rémondi

?" Flobula

$"$ (= Gyrodes) curyomphate

Scalaria arancana

Chenopus? fenestratus

F'usus MLetzdorfi

" (= Struthiolariopsis) Ferrieri
Pyrula rugusa

Bulla subglobosa

?" hualpensis

$?$ nesuea

Nucula (= Mallctia) pencana Artemis (= Iosinia) vicentina Venus alta

" egregia

Mactra colossea

??" C'onchae

Teredina $(=$ Teredo) chilensis

Monopleura (= Naiadina?)

ambigza.

Von diesen sind 4 (mit einem ? versehen) mehr oder weniger zweifelhaft, so dass sich 1.9 sichere neue Arten elgeben. Die Summe der Arten wäre dann 51.

Es bleiben nun noch mehrere Arten zu besprechen, die in Philippi's Werk beschrieben und in der Liste der Quiriquina-Fossilien aufgeführt werden, nämlich:

Fusus heterocyclus

Voluta Domeylioana

Bulla Rémondi

Mitra Mualpensis

Tellina d'Orbignyana

Psammobia Hanetiana

Lutraria macilenta

Solen elytron

Cardium suave
Arca acutcingulata

$"$ pencana

$"$ involuta

Nucula arcacformis

$\begin{array}{ll} & \text { Barrosi } \\ " & \text { hualpensis } \\ " & \text { Quiriquinae } \\ \text { " } & \text { vicentinae } \\ \text { cornuta. }\end{array}$

Über diese ist Folgendes zu bemerken:

Fusus heterocyclus kommt nach dem Text nu bei Algarrobo vor.

Voluta Domeylioana. Ihr Vorkommen auf Quiriquina ist zweifelhaft ${ }^{1}$.

Scalaria Gabbi hat PhiLipp die Sc. chiliensis GabB genannt, weil es schon eine Sc. chilensis D ORB. gab, die nach Philipp von jener verschieden ist. Sie ist mit Sc. Steinmanni Mör. (s. diese) identisch und deshalb zu streichen.

${ }^{1}$ Steinmand, Das Auftreten und Alter der Quiriquina-Schichten, dies. Jahrb. Beil.-Bd. X. p. 24. 
Bulla Rémondi ist eine von den Arten, die Kreide und Tertiär in Chile gemeinsam haben sollen. Steismann führt sie in seiner Liste dieser Arten ${ }^{1}$ nicht mit an. Ich halte es nicht für ausgeschlossen, dass die Bulla, welche PhiLipri „in der Sammlung des verstorbenen D. Francisco Ovalle gesehen" hat, einer der anderen Bulla-Arten aus den Quiriquina-Schichten zuzurechnen ist. Direct verglichen hat PHILIPPI offenbar dies Exemplar nicht mit den tertiären Arten und endlich ist diese Schneckengattung ziemlich conservativ und nicht sehr charakteristisch. Die Identität der QuiriquinaArt mit einer tertiären dürfte daher auch in diesem Fall sehr zweifelhaft sein.

Mitra hualpensis PhIL. (Taf. 8 Fig. 6) liegt mir auch vor. Es ist aber ein abgeriebenes und schlecht erhaltenes Exemplar einer Schnecke, die jedenfalls keine Mitra ist (da Spindelfalten fehlen), über die sich aber im Übrigen nichts aussagen lässt.

Tellina d'Orbignyana ist eine tertiäre Art, die sich versehentlich in Philippi's Liste der Quiriquina-Arten verirrt hat. Dasselbe ist mit

Psammobia Hanetiana D'OrB. der Fall. Übrigens hat Mörıcke diese beiden Arten aus der PhiLıppI'schen Liste in die seinige ${ }^{2}$ ïbernommen. Sie sind also auch zu streichen.

Lutraria macilenta. Bei PhiLIPpI's Art, zu sehen, halte ich es nicht für unmöglich, dass es sich hier um einen Steinkern der Panopea simplex Hupé handelt (die Phisıpp nach seiner Angabe nicht vorgelegen hat).

Solen elytron ist wieder eine von den Arten, die der Kreide und dem Tertiär gemeinsam sein sollen, die aber aus der Liste der Quiriquina-Fossilien zu streichen ist ${ }^{3}$, da nur äusserst dürftige Reste vorgelegen haben, die jedenfalls der Ceronia australis GABB sp. angehören.

'Dies. Jahrb. Bcil.-Bd. X. p. 22 ff. - Auch Mactra simplex will Philip an ansser von Navidad ans der Kreide von Algarrobo lıaben. Es ist ihm aber selbst zweifelhaft, ob die Stiicke e iner Art angehören. Irgendwelches Gewicht ist deshalb auf diese Angabe nicht zu legen.

2 Möricke, Gastr. Biv. d. Quir.-Schicht. p. 113.

3 Steinmann, Das Auftreten und Alter der Quiriquiua-Schichten. p. 23. 
Cardium suave ist auf einen verquetschten Steinkern gegründet und zweifelhaft.

Arca acutangulata und $A$. pencana liegen mir nicht vor.

Arca involuta, nebenbei bemerkt als Arca mehr als zweifelhaft, ist eine tertiäre Art und steht irrthümlich in der Liste der Kreidefossilien.

Nucula arcacformis, N. vicentina, N. Quiriquinae ${ }^{1}$ und $N$.? cornuta ${ }^{2}$ liegen mir nicht vor.

Nucula Barrosi ist eine tertiäre Art vom Rio Rapel und gehört nicht in die Liste der Kreidefossilien.

Das wären also noch 6 neue Arten aus den QuiriquinaSchichten, so dass also PhiLIPPI's Werk im Ganzen 25 (resp. 29) neue Arten aus den Quiriquina-Schichten bekannt gemacht hat. Insgesammt weist das Verzeichniss der Arten dann 57 Nummern auf.

Möricke hat neu beschrieben (1895):

\section{Scalaria Quiriquinae \\ "Steinmanni \\ Ovulopsis Philippii.}

Auf eine Besprechung der Liste der Gastropoden- und Bivalven-Arten aus den Quiriquina-Schichten, die er am Schluss seiner Arbeit giebt, kann hier verzichtet werden. Dies Verzeichniss enthält die Irrthümer der PhiLıppı'schen Liste, während D'Orbigny's Arten aus den Voy. Pol Sud fehlen. Ferner ist es durch Druckfehler und allerlei kleine Versehen entstellt. Was davon zu streichen und was zu ändern ist, zeigt der Vergleich mit der unten gegebenen Liste der QuiriquinaFossilien.

Auf den vorhergehenden Seiten sind noch neu beschrieben ${ }^{3}$ :

\section{Triton Luisae \\ Ostrea sp.}

Somit ergiebt sich die folgende corrigirte Liste der Fossilien der Quiriquina-Schichten, die von den in der Um-

1 Wohl eine Leda oder Yoldia. Vergl. Yoldia obtusa SroL.

${ }^{2}$ Diese merkwürdig spitze Nucula, die fast die Form einer Aucella hat, ist vielleicht mit Nucula terminalis DEsh. (Anim. sans rertèbres. 1. Atlas. Taf. 64 Fig. 5) verwandt.

${ }^{3}$ Abgesehen von dem Scaphites constrictus var. quiriquinensis. 
gegend von Concepcion gelegenen Fundorten Quiriquina, Tomé, San Vicente, Tumbez und Hualpen bekannt geworden sind:

\section{Revidirte Liste der Fossilien der Quiriquina-Schichten.}

\section{A. Vertebrata.}

Pliosaurus chitensis Gray sp. Cimotiasaurus Andium DEECKE Haifischzähne.

\section{B. Mollusca.}

a) Cephalopoda.

Nautilus subplicatus PHrL. Holcodiscus gemriatus Hupé Puzosia Darwini Phil.

Pachydiscus Quiriquinae PHIL.

Phylloceras Surya Forbes " ramosum MEEK

Lytoceras Varuna ForBes Kayei Forbes

Hamites cf. cylindracens DFr. sp. Baculites vagina ForBEs Scaphites constrictus Sow. var. quiriquinensis WIrck.

b) Gastropoda.

Patella auca GABB

Solariella unio PHIL.

Trochus Ovallei PHIL.

Galeropsis lacvis Phru. sp.

Gyrodes euryomphala PHIL. sp.

$" \quad$ chilina D'ORB. sp.

Ampullina australis D'ORB.

Natica Rémondi PHIL.

" Ferricri Phil.

? " globula Phil.

Scalaria arancana PHis.

? chilensis D'Orb.

" Quiriquinae Mör.

"Steimmanni Mör.

Eutima seminosa GABB

"Chenopus?" fenestratus PHiL.

Pugnellus tumidus GABB

Struthiolariopsis Ferrieri PHIL. sp.

Ovulopsis Phitippii Mör.
Triton Luisae WILCK.

Fusus difficilis D'ORB.

Metzdorfi Pнis.

Pyropsis Hombroniana D'ORB.

Pyrula rugosa PHIL.

Pleurotoma arata $\mathrm{G}_{\mathrm{ABB}}$

Pleurotoma d'Orbignyana $\mathrm{G}_{\mathrm{ABB}}$

Surcula araucana D ORB. sp.

Eriptycha chitensis D'ORB. Sp.

Cylichna chilensis D'ORB.

Bulla subglobosa Рнгц.

? " hualpensis PHIL.

? " nesaea Phir.

c) Scaphopoda.

Dentalium chilense D ORB.

d) Lamellibranchiata.

Pecten gramilatus D'ORB.

$"$ chilensis D'ORB.

Naiadina? ambigua PHIL. sp.

Pinna minuta $\mathrm{G}_{\mathrm{ABB}}$

Anomia parva $\mathrm{G}_{\mathrm{ABB}}$

Ostrea sp.

Modiola araucana D'ORB. $s p$.

Nucula Cecileana D'ORB. sp.

"arcaeformis PHIL.

" ?Quiriquinae PнIц.

$"$ vicentina $\mathrm{PHIL}_{\text {H. }}$

" ?comita PHIL.

Arca acutanyulata PHus.

" pencana PHIL.

Malletia pencana PHic. sp.

Trigonia Hanctiana D'ORB.

Cardium acuticostatum D'ORB.

Amathusia veneriformis Hupé sp.

Dosinia viccntina PHrL.

Cytherca auca D'ORB. sp.

Venue egregia Puns.

?" alta PнiL.

? " insulsa Huṕ́ 
Tellina Largillierti пे Orг. Ceroniola anstralis Gans: sp. IIactra araucana $\mathrm{D}^{\circ} \mathrm{O} \mathrm{k} 1$. colossea Phit. Panopea simplex Huri:
Corbula chilensis D ORr. Teredo chilensis Pur. sp.

C. Coelenterata. Astrocoenia retifera S'Tos.

Bemerkungen zu der vorhergehenden Liste.

Die vorstehende Liste darf nicht als erschöpfend betrachtet werden. Nur ungern habe ich darin eine Reilıe von Arten PhisıppI's und GabB's aufgenommen, zu deren Nachpriifung das mir vorliegende Material nicht ausreichte. Es wird sich also sicher die Nothwendigkeit ergeben, die Liste noch einmal an der Hand weiteren Materials zu revidiren, und andererseits wird sich zweifellos auch noch eine Vermehrung der Artenzahl ergeben. Schon in der Dusex'schen Sammlung finden sich noch einige Reste, deren Erhaltungszustand eine Bestinmung und Beschreibung nicht erlaubt, wie ja auch fïr mehrere der hier angeführten Arten das Material noch durchaus ungenügend ist, und manche Frage leider noch offen gelassen werden musste. Es sind in der obigen Liste angeführt: 2 Saurier, Haifischzähne (verschiedene Arten), 11 Cephalopoden, 32 Gastropoden, 29 Lamellibranchiaten und 1 Koralle.

Die Faunen der 3 Fundpunkte Quiriquina, Tomé und San Vicente weichen im Wesentlichen nicht voneinander ab. Unterschiede machen sich dagegen wohl in der Individuenzahl einiger Arten geltend. So findet sich der Scaphites constrictus var. quiriquinensis fast nur bei Tomé, Pugnellus tumidus auf Quiriquina, ebenda Fusus difficitis weit häufiger als an den anderen Punkten, ebenso Bulla subglobosa. Diese kleinen Verschiedenheiten, die nicht auf der etwas ungleichen Materialmenge beruhen (das von San Vicente ist kleiner als von den beiden anderen Fundorten), haben wohl ihre Ursache in geringen Unterschieden der ja nicht weit auseinander liegenden Localitäten in Bezug auf die Lebensbedingungen der verschiedenen Arten.

\section{Die Beziehungen der Molluskenfauna der Quiriquina- Schichten zu derjenigen anderer Gebiete.}

Bei der Vergleichung der Quiriquina-Fauna mit derjenigen anderer Gebiete muss in erster Linie diejenige des FundN. Jahrbuch f. Mineralogie etc. Beilageband XVIII. 
punktes Algarrobo herangezogen werden. Algarrobo ${ }^{1}$ liegt bei Valparaiso, 210 Seemeilen von Quiriquina entfernt, und die Kreideformation ist dort am Meeresstrande auf $4-5 \mathrm{~km}$ Länge in einer Breite von etwa 40 Schritt aufgeschlossen und scheint unmittelbar auf Granit zu liegen. PHILIPPI lagen von dieser Localität folgende Arten vor:

Dentatium subcylindricum.

Turritella affinis

" angusta

" Landbeclii

" leptagramma

Natica globula

Gastridium retusum

Fusus heterocychus

Pymla scalaris

Pleurotoma acutinoda

Actaeon Landbecki

Nucula angusta

Trigonia Hanetiana

Lucina subpentagona

Cardium acuticostatum
Cardium hualpense

Vemis alta

\section{Landbecki}

" obliquatum

, Landbecti

" subsulcata

Tellina algarrobensis

:, complanata

"Landbectii

Pholadomya Landbecti

, obcsa

Solen clytron

Mactra simplex

.. subangulata

" scolia ${ }^{2}$.

Von diesen Arten sollen 6, nämlich

Turritella affuis

$$
\text { , angusta }
$$

Pleurotoma acutinocla
Tellina complanata

Solen elytron

Mactra simplex

in Tertiär vorkommen. Dass diese Angabe unrichtig ist, hat Steinmann ${ }^{3}$ nacligewiesen.

Folgende 7 Arten finden sich nach PhiLippi sowohl bei Algarrobo wie auch bei Concepcion:

Natica globula

Trigonia Hanetiana

Cardium acuticostatum $"$ hualpense

\section{Cardium Landbecki obliquatum \\ Solen elytron.}

1 Philıppi, Tert. quart. Verst. Chiles. p. 11.

${ }^{2}$ Diese Liste dürfte sich vielleicht auch noch etwas verkürzen. Tellina Landbecki und T. complanata sind z. B. höchst wahrscheinlich rechte und linke Klappen derselben Art. Mactra subangulata und Lucina subpentagona sind zweifelhaft. Dass die drei Arten Venus wahrscheinlich nur eine sind, wurde schon p. 113 erwähnt.

3 Auftreten und Alter der Quiriquina-Schichten. p. 23, 24. SteinmaxN erwähnt Pleurotoma acutinoda nicht. Doch diirfte auch diese Art nicht beiden Furmationen angehören. 
Von diesen müssen Solen elytron, eine ganz dubiöse Art (s. p. 270), und Curdium obliquatum (s. p. 235)) gestrichen werden. Da Phnsres die wahre Gestalt des C. acuticostalum offenbar nicht bekannt war, so kann auf die Angabe, diese Art käme bei Algarrobo vor, kein Gewicht gelegrt werden. Ebensowenig auf C. hualpense. Natica-Arten sind wenig charakteristisch, es bleibt also nur die Trigonia Hunetion als gemeinsame Art. Diese ist ja allerdings charakteristisch genug, und man darf wohl annehmen, dass PHurpr sie richtigr erkannt hat. Die Gleichaltrigkeit der Schichten von Algal'robo mit denjenigen von Quiriquina wäre damit bewiesen. Es muss aber doch noch einmal betont werden, dass die Fauna voln Algarrobo sehr verschieden von der von Quiriquina ist, und dass also, wenn nicht eine zeitlich verschiedene, so doch eine locale, selı abweichende Fauna rorliegt 1.

Der wichtigste Schritt zur Kennzeichnung der stratigraphischen Stellung der Quiriquina-Schichten ist zweifellos bereits mit Steinmann's Arbeit über die Cephalopoden dieser' Ablagerungen gethan. Im Folgenden können nur kleine Ergänzungen dazu geliefert werden. Der Werth der Cephalopoden als Leitfossilien übertrifft ja den der Lamellibranchiaten und Gastropoden um ein Beträchtliches. Besonders die letzteren pflegen sich local eigenartig zu entwickeln, und nicht in ihren Species, sondern nur in ihren Gattungen und Gruppen kann man die faunistische Verwandschaft verschiedener Gebiete sich wiederspiegeln sehen.

Auf den folgenden Tabellen sind die Arten zusammengestellt, mit denen wir die Arten der Quiriquina-Fauna verglichen haben. Anfgeführt sind nur diejenigen Species, ron denen vollständige Exemplare vorliegen, und die deshalb gut charakterisirt sind.

1 Die Fauna von Algarrobo scheint sich zum grossen Theil in einem schlechten Erhaltungszustand zu befinden. - Das Dusex'sche Jaterial enthält wenig Fossilien, die denen von Algarrobo ähnlich sind. Die grosie Cytherea von 'Tomé älnnelt allerdings sehr der Veuus subsulcala PHrL., und ebenfalls von Tomé liegt der Steinkerı einer Nucula vor, der Ähnlichkeit mit Nucula angusta hat. Die Fama ron Algarrobo weist aber mehrere Gattungen auf, die Quiriquina fehlen. 
276 O. Wilckens, Revision der Fauna der Quiriquina-Schichten.

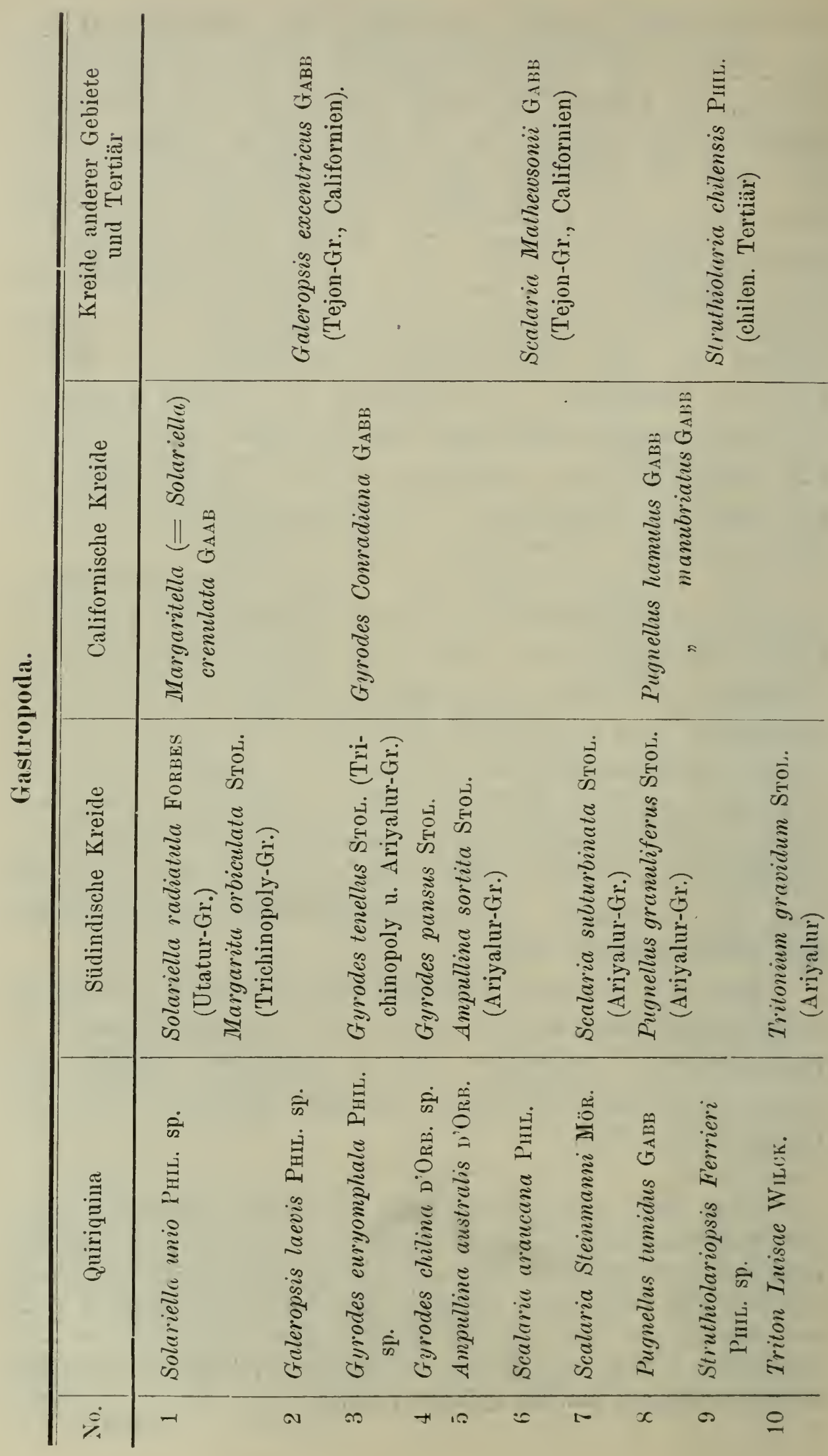




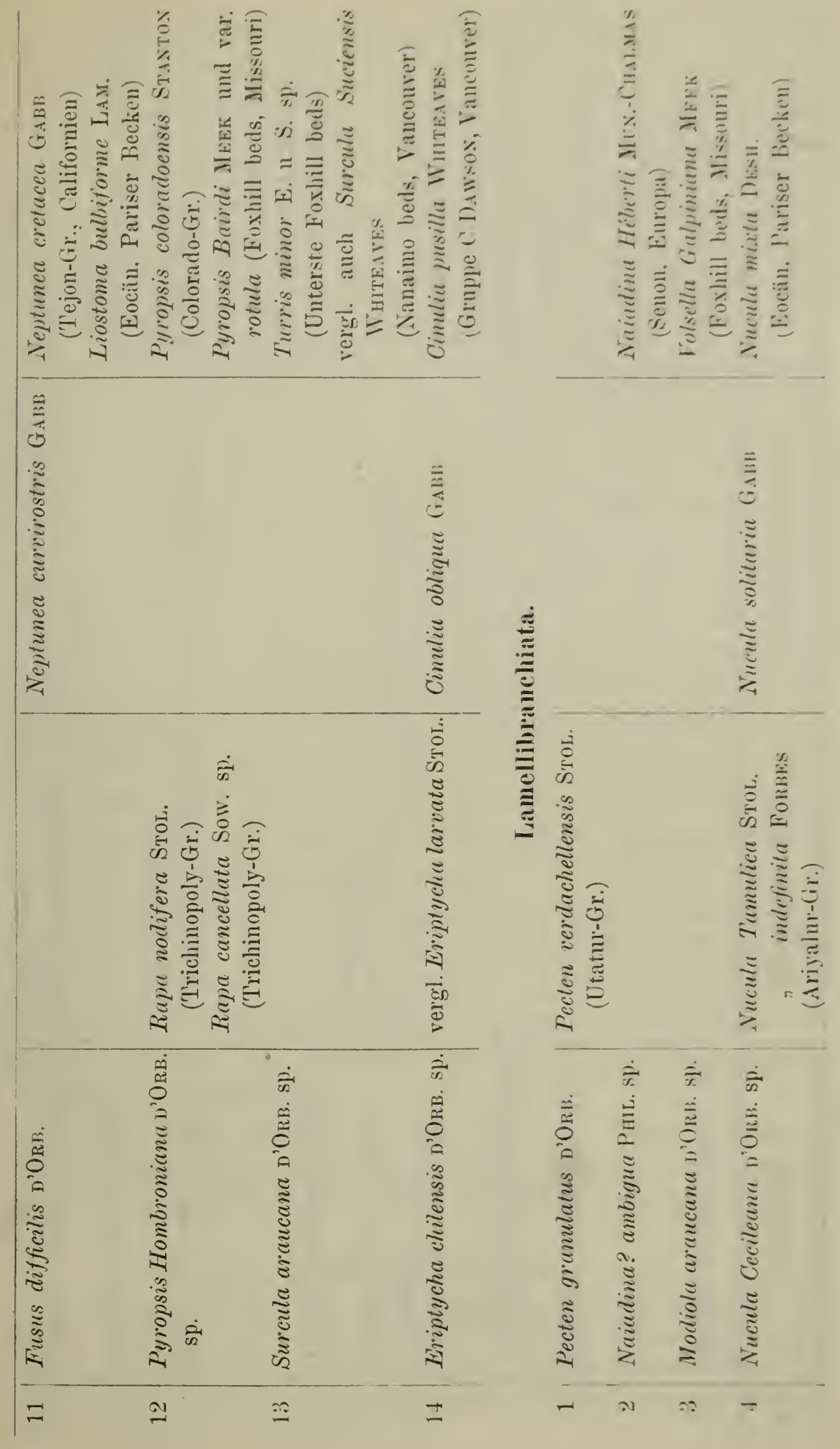


278 0. Wilckens, Rerision der Fauna der Quiriquina-Schichten.

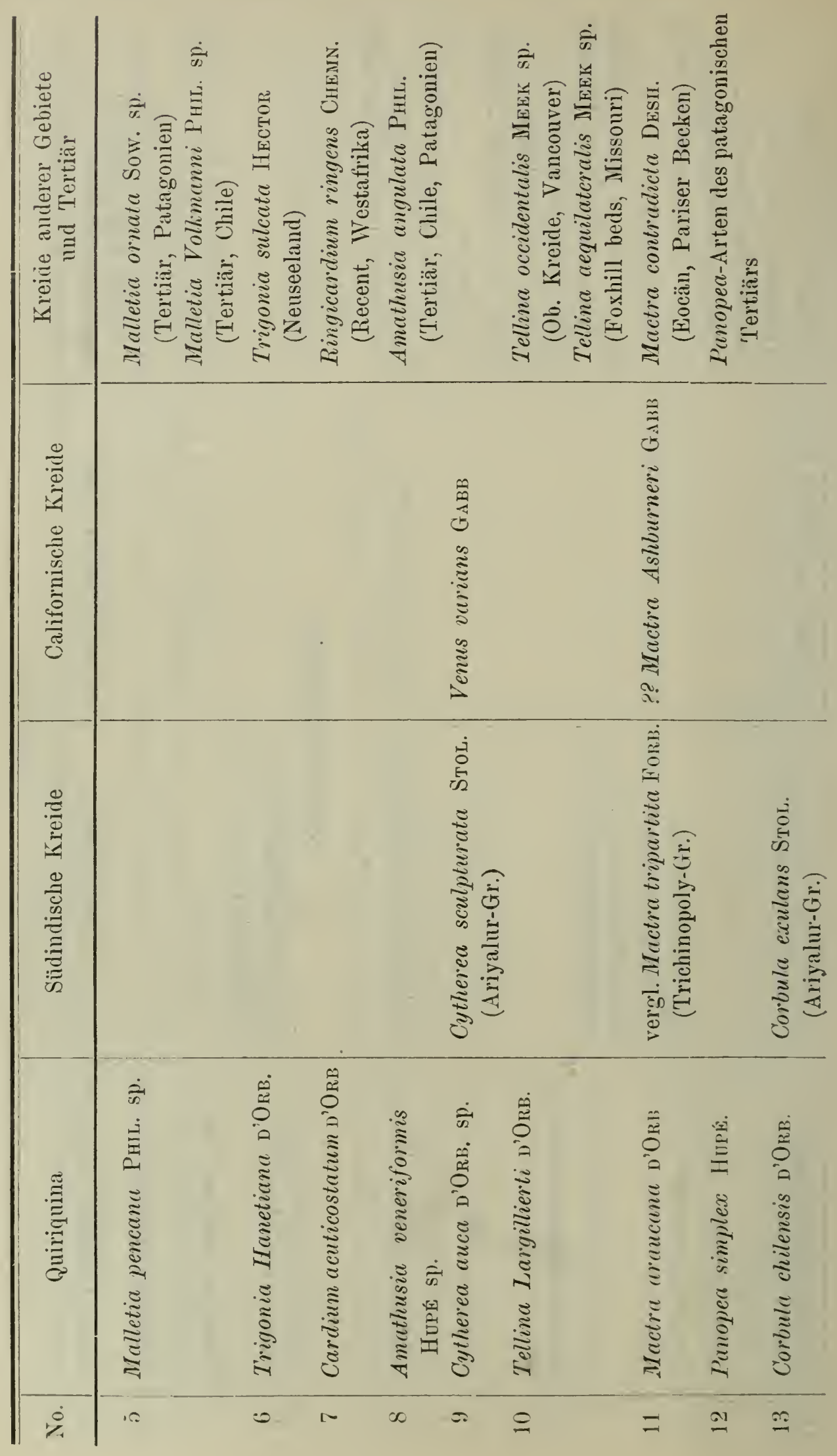


Der pacifische Charakter der Fauna der Quiriquina-Schichten steht fest, seitdem STEINmaxn die chilenischen Cephalopoden mit den indischen theils identificiren, theils parallelisiren konnte. Andererseits lassen sich die Beziehungen zum norddeutschen Senon, für die die Auffindung des Scaphites constrirtus var. quiriquinensis ein neuer Beweis ist, nicht verkennen.

Stenmaxy vergleicht 3 Gastropoden von Quiriquina" "mit anderen Schnecken der pacifischen Region ${ }^{1}$. P'ugnellus uncutus kommt aber wahrscheinlich nicht in den Quiriquina-Schichten vor. Cinulia pusilla WhrTeaves ist zun näheren Vergleich mit der Eriptycha chilensis wegen ihrer mangelhaften Erhaltung nicht so sehr geeignet wie Cinulia obliqua GaBs, und endlich stehen der Pyropsis Hombroniana D'OrB. die nordamerikanischen Pyropsis-Arten aus den Foxhill beds näher als die indischen aus der Trichinopoly-Group. Es wäre noch hinzuzufügen, dass die Gattung Pugnellus sehr charakteristisch für das Senon, und speciell auch gerade für das pacifische Senon ist. Die Gattung taucht zwar in der Colorado-Group Nord-Amerikas auf (die sich etwa mit dem T'uron parallelisiren lässt), erreicht aber im Senon ihre grösste Entwickelung, so in Indien und Californien ${ }^{2}$. Unter den Muscheln fand sich eine nahe Verwandte von Cytherea auca in der indischen C. sculpturata und Mactra araucana zeigte Beziehungen zu californischen und indischen Formen.

Die Kenntniss der verschiedenen Gebiete der pacifischen Kreide ist eine sehr ungleichartige und vielfach noch recht lückenhafte. Ist sie auch genügend, um die stratigraphische Stellung der Quiriquina-Schichten genan zu präcisiren, so genügt sie doch noch nicht, um ïberall palaeontologische Vergleiche durchzuführen.

Von keiner Region gilt dies mehr als von Neu-Seeland, dessen Mesozoicum in palaeontologischer Hinsicht eine wahre terra incognita ist. Der kleine Katalog von Hғctor zur

${ }^{\imath}$ Auftreten und Alter der Quiriquina-Schichten. p. 27.

${ }^{2}$ Erinnert sei auch noch einmal an die Conchothyra parasitica aus der Cretaceous tertiary formation Hecton's, die im Wesentlichen obere Kreide sein dürfte. - Die von Noetcing aus der oberen Kreide ron Belutschistan beschriebenen Pugnellus-Arten weichen in ihrem Habitus einigermaassen von den pacifischen ab. 
neuseeländischen Abtheilung der Colonial-Ausstellung in London $1886^{1}$, den Steinmann bereits zur Vergleichung mit der Quiriquina-Fauna herangezogen hat, bildet neben ZiтteL's Untersuchung der von der Novara-Expedition gesammelten Fossilien beinahe die einzige Literatur über diesen hochwichtigen Gegenstand ${ }^{2}$. Herr Prof. Georg Böнm, der vor wenigen Jahren Neu-Seeland bereiste, hat sich vergeblich bemüht, die Originale zu den Hector'schen Abbildungen ausfindig zu machen oder überhaupt irgendwelche grössere Sammlung mesozoischer Fossilien - die der Geological survey nicht ausgenommen - zu sehen oder irgendwelche nähere Auskunft über diese merkwürdigen Fossilien, wie Trigonia sulcata HzстоR, zu erhalten ${ }^{3}$. Die ganze cretaceisch-tertiäre Formation Hector's, in der sich ein buntes pêle-mêle von Kreide- und Tertiärfossilien nebst jurassischen und recenten Pflanzenformen finden soll, ist jedenfalls mehr als zweifelhaft.

Auch die californische Kreide ist leider zu einem Vergleich mit den Quiriquina-Ablagerungen nur schwer heranzuziehen. Ihre Erforschung ist viele Irrwege gegangen, und noch immer ist manche Frage ungelöst, deren Beantwortung die nothwendige Voraussetzung wäre, wenn man die californische Kreide mit Erfolg zu stratigraphischen Vergleichen gebrauchen wollte. Dass die Chico-Formation Kreide, die TejonFormation Eocän ist, steht jetzt fest; aber in allen Einzelleiten versagt die bis jetzt vorliegende Literatur noch vollständig.

Die Chico- und Tejon-Serie war von CoNraD als tertiär, von GABB als Kreide bezeichnẹt. Dann erklärte WhiтE ${ }^{4}$,

1 Detailed catalogue and guide to the geological exhibition by JAMES Hector. Indian and colonial exhibition. New Zealand Court. 1886. London.

${ }^{2}$ Die Quiriquina-Schichten enthalten eine litorale Fauna und wemn es sich herausstellte, dass Neuseeland ganz nah verwandte litorale Formen birgt, so würde damit der Beweis geliefert sein, dass schon zur Zeit der oberen Kreide die Verbindung zwischen Südamerika und Patagonien existirte, die bei der Bildung ron Ablagerumgen der "patagonischen" Formation zur Miocänzeit sicher vorhanden war. (Vergl. OrTMass, Rep. Princ. Univ. 4. 2. p. 315.)

${ }^{3}$ s. Zeitschr. d. deutsch. geol. Ges. 52. (1900.) p. 171 ff. Eine baldige Änderung dieser Zustände steht glücklicher Weise in Aussicht.

4 White, On the mesozoic and cenozoic palaeontology of California. Bull. U. S. Geol. Surv. No. 15. - Derselbe, Correlation papers. Cretaceous. Dasselbe. No. 82. 
es gäbe nur ein e Chico-Tejon-Gruppe, die einen allmählichen Übergang aus der oberen Kreide ins Eocän darstellte. Dieser Auffassung widersprechen die späteren Beobachtungen. Wir verdanken insbesondere STANтоN ${ }^{1}$ eine sehr wichtige Arbeit, in der die völlige zeitliche Verschiedenheit der Chicn- und der 'Tejon-Gruppe nachgewiesen wird. Die Chico-Group ist obercretaceisch, das 'Tejon eocän. Unter der Chico- liegt die Shasta-Group und nach Dilder und Stantox ${ }^{2}$ bilden beide zusammen eine continuirliche Formationsreihe. Dagegen weist Fairbanks ${ }^{3}$ in der californischen Coast Range eine Discordanz zwischen den Horsetown beds (obere Shasta) und der ChicoSeries nach. Es scheinen danach an verschiedenen Stellen recht verschiedene Verhältnisse vorzuliegen. Nach Dilukr und Stanton schliesst die Shasta-Chico-Series die ganze Kreide in sich. Nur das oberste Senon soll fehlen, weil in der obersten Chico-Group noch Schloenbachien vorkommen, die in Europa nicht über das Unter-Senon hinausgehen. Später weist STANToN ${ }^{4}$ aber doch auf die Ähnlichkeit hin, welche die Fauna der oberen Chico-Group mit derjenigen des oberen Senons Süd-Indiens zeigt. Damit würde die Auffassung White's, del' die Chico-Gruppe als oberstes Senon betrachtet, wieder zur Geltung kommen. Übrigens wird ja auch der Nanaimo-Group der canadischen pacifischen Kreide diese Stellung angewiesen. und der Parallelismus dieser Ablagerung mit dem oberen Chico ist nie angezweifelt worden ${ }^{5}$. Vergeblich sucht man aber in der amerikanischen Literatur nach Einzelheiten. Eine

1 Stanton, The faunal relations of the Eocene and Cretaceons on the pacific coast. 17. Ann. Rep. U. S. Geol. Surv. Part I. p. 1011 ff. 1896. Stanton führt in dieser Arbeit den Nachweis der famistischen Verschiellenheit von Chico und Tejon, sowie des eocänen Alters des letzteren.

${ }^{2}$ Diller and Stanton, The Shasta-Chico-Series. Bull. Geol. Soc. Amer. 5. p. 435 ff. 1894.

${ }^{3}$ Fainbanks, Geology of the southern coast ranges. Journ. of Geol. 6. (1898.) p. $560 \mathrm{ff}$.

4 The faunal relations of the Eocene and Cretaceous on the pacific coast. p. 1034.

$5 \mathrm{~s}$. White, Invertebrate fossils from the pacific coast. - U. S. Geol. Surv. Bull. No. 51. p. 34 findet sich eine Liste der gemeinsamen Arten aus der Chico-Group Californiens und der Nanaimo-Group ron Yancouver und Sucia-Island. 
Gliederung der Chico-Group fehlt, desgleichen eine Revision ihrer Fauna und Angaben, welche Formen der oberen Abtheilung dieser Schichtenserie angehöreu. Ebenso wie eine genaue Darstellung der Tektonik, die anscheinend durchaus nicht überall sehr einfach ist, sehr zu wünschen wäre, bedürften die neu entdeckten Kreidefossilien einer sorgfältigen Beschreibung. Ein Vergleich der californischen Kreide mit anderen Kreideablagerungen ist kaum versucht. Die grosse Verschiedenheit der pacifischen Fauna von den übrigen amerikanischen wird zwar mehrfach hervorgehoben ${ }^{1}$; aber die Ähnlichkeit der Fauna des oberen Chico mit der Fauna der anderen pacifischen Gebiete ${ }^{2}$ wird nur erwähnt ${ }^{3}$, nicht im Einzelnen dargethan.

Nach der Literatur lässt sich über die californischen Verhältnisse etwa Folgendes sagen: In Californien findet sich als oberstes Glied der Kreide eine Schichtenfolge von Schiefern und Sandsteinen, die nacheinander über die Glieder der unteren Kreide und weiter nach Osten über das krystalline Gebirge bis an den Fuss der Sierra Nevada ${ }^{4}$ transgredirt ${ }^{5}$. Die Fauna dieser Ablagerungen erweist sich durch ihre Ammoniten- und Baculiten-Fauna, sowie durch typische Vertreter der Gastropoden, wie Pugnellus, Gyrodes, als ober-

1 z. B. Smith, IIesozoic changes in the faunal geography of California (Journ. of Geol. 3.) p. 382: "There seems to have been little connection with the interior region."

${ }^{2}$ Cauada ansgenommen.

${ }^{3}$ Sмiтh (Journ. of Geol. 3. p. 382): No Chico species are referred to European or Indian species, but many have near relatives in those regions. - Stanton (Faunal relations of Eocene and Cretaceous pacific coast. 17. Ann. Rep. Geol. Surv. 1896. p. 1034/35): The affinities of our west coast Cretaceous faunas are. much closer with those found on the opposite side of the Pacific in southern India, Japan and Saghalien (- Sachaliu) than with other Cretaceous famas in the Uniterl States [and the ammonitic types above mentioned range up into beds in India, that are regarded as very late Cretaceous by European palaeontologist's]. (Die Kreide von Sachalin ist nach MrснneL (Jahrb. d. k. prenss. geol. Lanilesanst. 19. 1899) Untersenon.)

4 Diller, Cretaceous and early tertiary of north California. Bull. Geol. Soc. Amer. 4. p. 206.

${ }^{5}$ Es ist ja auch für die Quiriquina-Schichten charakteristisch, dass sie transgrediren. 
cretaceisch, und hat einen pacifischen Charakter, der sie meh. der indischen und der Quiriquina-Fauna nähert als den anderen amerikanischen Kreidebildungen.

Eine Liste ron Chico-Fossilien, die Aswersox ${ }^{1}$ von einer Localität in Oregon giebt, in der Phylloceras ramosum rorkommt, zeigt viele Arten oder doch Genera, die nahe Beziehungen zu denen der Quiriquina-Schichten haben; so Cinulia, Gyrodes, Largaritella. Auch Scaphiten werden angegeben.

Über die Fossilien der pacifischen Kreide in BritischColumbien ${ }^{2}$ verdanken wir WInTEaves sehr sorgfältige Untelsuchungen. Die Nanaimo beds von Vancouver Island sind das Aequivalent der oberen Chico-Group und weisen in ihrem Faunencharakter manche Ähnlichkeit mit den Quiriquina-Schichten auf. Wie diese transgrediren sie im sitdlichen Tancouver ïber krystalline Formationen. Besonder's die Cephalopoden beweisen die Verwandtschaft mit der suidindischen und chilenischen Kreide. Dass in der canadischen Kreide Formen aus der Interior region der Vereinigten Staaten vorkommen, erklärt Kossiat durch eine Verbindung von vorübergehender Dauer zwischen dem Atlantischen und dem Pacifischen Ocean. In der Chico-Group fehlt, wie Kossuat hervorhebt, das atlantische Faunenelement ganz.

Die indische Kreide ${ }^{3}$ besitzt in der Ariyalur-Group einen Schichtencomplex von weitgehender Ähnlichkeit in Bezug auf Fauna und Auftreten. Auch die Ariyalur-Group transgredirt. Ihre Cephalopodenfauna weist 4 mit Quiriquina gemeinsame Arten auf. Unter den Gastropoden sind in beiden Gebieten

1 Anderson, Some cretaceous beds of Rogue River Valley, Oregon. Journ. of Geol. 3. p. 460.

2 Die Verbreitung derselben ist gut zu iibersehen auf dem westlichen Blatt der Geol. map of the dominion of Canada. 50 miles to 1 inch. Edition of 1901.

${ }^{3}$ Vergl. dazu Kossmatr, Die Bedeutung der siidindischen Kreileformation für die Beurtheilung der geographischen Verhältnisse während der späteren Kreidezeit (Jahrb. k. k. Reichsanst. 1894. 44. p. 471, 472) und: Kossmat, The cretaceous deposits of Poudicherri (Rec. Geol. Surr. Ind. 30. 1897. p. 72, 73). - Als Localitäten äquivalenter Bildungen zïhlt Kossuat hier anf: Natal, Madagascar, Assam, Borneo, Yesso, Vancourer, Quiriquina. Kossmat fiigt hier also Californien nicht ein, während er es in der ersteren Schrift mit zum Vergleich heranzieht. 
Pugnellus, Gyrodes, Pyropsis, Eriptycha charakteristisch, und die Lamellibranchiaten zeigen $z$. Th. nahe Verwandtschaft, wie die Cytherea auca mit C. sculpturata StoL. und Mactra araucana und M. tripartita STOL.

Dass ein Meer alle diese Regionen ähnlicher Faunenentwickelung an der Umrandung des Stillen Oceans verbunden haben muss, ist danach offenkundig. Es überfluthete zur späteren Senonzeit seine Küsten und schuf an ihnen Ablagerungen von der Art der Quiriquina-Schichten. Die Fauna derselben hat demn auch durchaus pacifischen Charakter. Gleichwohl fehlen Anklänge an die atlantische Region nicht vollständig, doch diurfte eine Verbindung in dieser Richtung vielleicht eher vor der Ablagerung der Quiriquina-Schichten, als während derselben bestanden haben. Auf diese Weise dürften sich die Anklänge an die Missourifauna erklären, - wemn so allgemeine Ausdrücke eine Erklärung genannt werden dürfen. Auch die Beziehungen zu Nord-Europa werden sich erst nach weiteren Entrleckungen und Studien genauer darthun lassen. Steinmans hat auf die Wahrscheinlichkeit einer Communication zwischen dem Pacifischen und dem Atlantischen Ocean über das nördliche Asien hingewiesen, Kossuat möchte eher an einen Faunenaustausch um Süd-Afrika herum glauben.

Nachkommen der Quiriquina-Fauna finden sich im patagonischen Tertiär. Noch ein wichtiges Problem liegt in ihren Beziehungen zu.der eocänen Fauna Mittel-Europas, in der es manche ähnliche Arten giebt, eines der merkwürdigsten aber in dem Vorhandensein von Nachkommen der chilenischen Senonfauna in der recenten Thierwelt West-Afrikas, wofiir Cardium ringens nicht das einzige Beispiel sein dürfte. 

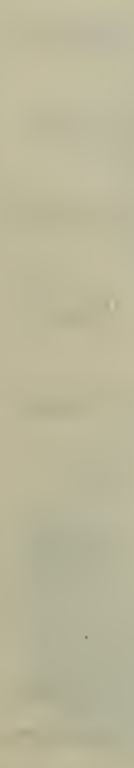

7 


\section{Tafel-Erklärungen.}

Die Originale zu den Abbildungen befinden sich, wo nicht ein Anderes ausdriicklich bemerkt ist, im Geologischen Institut der Universität Freiburg.

Quir. = Quiriquina, San Vic. = San Vicente.

\section{Tafel XVII.}

Fig. 1 a. Lamna sp. Zahn. Die IVurzel ist z. Th. ergänzt. Quir.

„1b. Derselbe von dẹr Seite.

"2. Otodus At. sp. Quir.

"3. Scaphites constrictus Sow. var. quiriquinensis WiLck. Grösstes Exemplar. Schale z. Th. beschädigt. San Vic.

" 3 a. Dasselbe, gegen die Iündung gesehen.

" 3 b. Dasselbe, gegen die Externseite gesehen.

"4. Scaphites constrictus Sow. var. quiriquinensis WILCK. Jüngeres Exemplar. Tomé.

"5. Scaphites constrictus Sow. rar. quiriquinensis Wruck. Unvollständiges Exemplar. Tomé.

"6. Scaplutes constrictus Sow. var. quiriquinensis WiLck. 'Tumé. Längsdurchschnitt.

„ 7. Scaphites constrictus Sow. var. quiriquinensis WILck. Tomé. Querdurchschnitt.

8. Scaphites constrictus Sow. var. quiriquinensis Wrluck. Tomé. Lobenlinie. $\times 10$.

9 a. Galeropsis laevis PHIL. sp. Quir.

" 9 b. Galeropsis laevis PhiL. Junges Exemplar, von oben gesehen. Quir. Die oberen Windungen sind abgebrochen.

"10a. Gyrodes euryomphala Phil. Tomé. Von der Seite gesehen.

$10 \mathrm{~b}$. Dasselbe, gegen den Nabel gesehen (bei senkrecht gestellter Axe des Gehäuses). In der Mündung liegen zwei kleine Scaphites constrictus var. quiriquinensis.

" 11 a. Ampullina australis D'OrB. Quir. Gegen die Iündung.

11 b. Dasselbe, von oben gesehen.

"12. Ampullina australis D'OrB. Quir. Umrisszeichnung eines anderen Exemplars, un die wechselnde Gestalt des Nabels zn zeigen. 
N. Jahrb. f. Mineralogie etc. Beil.-Ed, XVIII.
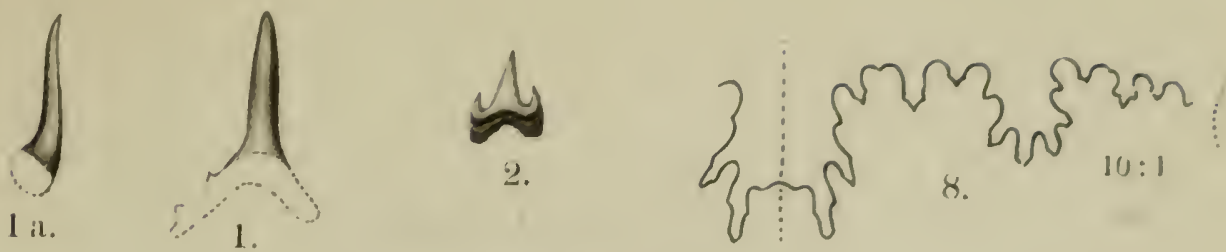

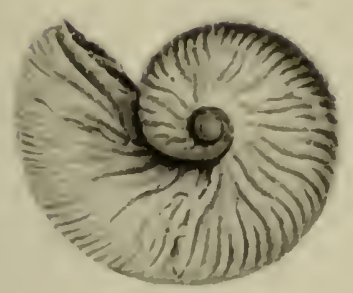

4.

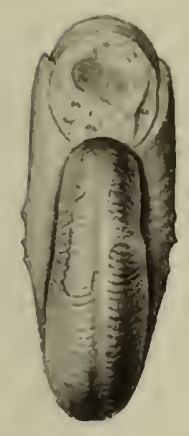

$3 \mathrm{a}$.
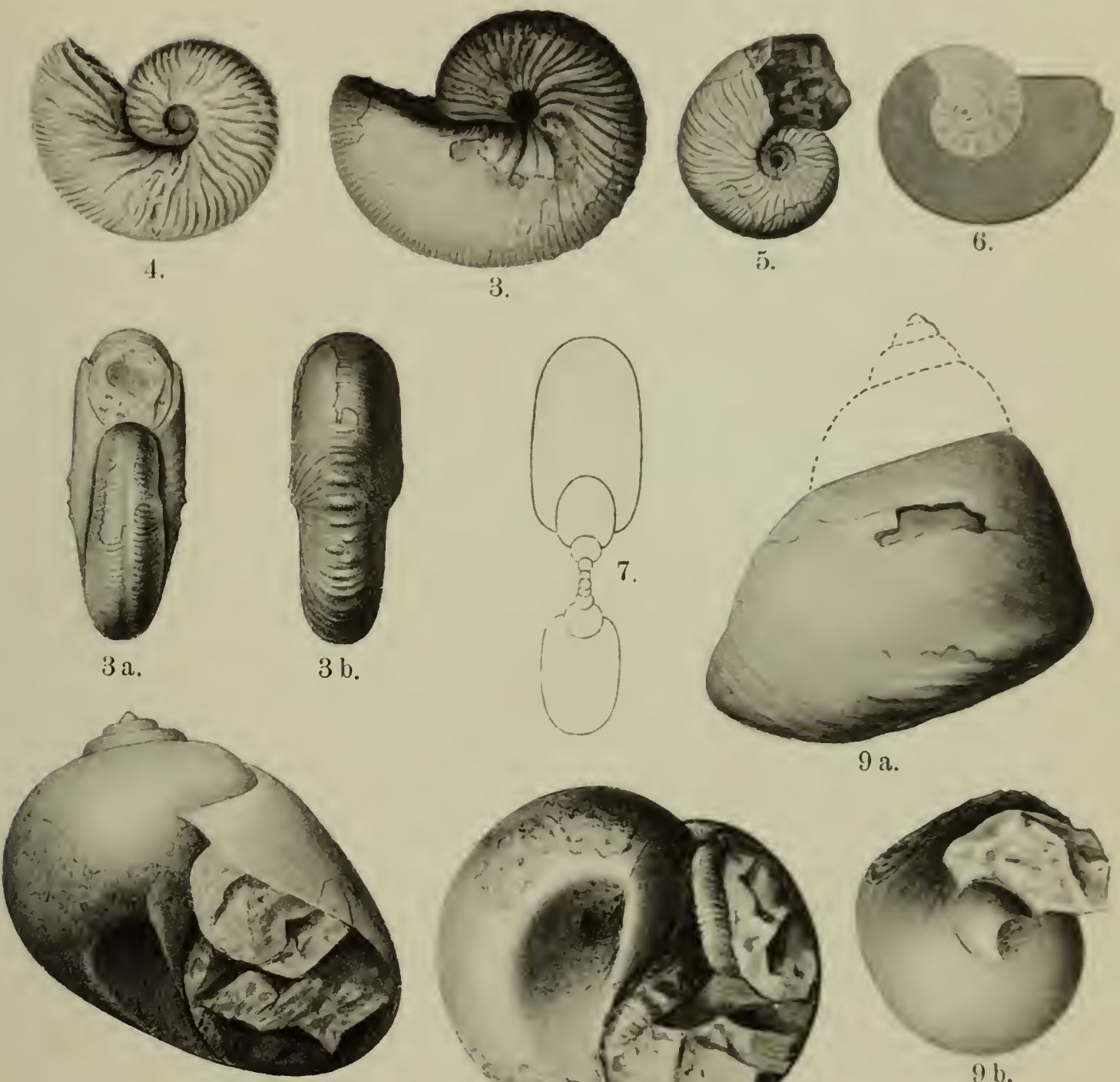

9 a.
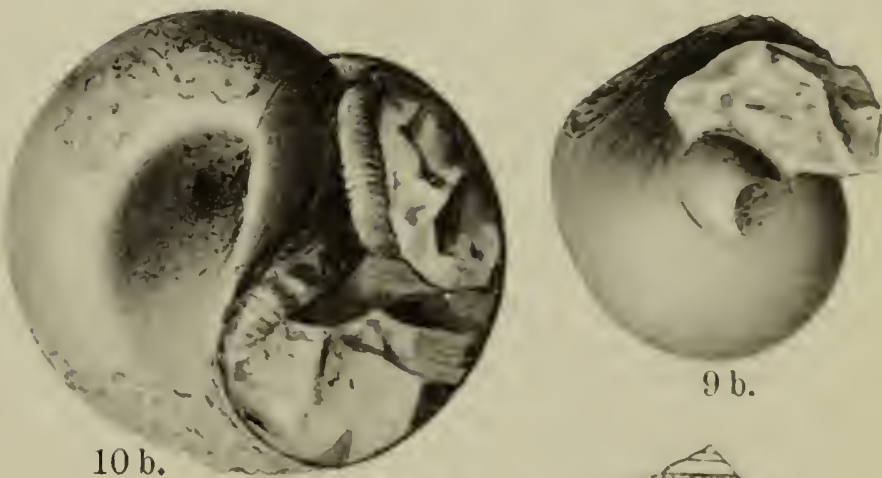

$9 \mathrm{~b}$.

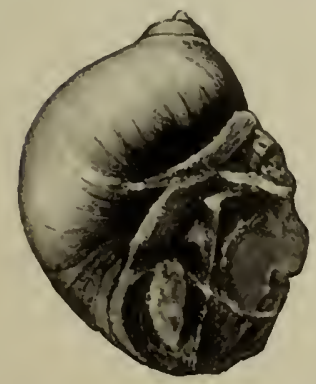

$11 \mathrm{a}$.

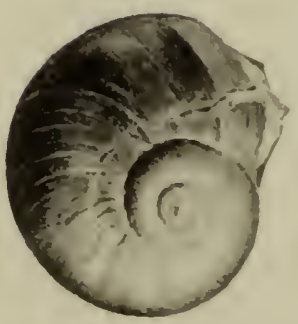

$11 \mathrm{~b}$.

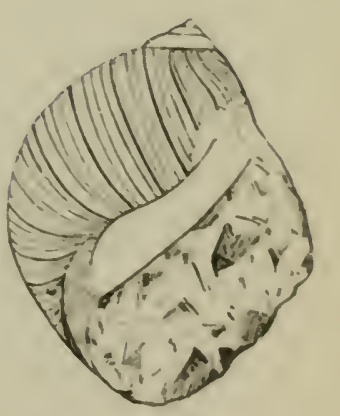

12.

Wilckens. Fauna der Quiriquina-Schichten. 

. 


\section{Tafel XVIII.}

Fig. 1. Scalaria araucana PHIL. Quir.

"2a. Pugnellus tumidus Gabb. Quir.

" 2 b. Dasselbe, gegen die Mündung gesehen.

"3a. Conchothyra parasitica IIc Coy. Waipara-Formation, Australien.

\# 3 b. Dieselbe, gegen die Mündung gesehen.

"4. "Chenopus?" fenestratus PHiL. Quir.

, 5. Struthiolariopsis Ferrieri PHIL. sp. Tomé.

"6a, b. Fusus difficilis D'Orb. Junge Exemplare. Quir.

"7a. Triton Luisae Wilck. Tomé. $\times 2$.

" $7 \mathrm{~b}$. Derselbe, gegen die Mündung gesehen.

* 8. Pyropsis Hombroniana D'Orb. (Der Canal ist abgebrochen.) Quir. Aus der Sternuann'schen Sammlung im Geol. Institut der Universität Strassburg.

9. Pyropsis Hombroniana D'ORB. Jüngeres Exemplar. Quir.

" 10 a, b. Eriptycha chilensis D'Orb. sp. San Vic. $\times \frac{5}{3}$.

"11. Bulla subglobusa PHIL. Quir.

12. Dentalium chilense D'Orв. Tomé.

13. Dentalium sp. Quir. 


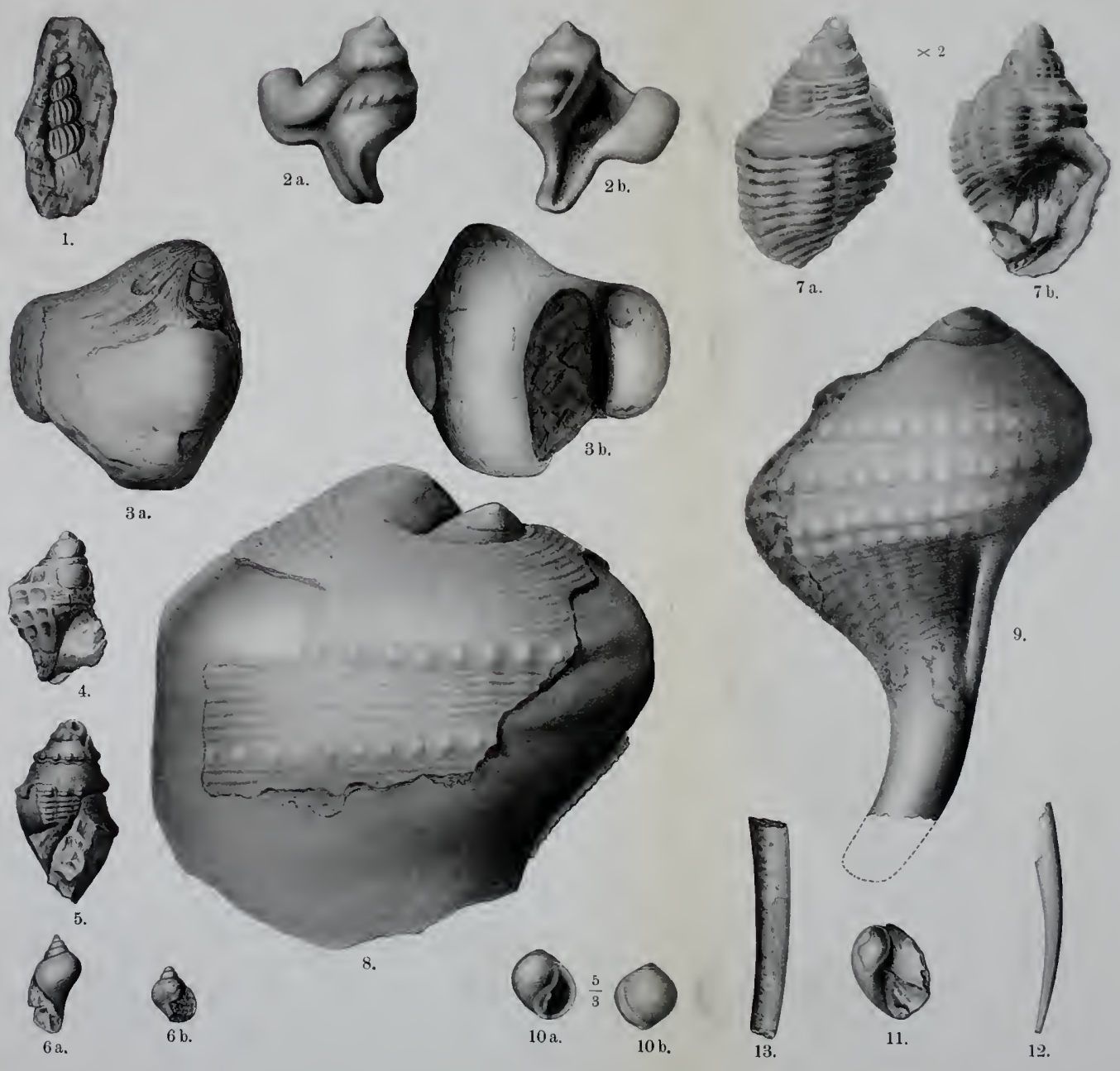






\section{Tafel XIX.}

Fig. 1. Naiadina? ambigua PHIL. sp. Rechte Klappe. Quir.

» 2. Naiadina? ambigua PHiL. sp. Linke Klappe. Quir.

"3. Ostrea sp. Quir. Sammlung Steinmans im Geol. Institut der Universität Strassburg.

4. Modiola araucana D'OrB. sp. Toiné.

. 5. Nucula Cecileana D'Orв. sp. Tomé.

" 6. Malletia pencana Phis. sp. Linke Klappe. Quir.

"7. Cardium acuticosiatum D'Orb. Schloss der linken Klappe (stark beschädigt). San Vic.

^ 8. Cardium acuticostatum D'ORB. Schloss der rechten Klappe. San. Vic.

9. Cardium acuticostatum D'Orb. Steinkern. Sammlung StenNand im Geol. Institut der Universität Strassburg. (Die beiden Ausgüsse der Einkerbungen des Schalenrandes sind ergänzt nach einem Exemplar von Tomé.)

"10. Cardium acuticostatum D'OrB. Stïck der Schale von innen. San Vic.

"11. Ringicardium ringens Chems. Linke Klappe. Westafrika. Lebend. 12. Cytherea auca D'OrB. sp. Schloss der rechten Klappe. San Vic. 13. Cytherea auca D'ORB. sp. Schloss der linken Klappe. San Vic.

14. Cytherea auca D'OrB. sp. Steinkern. Sammlung Steinmann in Geol. Institut der Universität Strassburg.

" 15. Cytherea sp. (s. p. 247 Anm. 2). Tomé. 


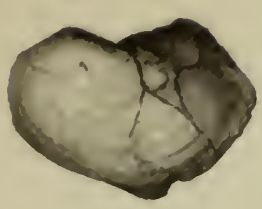

1.
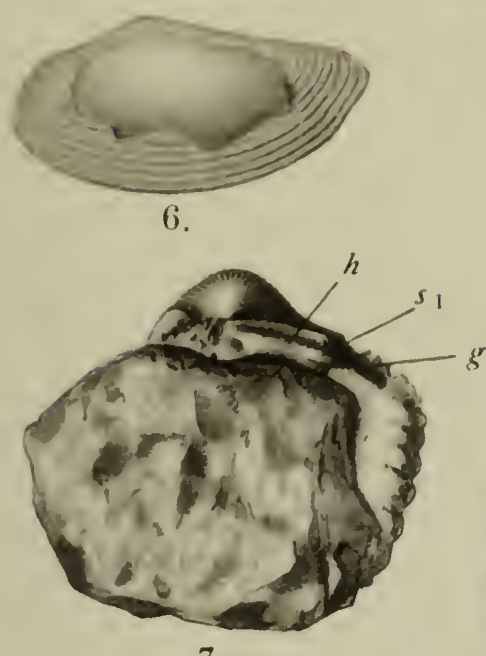

7.

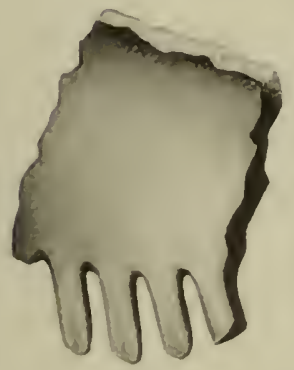

10.

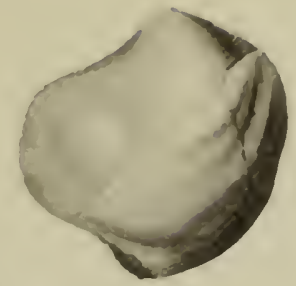

2.

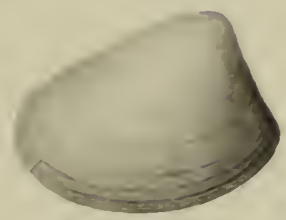

5.
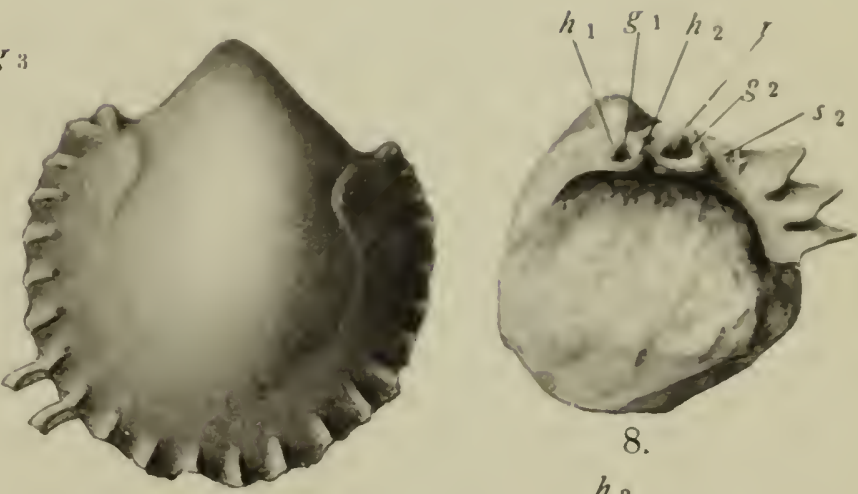

8.
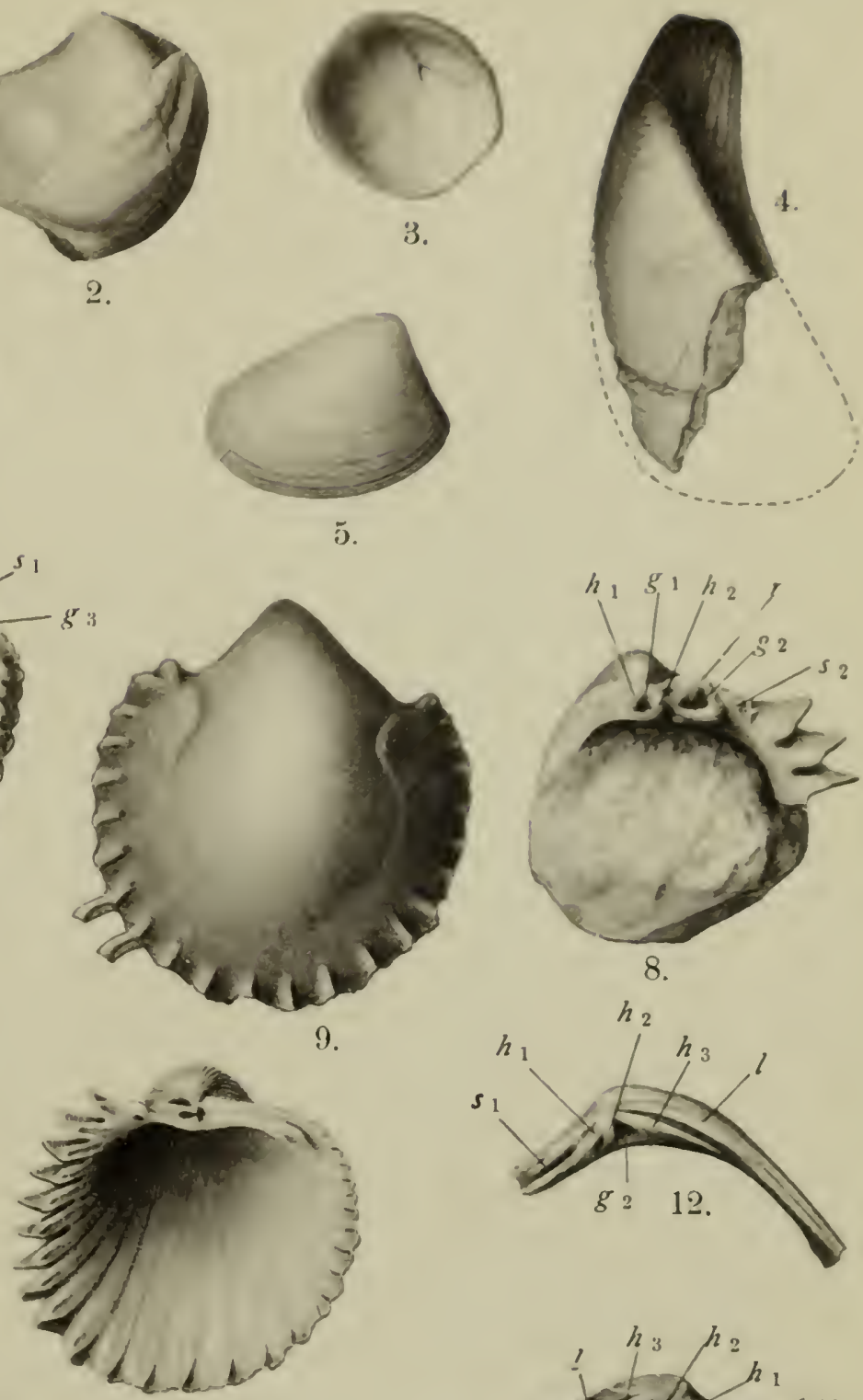

11.

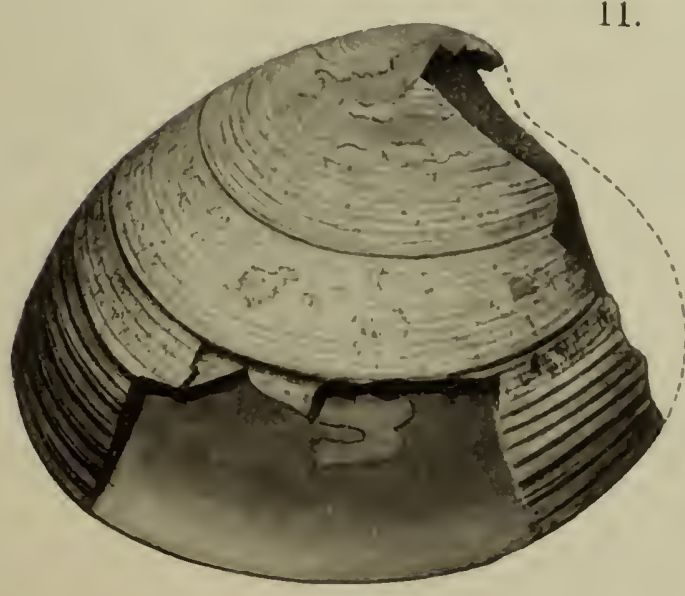

15.

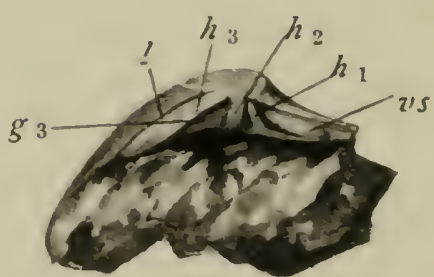

13.

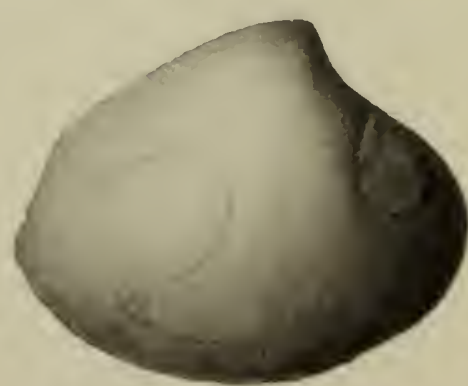

14.

Lichsdruck der Hofkunstanstalt von Martin Kommel \& Cu., Htuttgare

Wilckens: Fauna der Quiriquina-Schichten. 



$$
-
$$




\section{Tafel XX.}

Fig. 1. Amuthusia veneriformis Hupé sp. Rechte Klappe. Quir.

"2. Amathusia veneriformis Hupé sp. Linke Klappe. San Vic.

"3. Amathusia veneriformis HuPÉ sp. Rechte Klappe, gegen den Wirbel gesehels.

" 4. Amathusia angulata PHIL. Patagonien. 'Tertiär. $\frac{1}{2}$ der natürl. Grösse. Nach zwei Exemplaren aus einer Sammlung Hauthal's, z. Z. in Freiburg i. B.

"5. Mactra araucan D'Orb. Steinkern eines jungen Exemplars. Quir.

* 6. Mactra araucana D'Orв. Schloss der rechten Klappe. Quir.

"7. Mactra araucana D'Orв. Schloss der linken Klappe. Quir.

" 8. Mactra colossea PHis. Schloss der linken Klappe. Quir.

" 9. Mactra colossea Phil. Schloss der rechten Klappe eines jïngeren Exemplars. Quir.

" 10. Panopea simplex Hu'É. Nach zwei Exemplaren combinirt. Quir. 11 a. Ceroniola australis GabB sp. Schloss der linken Klappe. Quir. 11 b. Ceroniola australis GABB sp. Schloss der rechten Klappe. Quir. 12. Ceroniola austr lis GABB sp. Nach mehreren Exemplaren combinirt. 13. Ceroniola australis GABB sp. Linke Klappe gegen den Wirbel gesehen. Quir.

Die Zeichnungen sind sämmtlich von Herm TH. Johnsen in Freiburg i. B. gezeichnet, ausser Taf. I Fig. 8 und Taf II Fig. 10, die von Herrn Universitätszeichner Schilling daselbst angefertigt sind.

Grösse natïrlich, wo nicht anders bemerkt. 


$$
\text { . }
$$


N. Jahrb. f. Mineralogie etc. Beil.-Bd. XVIII.

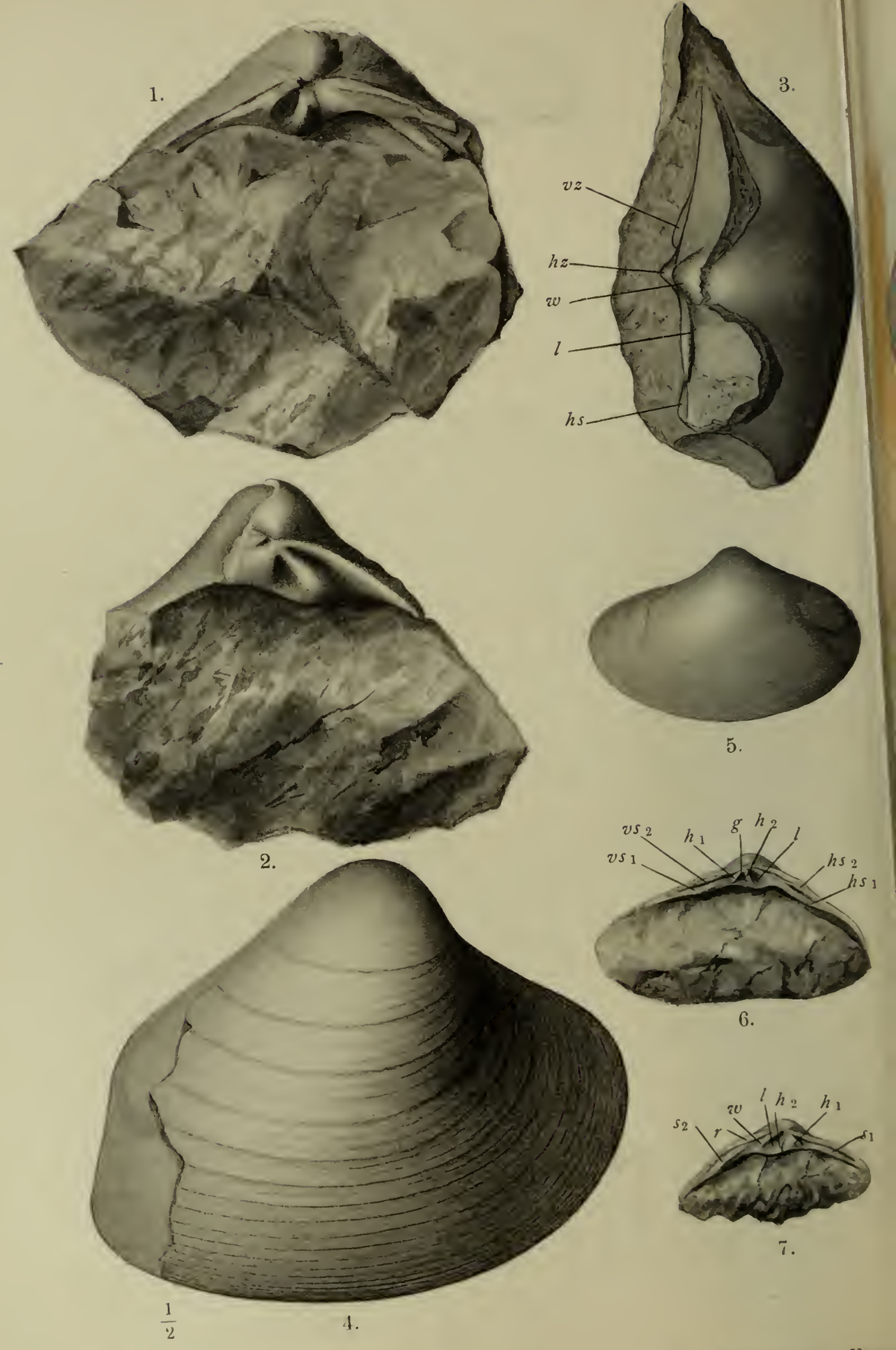

Otto Wilckens: Faun 
'Tap. XX.
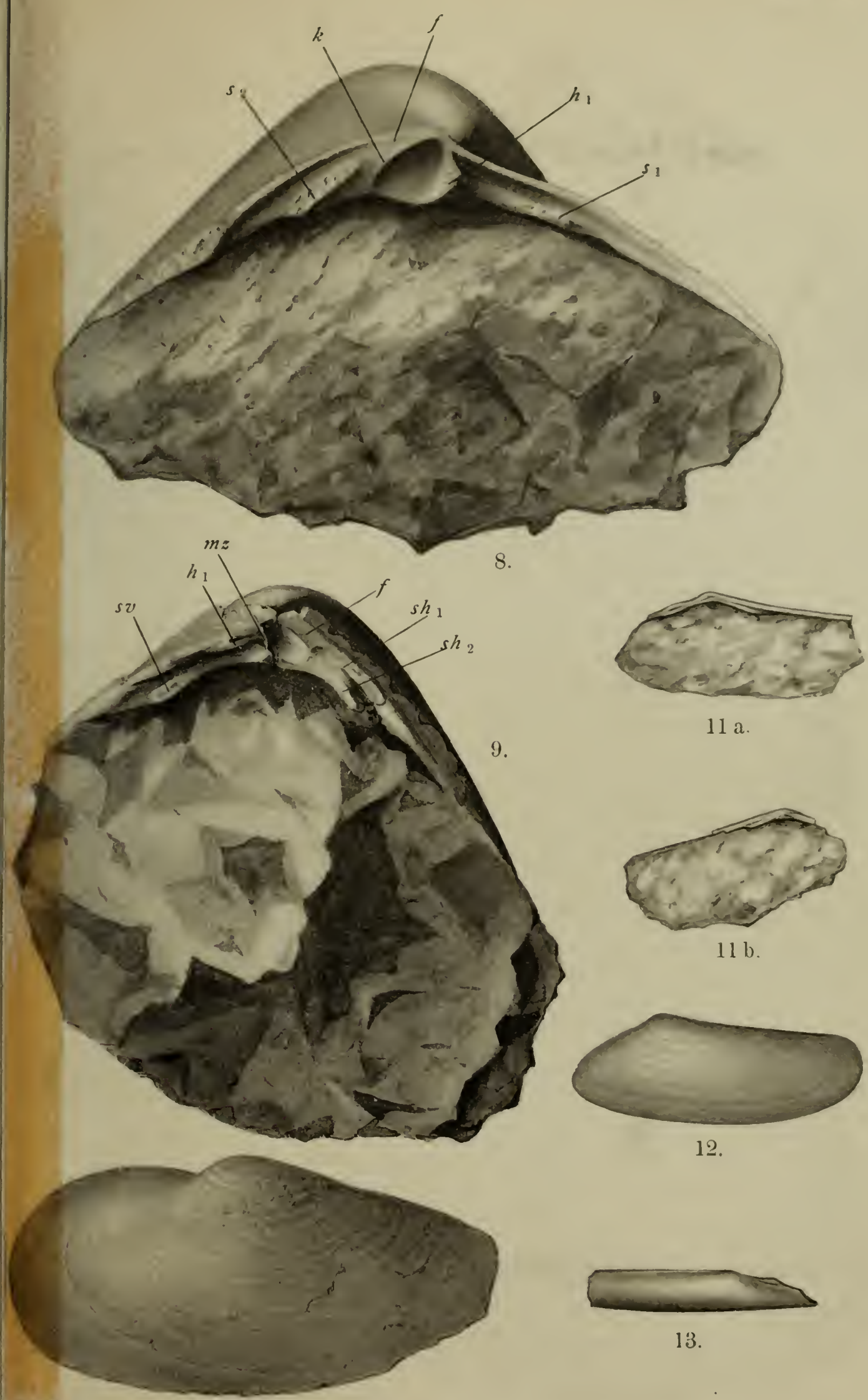

$11 \mathrm{a}$.

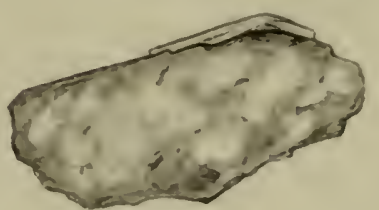

$11 \mathrm{~b}$.

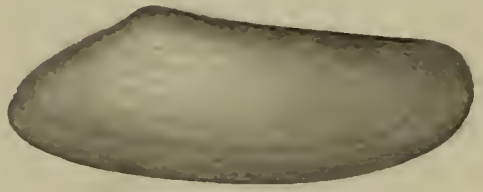

12.

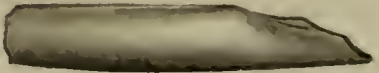

13.

10.

Lichtdruck der Hofkunatanatalt vo Asartug doumel \& Vo., stuttisart.

uiriquina-Schichten. 


Druck von Carl Grüninger, Stuttgart. 


\section{Neues Jahrbuch f Mm BeiL. B. 18,1904}

QE

734

W55

Ceology

\section{Wilckens, Otto Revision der Fauna der Quiriquina-Schichten}

\section{PLEASE DO NOT REMOVE CARDS OR SLIPS FROM THIS POCKET}

UNIVERSITY OF TORONTO LIBRARY 


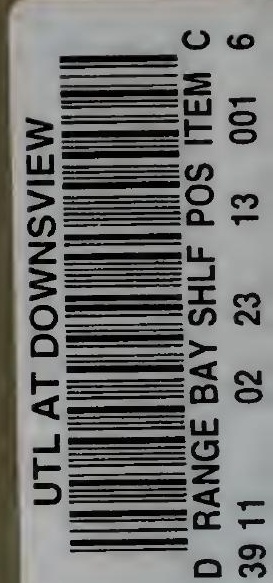

